Check for updates

Cite this: Mater. Adv., 2022, 3, 779

\section{Highly-dispersed and high-metal-density electrocatalysts on carbon supports for the oxygen reduction reaction: from nanoparticles to atomic-level architectures}

\author{
Zesheng Li, (D)* Bolin Li, Yifan Hu, Shaoyu Wang and Changlin Yu*
}

\begin{abstract}
Electrocatalysts for the oxygen reduction reaction (ORR) are crucial for a variety of renewable energy applications (e.g., proton exchange membrane fuel cells, PEMFCs). The synthesis of highly-dispersed and high-metal-density ORR electrocatalysts (e.g., nanoscale and atomic-level structures) on carbon supports with strong durability is extremely desirable but remains challenging. Carbon-supported high-loading noble metal catalysts with nanoscale structures (e.g., Pt-based nanoparticles) are the most widely used catalysts with the best catalytic performances. Single atom catalysts (SACs) that integrate the merits of homogeneous and heterogeneous catalysts have attracted considerable attention in recent years. Aside from the manipulation of the geometric and electronic structures of active metal sites, another key challenge in this field is the development of strategies for preparing high-metal-density SACs, thus rendering atomic-level ORR electrocatalysts dramatically reactive, selective, and stable compared to their nanoscale counterparts. This review summarizes the recent advancements in carbonsupported nanoscale and atomic-level ORR electrocatalysts with high metal density (namely high loading) for fuel cells. Special emphasis is placed on the basic principles, preparation strategies and catalytic applications of these highly-dispersed and high-metal-density ORR electrocatalysts on carbon supports from nanoparticles to atomic-level architectures.
\end{abstract}

Received 16th September 2021 Accepted 27th November 2021

DOI: $10.1039 / \mathrm{d} 1 \mathrm{ma} 00858 \mathrm{~g}$

rsc.li/materials-advances

\section{Introduction}

In recent years, in order to deal with the problems of energy shortage and environmental pollution caused by traditional fossil fuels, numerous research institutions in many countries have committed to developing sustainable clean energy technologies. ${ }^{1}$ In this context, proton exchange membrane fuel cells (PEMFCs) have attracted extensive attention because of their high specific power density, high energy conversion efficiency, environmental friendliness, and low starting and working temperatures, and are thus considered to be one of the most ideal classes of energy conversion devices that can replace traditional internal combustion engines as automobile power sources. ${ }^{2}$ In PEMFCs, the design of cathode "oxygen reduction" electrocatalysts is more important and complex than that of anode "hydrogen oxidation" electrocatalysts. The main reasons are the following: (1) the kinetics of oxygen reduction is very slow, and its exchange current density is only $1 / 100$ th of that of anodic hydrogen oxidation, and thus oxygen reduction has become the restrictive step of the electrocatalytic

College of Chemistry, Guangdong University of Petrochemical Technology, Maoming, 525000,China. E-mail: lzs212@163.com,yuchanglinjx@163.com reaction of PEMFCs; and (2) the process of oxygen reduction is relatively complex, involving multiple elementary steps and a variety of intermediates, which often leads to a decrease of energy conversion efficiency and an increase of oxygen reduction overpotential. ${ }^{3}$ Therefore, the design and development of high-performance cathode oxygen reduction electrocatalysts is of great significance in promoting the development of PEMFCs.

The oxygen reduction reaction (ORR), that is, the electrochemical reduction of oxygen molecules, is a relatively complex process in fuel cells or metal-oxygen cells. ${ }^{4}$ The oxygen reduction reaction of cathodes has many possible reaction mechanisms; the main reaction pathways are as follows:

(i) Oxygen molecules can be reduced to form water through a direct "four-electron mechanism" (taking metal Pt as an example):

$$
\begin{gathered}
2 \mathrm{Pt}+\mathrm{O}_{2} \rightarrow 2 \mathrm{Pt}-\mathrm{O} \\
2 \mathrm{Pt}-\mathrm{O}+2 \mathrm{H}^{+}+2 \mathrm{e}^{-} \rightarrow 2 \mathrm{Pt}-\mathrm{OH} \\
2 \mathrm{Pt}-\mathrm{OH}+2 \mathrm{H}^{+}+2 \mathrm{e}^{-} \rightarrow \mathrm{Pt}+2 \mathrm{H}_{2} \mathrm{O}
\end{gathered}
$$

The total reaction is: 


$$
\mathrm{O}_{2}+4 \mathrm{H}^{+}+4 \mathrm{e}^{-} \rightarrow 2 \mathrm{H}_{2} \mathrm{O} \quad E=1.23 \mathrm{~V} \text { vs. } \mathrm{SHE}\left(25^{\circ} \mathrm{C}\right)
$$

(ii) Oxygen molecules can also be reduced by a "two-electron mechanism"; that is, two electrons can be obtained to be reduced to hydrogen peroxide:

$$
\mathrm{O}_{2}+2 \mathrm{H}^{+}+2 \mathrm{e}^{-} \rightarrow \mathrm{H}_{2} \mathrm{O}_{2} \quad E=0.69 \mathrm{~V} \text { vs. } \operatorname{SHE}\left(25^{\circ} \mathrm{C}\right)
$$

The intermediate product $\mathrm{H}_{2} \mathrm{O}_{2}$ can be further reduced to water:

$$
\mathrm{H}_{2} \mathrm{O}_{2}+2 \mathrm{H}^{+}+2 \mathrm{e}^{-} \rightarrow 2 \mathrm{H}_{2} \mathrm{O} \quad E=1.77 \mathrm{~V} \text { vs. } \mathrm{SHE}\left(25^{\circ} \mathrm{C}\right)
$$

From the above reaction process, it can be seen that the theoretical potential of the four electron process is $1.23 \mathrm{~V}$ (eqn (4)), while that of the two electron process is only $0.68 \mathrm{~V}$ (eqn (5)). The electron transfer number of the four-electron process is twice that of the two-electron process; that is, the energy conversion is also double. From the output voltages and energy conversion efficiency of the cell devices, the fourelectron process is more beneficial. ${ }^{5}$ Therefore, in the design of electrocatalysts for the cathode oxygen reduction reaction, we should strive to create an environment conducive to the four-electron process, so as to improve the catalytic efficiency of the oxygen reduction process and the whole cell system.

The development of ORR electrocatalysts with high performance and low cost is of great strategic significance in the development of advanced energy conversion devices. In essence, platinum $(\mathrm{Pt})$ is still the most effective ORR electrocatalyst. ${ }^{6}$ However, its high price has restricted the development of PEMFCs. At present, effective countermeasures include: (i) reducing the use of Pt by optimizing the utilization of Pt catalyst, (ii) reducing the use of Pt by improving the performance of Pt catalyst, and (iii) developing other catalysts that can replace Pt metal. ${ }^{7}$ At present, the design direction of ORR electrocatalysts mainly includes "low-Pt electrocatalysts", "Pt-free electrocatalysts" and "non-noble-metal electrocatalysts". According to their action mechanism, low-Pt electrocatalysts can be divided into three types: (i) core-shell structure low-Pt electrocatalysts, (ii) alloy structure low-Pt electrocatalysts, and (iii) synergistic-effect low-Pt electrocatalysts (facilitated using co-catalysts). ${ }^{8}$ Pt-free electrocatalysts refer to other lower-price noble-metal electrocatalysts such as palladium (Pd), iridium (Ir) and silver (Ag). ${ }^{9}$ Non-noble-metal electrocatalysts refer to transition metal catalysts especially those of iron (Fe) and cobalt (Co), which are alternative electrocatalysts with rich resources and low price. ${ }^{10}$ These noble-metal or nonnoble-metal ORR electrocatalysts have their own characteristics and advantages, and they are related to each other, and even complement each other in specific dimensions and environments.

Recently, several reviews have summarized the preparation methods and structural modification of noble-metal ${ }^{11,12}$ and non-noble-metal ${ }^{13,14}$ ORR electrocatalysts. They all are very much concerned with the relationship between the nanostructures, crystal structures, and electronic structures of metals and their electrochemical performances. Some of them only focus on the design of individual nano-morphologies and ignore the interaction with carbon supports. However, electrocatalysts for the actual application in PEMFCs are typically composed of highly dispersed active metal nanoparticles (NPs) on a variety of carbon supports, often with a high metal content (40-50 wt\%), to guarantee the formation of thin catalyst layers along with metallically conducting interfaces. ${ }^{15-17}$ Therefore, it is necessary to pay attention to summarizing the synthetic strategies and structural properties of high-metal-loading ORR electrocatalysts, to meet the demands of practical applications of PEMFCs.

On the other hand, the dimensions and distribution of these high-loading active metal components on carbon supports have a great impact on the catalytic activity, product selectivity (i.e., two electron or four electron mechanism), and electrochemical stability of ORR electrocatalysts. ${ }^{18-20}$ In recent years, in order to improve the catalytic activity and selectivity and increase the utilization of active metals, ORR electrocatalysts have been developed from nanosize to sub-nanosize ${ }^{21}$ and even atomiclevel $^{22}$ architectures. Therefore, the development of highlydispersed and high-metal-content (or high-metal-density) electrocatalysts with reduced dimensions (or atomic level structures) on carbon supports is very critical for the ORR in the practical application of fuel cells.

Single atom catalysts (SACs) usually consist of dispersed metal atoms and appropriate support materials, where the supports are employed to anchor onto, confine to, and/or coordinate with isolated metal atoms. ${ }^{23}$ Therefore, the features of SACs allow achieving maximum atom utilization $(\sim 100 \%)$, which is of particular significance for the development of carbon-supported SACs for ORR electrocatalysis. In recent years, several reviews have discussed the synthesis strategies, coordination regulation, electrocatalytic applications, and structure-property relationships of carbon-supported SACs. ${ }^{24-26} \mathrm{How}^{-}$ ever, these reviews to some extent have not addressed the regulation of metal density and site distance effects of SACs, or the synergistic effects of high-density single atoms, dual atoms, or atom clusters in ORR electrocatalysis. So, in order to deeply understand the ORR mechanisms and structure-property relationship of high-density SACs, a relevant review study is very necessary.

In this review, the preparation methods and ORR performances of carbon-supported high-metal-density ORR electrocatalysts (including nanosize NPs and atomic-level structures) are systematically summarized (see Scheme 1 for an overview of the topics covered here). The promising carbon supports for ORR electrocatalysts are introduced. The basic principles and applications of highly-dispersed and high-metal-density ORR electrocatalysts on different carbon supports are reviewed and analyzed. Particularly, the development process of carbonsupported SACs, the synthetic strategies of high-density SACs, and the synergistic effect of high-density SACs on carbon supports for the ORR are discussed. The fundamental understanding of the synthesis-construction-performance correlations for carbon-supported high-metal-density ORR 


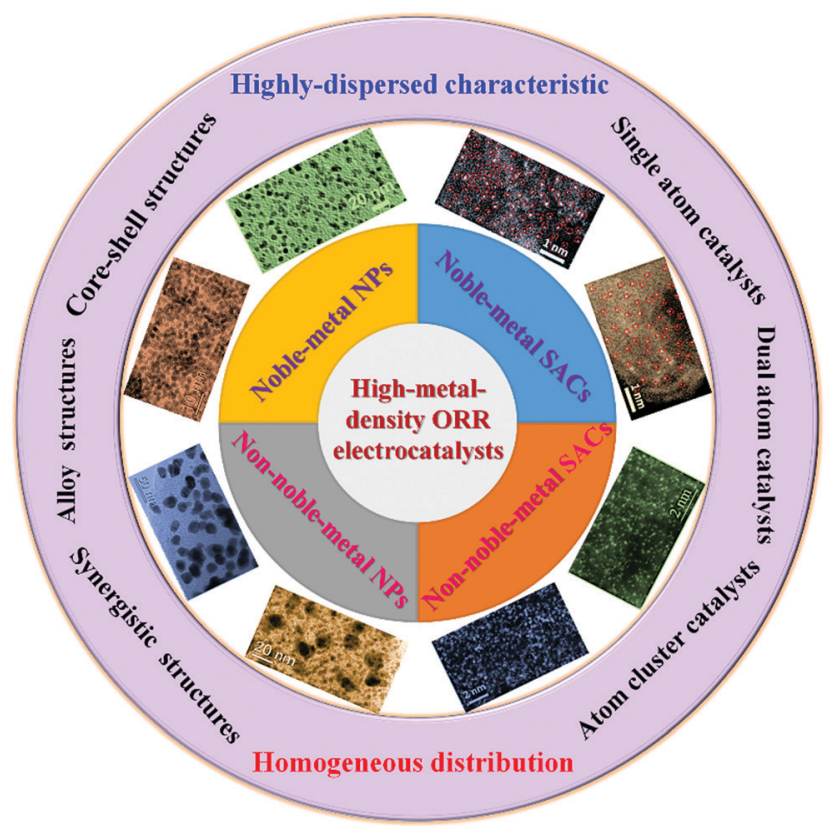

Scheme 1 Overview of the topics covered in this review.

electrocatalysts is preliminarily demonstrated. Finally, the challenges and prospects for the development of high-metal-density ORR electrocatalysts on carbon supports are highlighted.

\section{Carbon supports for ORR electrocatalysts}

In order to design high-performance ORR electrocatalysts, carbon supports should have the following three pivotal characteristics: (i) high specific surface area, accommodating highcontent metal components with maximized catalytically active area; (ii) high electronic conductivity, minimizing the ohmic resistance-induced voltage loss of cell systems; and (iii) high chemical and electrochemical corrosion resistance, offering high stability and durability for electrocatalysis. ${ }^{27}$ Currently, the widely used carbon supports for ORR electrocatalysts include carbon black, carbon nanotubes, graphene, templatebased porous carbon, and other pyrolytic carbon materials.

\subsection{Carbon black}

Carbon black (CB) is a low-cost support for the cathode of PEMFCs. CB materials produced by pyrolysis or incomplete combustion of hydrocarbons have a turbine layered structure and high conductivity and specific surface area. Oxygen groups (such as hydroxyl, carbonyl and carboxyl) usually exist on the surface of carbon black, and play an important role in the dispersion and stability of the metal component. Modifying the hydrophilic or hydrophobic properties of carbon black by oxidizing or doping it with nitrogen, fluorine and other heteroatoms can also improve the service life and gas transport characteristics of carbon black. The surface functionalization of carbon black will affect the ionomer coverage in the catalyst layer and its performance and life in fuel cell devices. ${ }^{28}$

\subsection{Carbon nanotubes}

Carbon nanotubes (CNTs) have become one of the most widely used supports because of their large specific surface area, high conductivity, good thermal stability, and surface modification feasibility. CNTs often need to be oxidized with nitric acid or mixed acid to form oxygen-containing functional groups as nucleation centers to anchor metal nanoparticles or metal atoms, which will also introduce defects in the carbon matrix, increasing the surface-active sites. At present, the research work on CNTs mainly focuses on the methods of loading active metal components onto the surfaces of CNTs and the encapsulation of metal components into CNTs, and the influence of the surface properties of CNTs on metal dispersion and electrocatalytic performances. ${ }^{29}$

\subsection{Graphene}

Graphene is a recently-discovered carbon nanomaterial with a two-dimensional planar structure, which has many unique properties, such as large specific surface area, an excellent electron conduction ability and high chemical stability, making it as an ideal catalyst support for fuel cells. Graphene plays a very important role in reducing the use of noble metals and improving the catalytic performance of non-noble metals. The synthesis of graphene with a porous structure can effectively limit the size of metal and inhibit agglomeration, greatly improving the catalytic activity and stability of catalysts. By adjusting the three-dimensional structure of graphene, the transmission of fuels and products can be effectively controlled and the catalytic performance of catalysts can be improved. ${ }^{30}$

\subsection{Template-based porous carbon}

Porous carbon materials show bright prospects for energy conversion and storage devices due to their outstanding properties such as high surface area, accessible active sites, mass transport, and diffusion. Template-based (e.g., $\mathrm{SiO}_{2}$ and micelle based) porous carbon materials have more regular and controllable pore structures, which are more suitable for electrocatalyst supports. Template-based porous carbon materials include ordered mesoporous carbon (narrow mesoporous structure) and ordinary porous carbon (mesoporous or macroporous structure) materials. The controllable pore structures (2-500 $\mathrm{nm})$ of template-based porous carbon materials provide adjustable void spaces for limiting metal catalysts and preventing agglomeration, as well as promoting the diffusion and migration of substances. ${ }^{31}$

\subsection{Other pyrolytic porous carbon materials}

Porous carbon materials can also be synthesized by direct pyrolysis of a variety of carbon precursors (e.g., biomass, polymer, and metal-organic frameworks (MOFs)) without extraneous templates. ${ }^{32}$ Biomass-derived porous carbon has some advantages, such as abundance in nature, sustainability, economic viability, and environmental friendliness. Polymer-derived porous 
carbon also has some advantages, such as high carbon content, controllable constituent elements, and low price. As a typical class of MOFs, zeolitic imidazolate frameworks (ZIFs) have the characteristics of both MOFs and zeolites. ZIF-derived porous carbon and that coupled with metal components have exhibited remarkable activity and stability for a broad range of electrocatalysis applications. $^{33}$

When preparing high-metal-density ORR electrocatalysts, nano-scale carbon materials with high specific surface area are preferentially selected as supports, so that the active sites of metal NPs (or metal atoms) are fully exposed and participate in the catalytic reaction to maximize the mass activity. ${ }^{34}$ Because of the high metal loading, the metal components can very easily agglomerate, so the high dispersion of the catalyst is particularly critical. The pore structure (defects and nanopores) and surface state (doped N, P, and S atoms) of carbon materials play important roles in anchoring metal nanoparticles and dispersing metal atoms by coordination. ${ }^{35}$ Therefore, it is demonstrated that carbon supports with favorable porous structures, optimized surface defects and suitable functional groups should be considered to fabricate high-metal-density ORR electrocatalysts for PEMFCs.

\section{Fundamental basis of highly- dispersed and high-metal-density ORR electrocatalysts}

\subsection{Highly-dispersed ORR electrocatalysts}

The dispersion degree refers to the ratio of the number of metal atoms exposed to the surface to the total number of metal atoms in a catalyst. The dispersion degree of a metal catalyst often affects its physical and chemical properties, which is directly related to its electroactive surface area. ${ }^{36}$ The finer the dispersion of a metal component, the higher the degree of dispersion, and the larger the surface area. The electrocatalytic reactions occur entirely on the surfaces of metal nanoparticles, so high dispersion is required to enhance the activity and reduce the amount of expensive noble metal used. Hence the better the dispersion of electrocatalysts, the higher their electrochemical performance. ${ }^{37}$ For example, highly dispersed Pt NPs on carbon black supports have been used as commercial ORR electrocatalysts in the practical application of PEMFCs. Notably, the high dispersion of metal components (including other Pt-free noble metals and transition metals) is also very important in ORR electrocatalysts for fuel cells. ${ }^{38}$ The wide variety of pore structures and chemical functional groups on the surfaces of carbon supports affects the dispersion of metal components. For this reason, various high-dispersion studies have been conducted by modifying the pore structure and chemical nature of carbon supports. ${ }^{39}$ In general, the development of highly-dispersed noble metal catalysts or non-noble metal catalysts on different supports is a key route to designing high-performance ORR electrocatalysts.

\subsection{High-metal density ORR electrocatalysts}

The reaction kinetics of the ORR at the cathode of PEMFCs is poor, and thus requires the participation of high-efficiency catalysts. In practical fuel cell applications, carbon-supported Pt NP catalysts with high Pt loading (more than $40 \mathrm{wt} \%$ ) have high practical value. ${ }^{17,40,41}$ On the one hand, the use of carbonsupported Pt based catalysts with high Pt loading can reduce the thickness of the catalytic layer in membrane electrode assemblies (MEAs), to reduce mass transfer loss at high current density. ${ }^{40}$ On the other hand, highly-dispersed Pt based catalysts with small particle size are recognized as one of the most promising classes of cathode catalysts, which have good activity in half cells and full cells. ${ }^{41}$ However, in recent years, there have been few reports on carbon-supported low-Pt electrocatalysts with high metal loading (such as core-shell, alloy, and synergistic effect low-Pt systems), which is mainly due to the severe challenges brought by particle agglomeration in the preparation of high load multi-metal catalysts and their poor stability in the electrochemical process. ${ }^{42}$ Therefore, it is of great significance to summarize the preparation methods and catalytic properties of existing high-loading (i.e., high metal NP density) ORR electrocatalysts, which helps in promoting the development of high-performance catalytic systems in the future.

In recent years, single-atom catalysts (SACs) have been widely studied because of their nearly $100 \%$ utilization of metal active sites and accurate and controllable coordination structures. ${ }^{43}$ However, due to the lack of multiple-atom connected group sites, monatomic sites are not competent in some multi-step complex catalytic reactions. For example, in the ORR catalytic process, monatomic Pt catalyst often cannot effectively catalyze the fracture of the $\mathrm{O}-\mathrm{O}$ bond, so it is difficult to effectively catalyze the ORR in the four-electron mechanism. ${ }^{44}$ Due to the inability of isolated Pt single atoms to break the $\mathrm{O}-\mathrm{O}$ bond through lateral adsorption, the ORR tends to form the two-electron product $\left(\mathrm{H}_{2} \mathrm{O}_{2}\right)$ rather than the four-electron product $\left(\mathrm{H}_{2} \mathrm{O}\right)$ required by fuel cells. ${ }^{45}$ High-metal density (high loading) Pt SACs show much better ORR performance (with much higher mass activity) than low-metal density (low loading) Pt SACs and Pt NPs, in which the selectivity of high-metal density Pt SACs can be greatly inclined to the four-electron path. ${ }^{46}$ Therefore, for atomically-dispersed ORR electrocatalysts, the high-metal density strategy appears to be particularly important in the design of high-efficiency catalytic systems, in view of their distance-tunable metal sites and variable coordination environments.

\section{Preparation and application of highly-dispersed and high-metal- density ORR electrocatalysts}

Based on the above analysis, the design and synthesis of highlydispersed and high-metal-density ORR electrocatalysts on various carbon supports are of great theoretical and practical 
significance. In this section, we will introduce the preparation methods and catalytic performances of high-metal-density ORR electrocatalysts (including nanoscale and atomic-level architectures) by the analysis of several typical cases. For nanoscale ORR electrocatalysts, single metal NPs, metal alloy NPs, metal core-shell NPs, metal compound NPs, and metal compoundpromoted metal (or its alloy) NPs are presented. On the other hand, for atomic-level ORR electrocatalysts, single-atom catalysts, dual-atom catalysts, atom cluster catalysts, single-atom/ cluster catalysts and single-atom/NP mixed catalysts are introduced systematically.

\subsection{Nanoscale ORR electrocatalysts}

4.1.1 Single metal nanoparticles. Generally, metal Pt NPs (2-6 nm) with high metal content (above $40 \mathrm{wt} \%$ ) are usually loaded onto conductive carbon supports as ORR electrocatalysts in practical PEMFC applications. However, the types and surface properties of carbon supports will affect the dispersion and particle size of Pt NPs to a great extent, thus affecting the catalytic performances of these electrocatalysts. ${ }^{4-49}$ The surface properties (surface area, porosity, and functional groups) and the degree of graphitization of carbon supports strongly affect the growth mechanism during Pt deposition. Recently, several commercial carbon-supported Pt catalysts (40 wt\% Pt) have been systematically evaluated in terms of their activity and stability for the ORR using a rotating ring disk electrode (RRDE) (see Fig. 1A-F). ${ }^{50}$ The five commercial carbon supports are as follows: (1) carbon black (Vulcan XC-72R), (2) high surface area graphite (HSAG300), (3) ordered mesoporous carbon (OMC), (4) graphite nanoparticles (GNP10), and (5) mesoporous graphitized nanoparticles (GNP500). The Pt/C catalysts were prepared first by impregnating the carbon support with the desired amount of chloroplatinic acid, followed by a reduction reaction in formaldehyde stabilized with methanol at $80{ }^{\circ} \mathrm{C}$ under reflux conditions. For the sake of contrast, another two commercial $\mathrm{Pt} / \mathrm{C}$ benchmark catalysts (40 wt\% Pt) were also used, namely $\mathrm{Pt} / \mathrm{C}_{\mathrm{JM}}$ (Johnson Matthey) and $\mathrm{Pt} / \mathrm{C}_{\text {Heraeus }}$ (Heraeus $\mathrm{GmbH}$ ).

Fig. 1A and $\mathrm{B}$ show the TEM images of a variety of carbonsupported $\mathrm{Pt}$ catalysts (40 wt\% Pt) and the corresponding particle size distribution histograms of Pt. The Pt NPs are uniformly dispersed on Vulcan, OMC and GNP500 supports, while some particle agglomerates are observed on HSAG300 and GNP10 supports. The highly graphitized structure and lack of oxygen functional groups in HSAG300 and GNP10 are not conducive to the uniform nucleation and dispersion of Pt NPs on their surfaces. The average particle sizes of Pt NPs were as follows: $3.11 \mathrm{~nm}(\mathrm{Pt} / \mathrm{OMC})<4.20 \mathrm{~nm}(\mathrm{Pt} / \mathrm{GNP} 10)<4.22 \mathrm{~nm}$ $($ Pt/Vulcan $)<4.41 \mathrm{~nm}(\mathrm{Pt} / \mathrm{GNP} 500)<6.57 \mathrm{~nm}(\mathrm{Pt} / \mathrm{HSAG} 300)$. The ordered mesoporous carbon (OMC) with an internal porosity can offer a high surface area $\left(1000 \mathrm{~m}^{2} \mathrm{~g}^{-1}\right)$ for accommodating a large number of small Pt NPs compared with the solid carbon black (Vulcan) and graphitized carbons (HSAG300). The mesoporous graphitized nanoparticle (GNP500) support has favorable mesoporous structures (5$10 \mathrm{~nm}$ ), moderately graphitized structures (namely moderate oxygen content), and small nanoparticle structures $(\sim 50 \mathrm{~nm})$, and should be a better support for Pt NPs than the OMC with amorphous structures and larger nanoscale structures ( $>500 \mathrm{~nm})$. In addition, two commercial $\mathrm{Pt} / \mathrm{C}$ catalysts $\left(\mathrm{Pt} / \mathrm{C}_{\mathrm{JM}}\right.$ and $\mathrm{Pt} / \mathrm{C}_{\text {Heraeus }}$ with $40 \mathrm{wt} \% \mathrm{Pt}$ ) also showed larger Pt NPs and poorer dispersion.

Fig. 1C shows the cyclic voltammograms (CVs) of the seven carbon-supported Pt catalysts (with $40 \mathrm{wt} \% \mathrm{Pt}$ ). In all these CVs, typical electrochemical potential sweep responses for Pt metal, such as $H_{\text {ads/des }}(0-300 \mathrm{mV})$, double-layer capacitance $(300-750 \mathrm{mV})$ and oxide formation (750-1200 mV) regions, are clearly presented. The electrochemically active surface areas (ECSAs) of all these catalysts were evaluated by integrating $H_{\text {des }}$ peaks. This showed that Pt/OMC had the highest ECSA (34.3 $\mathrm{m}^{2} \mathrm{~g}_{\mathrm{Pt}}{ }^{-1}$ ) and the widest double-layer capacitance region. These are attributed to the smallest Pt NPs and the largest specific BET surface area of the carbon support for Pt/OMC. Fig. 1D shows the linear sweep voltammograms (LSVs) of the catalysts for the ORR in oxygen-saturated $0.5 \mathrm{M} \mathrm{H}_{2} \mathrm{SO}_{4}$ electrolyte. In the kinetic regime, the ORR activity was evaluated at a half-wave potential $\left(2.5 \mathrm{~mA} \mathrm{~cm}^{-2}\right)$, in which the two GNP-supported catalysts (Pt/GNP10 and Pt/GNP500) obviously showed better performance than the other catalysts. About $85 \mathrm{mV}$ less overpotential for the ORR was obtained at Pt/GNP500 compared with that at Pt/Vulcan. Obviously, Pt/GNP500 showed the highest mass activity (Fig. 1E) and desirable stability (Fig. 1F) for the ORR. The results of this study demonstrated that the moderate graphitization level (namely moderate oxygen content and specific surface area), suitable mesoporous structure (5-10 $\mathrm{nm})$, and interconnected small spherical morphology $(\sim 50 \mathrm{~nm})$ of carbon were found to be ideal properties for designing well-performing and highlystable Pt NPs on carbon ORR electrocatalysts. ${ }^{50}$

On the other hand, three-dimensional (3-D) Pt-based nanostructures with a dendritic morphology have received much attention as ORR electrocatalysts. ${ }^{51-53}$ These unique Pt-based nanodendrites (NDs) generally have the advantages of high surface area and enhanced performances due to their dominant crystal planes and highly branched shapes. ${ }^{53}$ Previously, Li et al. reported carbon-supported Pt-on-Co NDs with high-Ptcontent (37.52 wt\% Pt) as an efficient ORR electrocatalyst for the first time (see Fig. 1G-J). ${ }^{54}$ These Pt-based NDs were spontaneously generated and deposited on polymer-derived carbon by a simple cobalt-induced and carbon-mediated galvanic cell reaction approach. The TEM images clearly reveal that the carbon-supported Pt NDs have distinct 3-D flower-like structures and an average diameter of $20 \mathrm{~nm}$ (with individual Pt nanoparticles of $3 \mathrm{~nm}$ ) (Fig. 1G and H). The ORR LSV curves of the catalysts were recorded in oxygen-saturated $0.1 \mathrm{M} \mathrm{HClO}_{4}$ (Fig. 1I), and the mass activities at $0.9 \mathrm{~V}$ were calculated to be 122, 163 and $251 \mathrm{~mA} \mathrm{mg}^{-1} \mathrm{Pt}$ for commercial Pt/C (47.60 wt\% Pt), supported 3-D Pt NDs (37.52 wt\% Pt) and supported 3-D Pt-on-Co NDs (18.34 wt\% Pt), respectively. More recently, Feng and co-workers synthesized branched Pt-Pd NDs supported on reduced graphene oxide (rGO), which exhibited enhanced ORR activity (onset potential of $0.05 \mathrm{~V}$, half-wave potential of $-0.15 \mathrm{~V}$, electron transfer number $>3.99$ ) and 

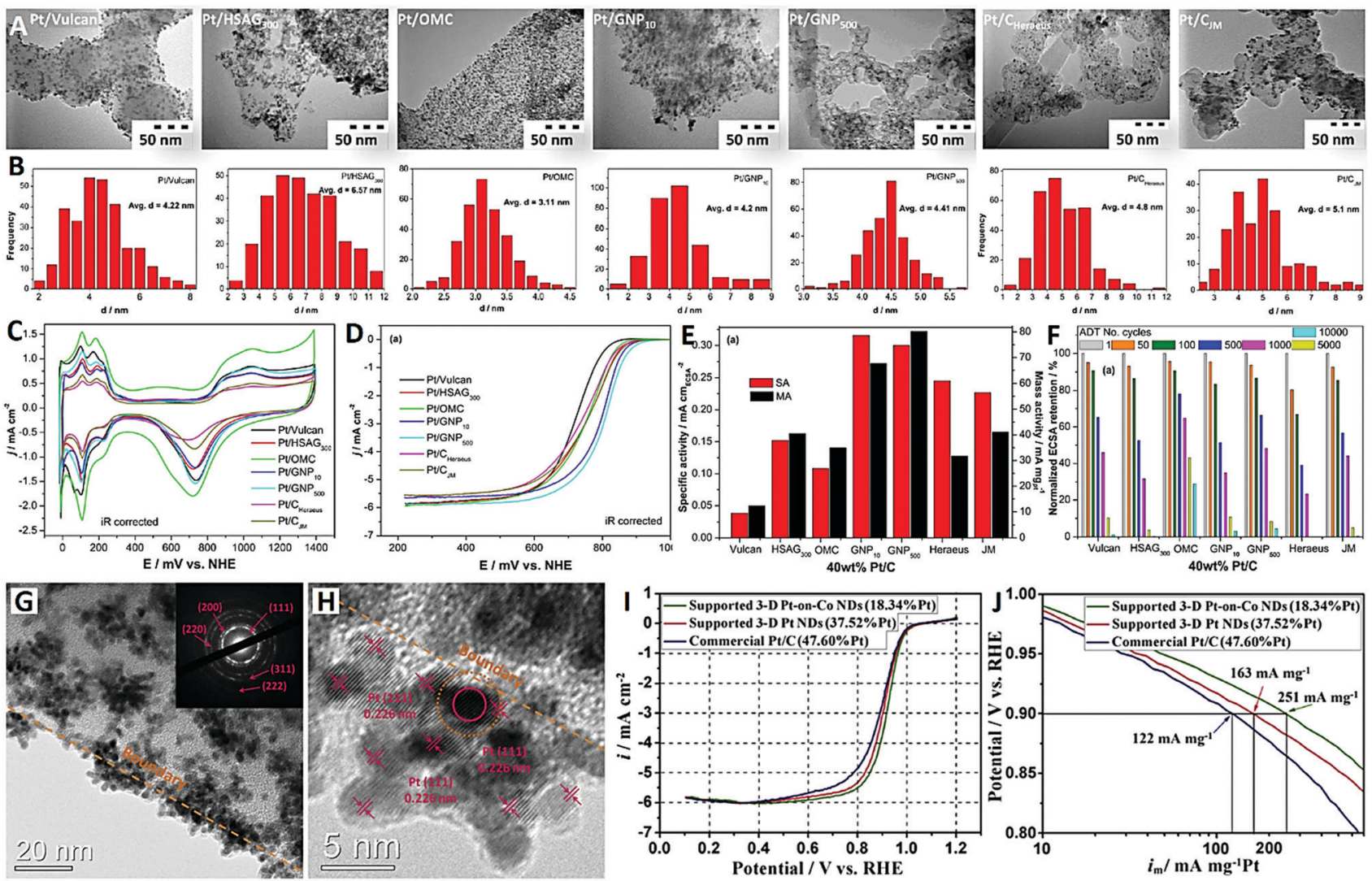

Fig. 1 A series of carbon-supported Pt nanoparticles (reprinted with permission from ref. 50): (A) TEM images, (B) particle size distribution histograms of $\mathrm{Pt}$, and (C-F) electrochemical performances; and typical carbon-supported Pt nanodendrites (reprinted with permission from ref. 54): (G and H) TEM images and (I and $\mathrm{J}$ ) electrochemical performances.

good stability in alkaline medium $(0.1 \mathrm{M} \mathrm{KOH}) .^{55}$ Besides, high-density Au ND-loaded GO (Au ND-GO) also exhibited high electrocatalytic activity (in a near four-electron pathway) and superior stability toward the ORR in alkaline medium $(0.1 \mathrm{M}$ $\mathrm{KOH}){ }^{56}$ Overall, the results of these studies indicated that the construction of 3-D dendritic nanostructures is an attractive strategy for designing high-metal-density ORR catalysts with remarkable catalytic activity and durability.

4.1.2 Metal alloy nanoparticles. Sufficient studies have shown that PtM (where $\mathrm{M}=\mathrm{Fe}, \mathrm{Co}, \mathrm{Ni}$, etc.) alloy ORR electrocatalysts, constructed by introducing the second element, can greatly improve the catalytic activity compared to single Pt catalyst. ${ }^{57,58}$ The improvement of oxygen reduction activity of Pt alloy catalysts is based on the comprehensive action of "electronic effects" and "geometric effects". The category, proportion, and number of elements in alloys have a great influence on the performances of Pt alloy catalysts. The properties of PtM alloy catalysts with different elements are different, where the catalytic activity order often is as follows: PtFe > $\mathrm{PtCo}>\mathrm{PtNi}>\mathrm{Pt}^{59}$ The element proportion is another key factor affecting the properties of PtM alloys, where the $\mathrm{Pt}_{3} \mathrm{M}$ alloy usually has high activity and stability. ${ }^{60}$ Furthermore, the introduction of a third element (such as noble metal $\mathrm{Au}$ ) into conventional PtM bimetal alloy electrocatalysts can further improve their ORR activity and stability. ${ }^{61}$
The development of carbon-supported PtM (where $\mathrm{M}=\mathrm{Fe}$, $\mathrm{Co}, \mathrm{Ni}$, etc.) alloys with high dispersion and high metal density is an important research direction for high-performance ORR electrocatalysts. ${ }^{62-64}$ Achieving the homogeneous formation of ultrasmall PtM alloy NPs directly on carbon supports, with high catalyst loading, promises a facile and scalable production of alloy ORR electrocatalysts. However, the precise control of nucleation and alloying of two different metals on carbon supports is still a great challenge. Recently, Sung and coworkers $^{63}$ reported a novel synthetic strategy to directly grow highly-dispersed MPt (where $\mathrm{M}=\mathrm{Fe}$, Co, and Ni) alloy NPs on various carbon supports with high catalyst loading, from a unique bimetallic compound composed of $\left[\mathrm{M}(\mathrm{bpy})_{3}\right]^{2+}$ cations (bpy $=2,2^{\prime}$-bipyridine) and $\left[\mathrm{PtCl}_{6}\right]^{2-}$ anions. Thereinto, the representative rGO-supported FePt catalyst (37 wt\%-FePt/rGO) with high homogeneity and narrow size distribution (5-6 nm) exhibited 18.8 times higher specific activity and 11.5 times higher mass specific activity than commercial $\mathrm{Pt} / \mathrm{C}$ catalyst at $0.9 \mathrm{~V}$ (see Fig. 2A-C). It is noteworthy that the high metal loading catalyst ( $37 \mathrm{wt} \%-\mathrm{FePt} / \mathrm{rGO}$ ) showed better electrocatalytic activity than the low metal loading catalyst (24 wt\%-FePt/ rGO), due to its high uniformity and high utilization efficiency. The high metal loading catalyst ( $37 \mathrm{wt} \%-\mathrm{FePt} / \mathrm{rGO}$ ) also demonstrated excellent electrochemical stability without degradation over 20000 cycles. $^{63}$ 

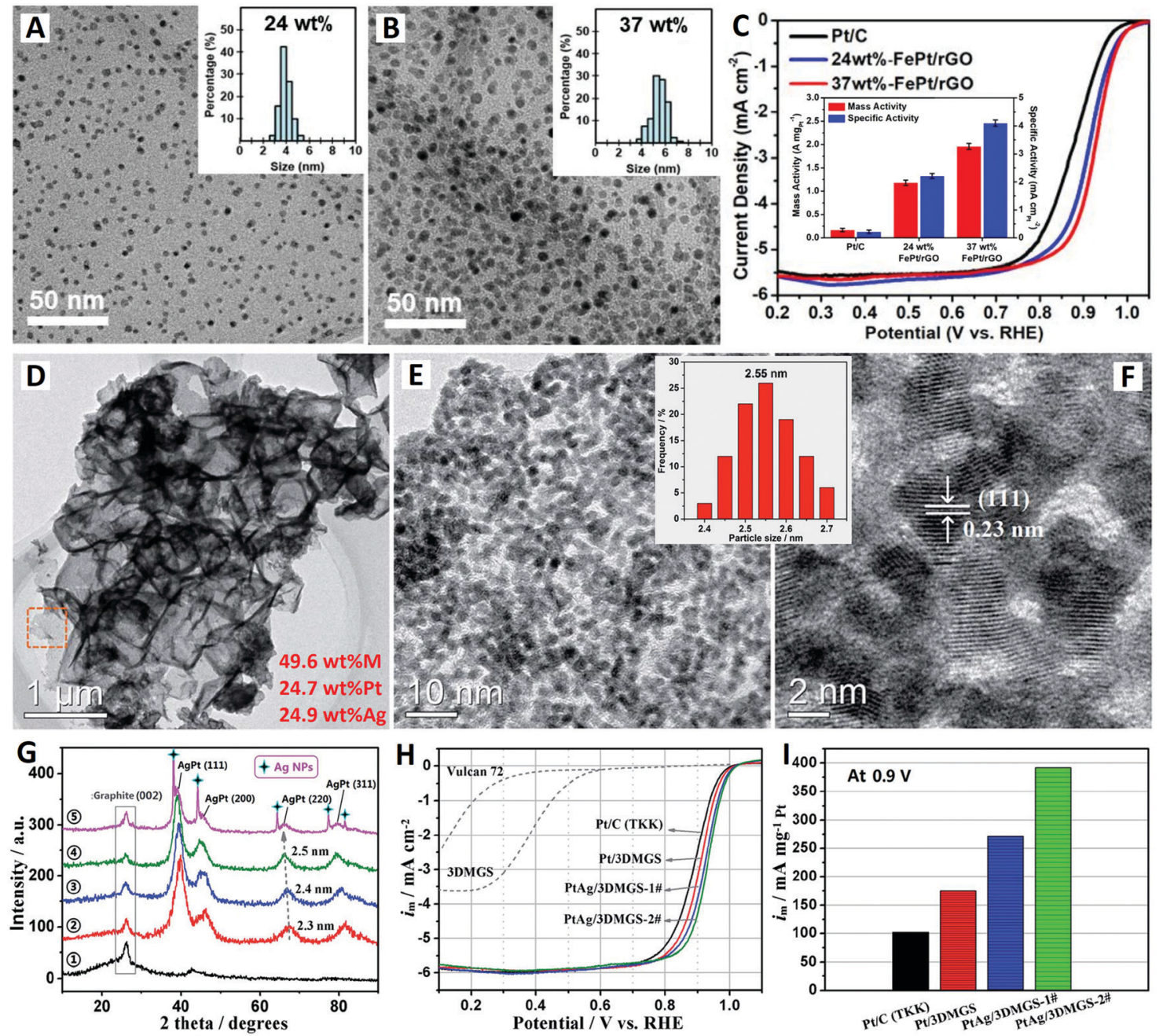

Fig. 2 The rGO-supported FePt alloy catalyst (reprinted with permission from ref. 63): (A and B) TEM images and (C) electrochemical performances. The 3-D MGS-supported PtAg alloy catalyst (reprinted with permission from ref. 70): (D-F) TEM images, (G) XRD patterns, and (H and I) electrochemical performances.

Fu and co-workers ${ }^{64}$ also demonstrated a general hydrogelfreeze drying and annealing joint strategy for the synthesis of rGOsupported $\mathrm{Pt}_{3} \mathrm{M}$ (where $\mathrm{M}=\mathrm{Mn}, \mathrm{Cr}$, Fe and $\mathrm{Co}$ ) alloy NPs $\left(\mathrm{Pt}_{3} \mathrm{M} /\right.$ rGO) with ultrafine particle size (about $3 \mathrm{~nm}$ ) and dramatic monodispersity. With $\mathrm{Pt}_{3} \mathrm{Mn} / \mathrm{rGO}$ as an example, after the annealing process at high temperature $\left(700{ }^{\circ} \mathrm{C}\right)$ for $12 \mathrm{~h}$, ultrasmall $\mathrm{Pt}_{3} \mathrm{Mn}$ ordered intermetallic NPs can be formed due to the confinement effect of the porous structure of rGO. The catalytic performance of $\mathrm{Pt}_{3} \mathrm{Mn} / \mathrm{rGO}(\sim 3 \mathrm{~nm}, 22.5 \mathrm{wt} \%)$ for the ORR was evaluated and compared with that of commercial Pt/C $(\sim 3.3 \mathrm{~nm}$, $20 \mathrm{wt} \%)$. The $\mathrm{Pt}_{3} \mathrm{Mn} / \mathrm{rGO}$ catalyst exhibited greatly improved kinetic activity (1.37 times) compared to the commercial Pt/C at $0.9 \mathrm{~V}$ potential. The improved catalytic activity can be due to three factors: (i) the ultrafine particle size of $\mathrm{Pt}_{3} \mathrm{Mn}$ NPs affords rich active sites, (ii) the ordered intermetallic phase promotes the shift of the d-band of $\mathrm{Pt}_{3} \mathrm{Mn}$ NPs, and (iii) the high graphitization degree of rGO improves the conductivity of the catalyst. ${ }^{64}$

For traditional PtM (where $\mathbf{M}$ is transition metal) alloy ORR electrocatalysts, their electrochemical stability is far from meeting the requirements of practical applications, and the dissolution of transition metal is always a key problem affecting fuel cell systems ${ }^{65}$ In order to design stable alloy electrocatalysts, the use of acid-soluble transition metals should be avoided or reduced as much as possible. Some noble metals with relatively low price or rich reserves, such as $\mathrm{Ag}$, Pd and even $\mathrm{Au}$, can be selected to prepare newly Pt-based alloy electrocatalysts. ${ }^{66-68}$ As a cheap noble metal with the highest conductivity, Ag can be used to design cost-effective AgPt alloy ORR electrocatalysts. In addition to the "structural adjustment" of alloys to improve their stability, the "support enhancement" of alloys can also be considered. For example, one can develop highly-stable support materials (e.g., 3-D porous graphene) to improve the stability of catalysts in terms of support enhancement.

Previously, Shen and co-workers prepared a new type of 3-D mesoporous graphene nanosheet conductive network (3-D MGS) material by an efficient synchronous graphitizationactivation technology. ${ }^{69}$ The 3-D MGS material has highly 
mesoporous structures with high permeability and well graphitized structures with high conductivity. Recently, Li et al. further synthesized a high-metal-content AgPt alloy ORR electrocatalyst based on this novel 3-D MGS as a support material (see Fig. 2D-I). ${ }^{70}$ Typically, when the total metal content is 49.6 wt\% (24.7 wt\% Pt + 24.9 wt\% Ag), highly-dispersed and highlydense AgPt alloy NPs with ultrafine size (2.4-2.7 nm) are loaded onto the surface of the 3-D MGS support without any agglomeration (see Fig. 2D-F). The uniformity of the particle size distribution of PtAg/3DMGS (49.6 wt\%) is much better than that of PtAg/Vulcan XC-72 (25.7 wt\%), ${ }^{71}$ indicating that the 3DMGS with small mesoporous structures $(2-10 \mathrm{~nm})$ is more beneficial for the preparation of catalysts with high metal content. The average crystal sizes of Pt/3DMGS (2) (46.1 wt\%), PtAg/3DMGS-1\# (3) (45.3 wt\%), and PtAg/3DMGS-2\# (4) (49.6 $\mathrm{wt} \%$ ) are estimated to be $2.3,2.4$, and $2.5 \mathrm{~nm}$ based on (220) planes in XRD patterns (see Fig. 2G).

The ORR electrocatalytic activities of the series of catalysts were evaluated using the RRDE in oxygen-saturated $0.1 \mathrm{M}$ $\mathrm{HClO}_{4}$ aqueous solution. The PtAg/3DMGS-2\# catalyst exhibits better ORR performance; it shows $43 \mathrm{mV}$ higher half-wave potential $\left(3.0 \mathrm{~mA} \mathrm{~cm} \mathrm{~cm}^{-2}\right)$ than commercial $\mathrm{Pt} / \mathrm{C}$ catalyst (47.6 wt\%, TKK) based on the same Pt loading $\left(10 \mathrm{mg}_{\mathrm{Pt}}\right)$ on the electrode (see Fig. 2H). This promising PtAg/3DMGS-2\# catalyst exhibits an ultrahigh mass activity (at $0.9 \mathrm{~V}$ ) of $392 \mathrm{~mA} \mathrm{mg}{ }_{\mathrm{Pt}}{ }^{-1}$, which is nearly 4 times that of commercial $\mathrm{Pt} / \mathrm{C}$ catalyst (102 $\mathrm{mA} \mathrm{mg}{ }_{\mathrm{Pt}}{ }^{-1}$ ) (see Fig. 2I). The PtAg/Vulcan XC$72(25.7 \mathrm{wt} \%$ ) catalyst shows a lower mass activity (at $0.9 \mathrm{~V}$ ) of $316 \mathrm{~mA} \mathrm{mg}{ }_{\mathrm{Pt}}^{-1}$ under the same test conditions. ${ }^{71}$ Moreover, comparable electrocatalytic stability $(81.6 \%$ of the initial activity) is also obtained for PtAg/3DMGS-2\# through an accelerated durability test with $1000 \mathrm{CV}$ cycles. The excellent electrocatalytic performances of the PtAg/3DMGS catalysts are mainly attributed to the structural advantages and electronic effects of the ultrafine PtAg alloy NPs. Meanwhile, the convenient binary channels for both electron transport and ion diffusion of 3DMGS conductive networks are also supposed to be beneficial for their performance improvement. ${ }^{70}$

4.1.3 Metal core-shell nanoparticles. For ORR electrocatalysts, the active component $\mathrm{Pt}$ is distributed on the surfaces of low-cost transition metal NPs to form M@Pt coreshell structure electrocatalysts (where $\mathrm{M}=\mathrm{Fe}, \mathrm{Co}, \mathrm{Ni}$, etc.), which can greatly improve the utilization efficiency and reduce the dosage of $\mathrm{Pt}^{72}$ At the same time, based on the particularity of the core-shell structure, the M@Pt electrocatalysts also exhibit the following special properties: (i) the formation of core-shell interface structures can adjust the charge properties of catalyst NPs; (ii) the surface modification with a curved coating layer can increase the stability of catalyst NPs; and (ii) the further assembly of core-shell NPs on carbon supports will produce new physicochemical properties. ${ }^{73}$ Therefore, the design of carbon-supported high-density metal core-shell NPs is considered to be an effective approach to obtain ORR electrocatalysts with excellent catalytic performances.

The M@Pt core-shell structure can be generally prepared by a seed-mediated galvanic replacement strategy by in situ displaced growth of a Pt shell on a $\mathrm{M}$ core (seed). ${ }^{74-76}$ Galvanic replacement usually takes place between a noble metal salt (high standard reduction potential) and transition metal (low standard reduction potential), which can be inhibited during the growth of Co@Pt NPs by using carbon monoxide as a stabilizing ligand and a reducing agent. ${ }^{75}$ However, these Co@Pt NPs need to be further loaded onto a carbon support before the measurement of electrochemical performances. Recently, Jia and co-workers developed a facile galvanic replacement method to achieve gradient Pt-Ni alloys (with Pt-rich surfaces), followed by a partial dealloying approach for the construction of core-shell (Pt-Ni alloy core with defective (D) Pt shell ( $\approx 3$ monolayers)) NPs directly on a graphene carbon support (Pt-Ni@Pt $/ \mathrm{G}$ ) as a high-performance ORR electrocatalyst (see Fig. 3A-D). ${ }^{76}$

The graphene (G)-supported Ni NPs were directly reacted in chloroplatinic acid to form gradient $\mathrm{Pt}-\mathrm{Ni}$ alloys on $\mathrm{G}$ by galvanic replacement reaction. Then, the $\mathrm{Pt}-\mathrm{Ni} @ \mathrm{Pt}_{\mathrm{D}} / \mathrm{G}$ coreshell catalyst was obtained by an acid leaching process to gradually etch surface $\mathrm{Ni}$ atoms in the $\mathrm{Pt}-\mathrm{Ni}$ alloys (see Fig. 3A). The high-density $\mathrm{Pt}-\mathrm{Ni} @ \mathrm{Pt}_{\mathrm{D}} / \mathrm{G}$ NPs were homogeneously dispersed on the graphene surface with particle sizes of around $5 \mathrm{~nm}$ (see Fig. 3B). The Pt-Ni@Pt $/ \mathrm{D}$ core-shell NPs performed as a promising catalyst for the ORR in $0.1 \mathrm{M} \mathrm{HClO}_{4}$ electrolyte with a mass activity threefold higher than that of the $\mathrm{Pt} / \mathrm{C}$ counterpart (see Fig. 3C and D), which is mainly due to the optimized electronic structure of Pt because of the synergetic effect between the Pt-Ni core and defective Pt shell. More importantly, the Pt-Ni@Pt $\mathrm{D}_{\mathrm{D}} / \mathrm{G}$ core-shell NPs showed extremely enhanced stability arising from the Pt shell preventing the dissolution of the Ni core, which solve a long-standing issue of unstable Pt-Ni alloy in an acidic ORR. ${ }^{76}$

On the other hand, PtM (where $\mathrm{M}=\mathrm{Fe}, \mathrm{Co}, \mathrm{Ni}$, etc.) alloys with Pt-skin surfaces can be produced by thermally-induced surface segregation in specific atmospheres $\left(\mathrm{CO}, \mathrm{NO}, \mathrm{O}_{2}, \mathrm{H}_{2}\right.$, etc.). ${ }^{77}$ Different PtM alloys require different atmospheres for the surface segregation of Pt atoms. For example, PtCo alloy NPs can be transformed into PtCo@Pt-skin NPs by heat treatment in a CO atmosphere. ${ }^{78}$ Recently, Li et al. successfully constructed an ultra-low-Pt $\mathrm{Pd}_{10} \mathrm{Pt}_{1}$ bimetallic catalyst (with a Pt-skin surface) by heat treatment in $\mathrm{a}_{2}$ atmosphere for the ORR (see Fig. 3E-K). ${ }^{79}$ Particularly, a novel active graphene-like nanosheet (AGN) material with high specific surface area and high conductivity was developed as an efficient support to form a high-metal-density Pt-skin $\mathrm{Pd}_{10} \mathrm{Pt}_{1} / \mathrm{AGN}$ catalyst (the total metal content was $32.04 \mathrm{wt} \%(29.19 \mathrm{wt} \% \mathrm{Pd}+2.85 \mathrm{wt} \% \mathrm{Pt})$ ) (see Fig. 3F-I). The $\mathrm{Pd}_{10} \mathrm{Pt}_{1} / \mathrm{AGN}$ catalyst exhibited excellent catalytic activity and superb durability for the ORR, giving a high mass activity of $1930 \mathrm{~mA} \mathrm{mg}_{\mathrm{Pt}}{ }^{-1}$ (equal to $1185 \mathrm{~mA} \mathrm{mg}_{\mathrm{Pt}}{ }^{-1}$ when the activity of $\mathrm{Pd}$ is taken into account) at $0.9 \mathrm{~V}$ in $0.1 \mathrm{M} \mathrm{HClO}_{4}$ electrolyte (see Fig. 3J and $\mathrm{K}$ ). Relying on the remarkable supporting effect of AGNs and the favorable Pt-skin core-shell structure, a highly active and stable ORR electrocatalyst was demonstrated in this study. ${ }^{79}$

Previously, Adzic et al. reported a novel core-catalyzed coating strategy for epitaxial growth of Pt atomic layers on the 

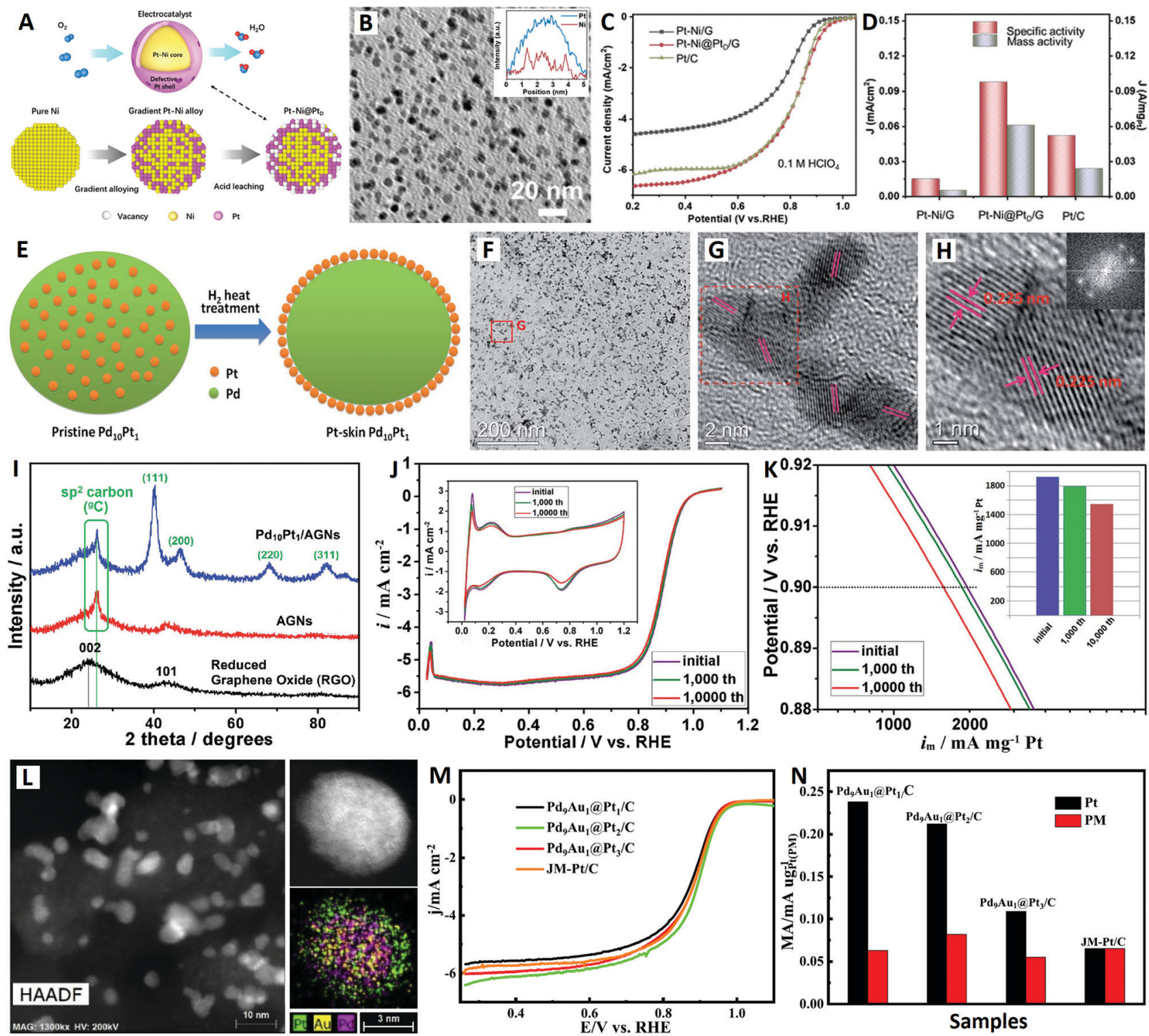

Fig. 3 The Pt-Ni@Pt $/ \mathrm{G}$ core-shell catalyst (reprinted with permission from ref. 76): (A) structural schematic diagram, (B) TEM image, and (C and D) electrochemical performances. The Pt-skin $\mathrm{Pd}_{10} \mathrm{Pt}_{1} / \mathrm{AGN}$ catalyst (reprinted with permission from ref. 79): (E) structural schematic diagram, (F-H) TEM images, (I) XRD patterns, and (J and K) electrochemical performances. The $\mathrm{Pd}_{9} A \mathrm{u}_{1} @ \mathrm{Pt} / \mathrm{C}$ core-shell catalyst (reprinted with permission from ref. 81): (L) TEM images and ( $M$ and $N$ ) electrochemical performances.

surfaces of Pd NPs, inspired by aerobic alcohol oxidation catalyzed by Pd cores (where alcohol is employed as both a reducing agent and solvent).$^{80}$ In addition, noble metal $\mathrm{Au}-$ incorporation is a promising strategy to retard compositionloss and boost the catalytic durability for Au-core/Pt-based-shell structured catalysts (via outward diffusion of $\mathrm{Au}$ atoms in the subsurface).$^{61}$ More recently, inspired by the above-mentioned two design strategies, Qin and co-workers developed a $\mathrm{Pd}_{9} \mathrm{Au}_{1} @ \mathrm{Pt} / \mathrm{C}$ core-shell catalyst via a $\mathrm{Pd}_{9} \mathrm{Au}_{1}$-catalyzed coating route in ethanol solution with carbon black (Vulcan XC-72) as support for the ORR (see Fig. 3L-N). ${ }^{81}$ The as-synthesized $\mathrm{Pd}_{9} \mathrm{Au}_{1} @ \mathrm{Pt} \mathrm{NP}$ catalyst presents well-defined core-shell structures superposed on a carbon support (see Fig. 3L), and the thickness of the Pt layers can be controlled by tuning the amount of Pt precursor during synthesis. The $\mathrm{Pd}_{9} \mathrm{Au}_{1} @ \mathrm{Pt} / \mathrm{C}$ catalyst with 2 atomic Pt layers exhibits the best mass activity for the ORR (see Fig. 3M and N), and excellent stability as evidenced by its even increased half-wave potential after 10000 $\mathrm{CV}$ cycles in oxygen-saturated $0.1 \mathrm{M} \mathrm{HClO}_{4}$ electrolyte. This greatly enhanced ORR stability can be attributed to the compressive strain and stabilizing effect of the $\mathrm{Pd}_{9} \mathrm{Au}_{1}$ core on the Pt shell. ${ }^{81}$

4.1.4 Metal compound nanoparticles. Diversified transition metal compounds (e.g., oxides, nitrides, carbides, phosphates, sulfides) have shown surprising ORR catalytic activity under alkaline and even acidic conditions, when interfacial coupling with heteroatom-doped carbon materials occurs. ${ }^{82,83}$ In the early period, a hybrid material consisting of high-metal-density 

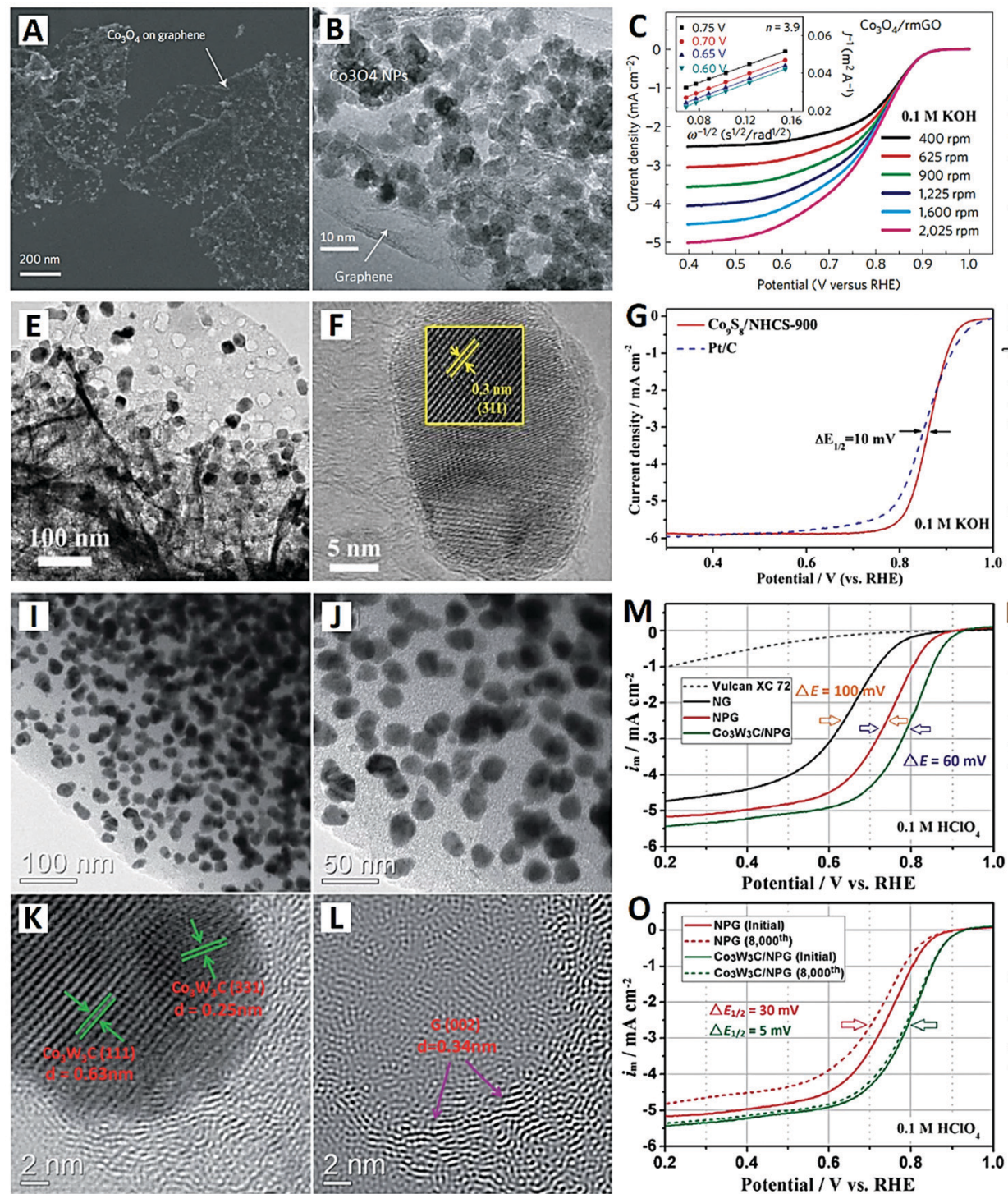
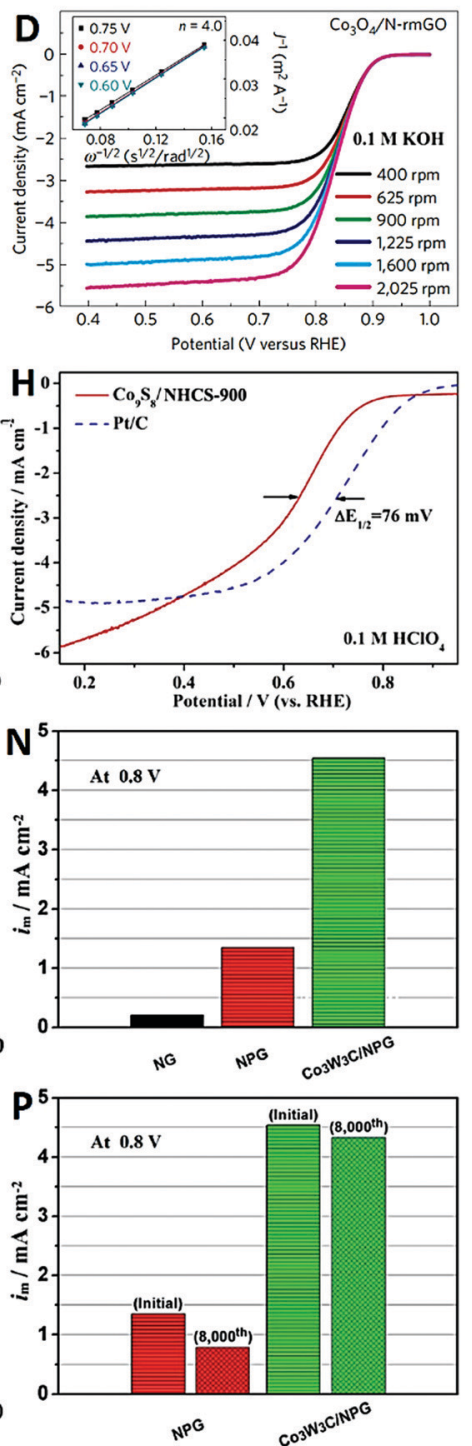

Fig. 4 The $\mathrm{CO}_{3} \mathrm{O}_{4} / \mathrm{N}$-rmGO catalyst (reprinted with permission from ref. 84): (A and B) SEM and TEM images, and (C and D) electrochemical performances. The $\mathrm{Co}_{9} \mathrm{~S}_{8} / \mathrm{NHCS}-900$ catalyst (reprinted with permission from ref. 85): (E and F) TEM images and (G and H) electrochemical performances. The $\mathrm{CO}_{3} \mathrm{~W}_{3} \mathrm{C} / \mathrm{NPG}$ catalyst (reprinted with permission from ref. 88): (I-L) TEM images and (M-P) electrochemical performances.

$\mathrm{Co}_{3} \mathrm{O}_{4}$ NPs grown on $\mathrm{N}$-doped reduced mildly oxidized GO (N-rmGO) nanosheets was developed as a high-performance ORR electrocatalyst in alkaline $(0.1 \mathrm{M} \mathrm{KOH})$ electrolyte (see Fig. 4A-D). ${ }^{84}$ Although $\mathrm{Co}_{3} \mathrm{O}_{4}$ or graphene oxide alone had little catalytic activity, their hybrid exhibited an unexpected, surprisingly high ORR catalytic efficiency $(n=3.9)$, and that was further enhanced by nitrogen doping of graphene $(n=4.0)$ (see Fig. 4C and D). The $\mathrm{Co}_{3} \mathrm{O}_{4} / \mathrm{N}-\mathrm{rmGO}$ hybrid electrocatalyst exhibited similar catalytic activity but superior stability to Pt in alkaline solutions, in which the catalytic activity originated from the synergetic chemical coupling effect (SCCE) between the high-metal-density $\mathrm{Co}_{3} \mathrm{O}_{4} \mathrm{NPs}$ and $\mathrm{N}$-doped graphene active support. ${ }^{84}$ This is a very promising ORR electrocatalyst for alkaline fuel cells and has recently gained attention as a solution for electrolyte carbonation in advanced energy conversion.
To achieve both high catalytic efficiency and outstanding stability, Wang et al. designedly synthesized monodispersed $\mathrm{Co}_{9} \mathrm{~S}_{8}$ NPs embedded in N-doped hierarchical carbon nanoflakes (denoted $\mathrm{Co}_{9} \mathrm{~S}_{8} / \mathrm{NHCS}$ ) as an ORR catalyst, by direct carbonization of metanilic anion-confined 2-D cobalt-aluminum layered double hydroxides (CoAl-LDHs) (see Fig. $4 \mathrm{E}-\mathrm{H}){ }^{85}$ The electrochemical results showed that the $\mathrm{Co}_{9} \mathrm{~S}_{8} / \mathrm{NHCS}$ material prepared at $900{ }^{\circ} \mathrm{C}$ exhibited superior ORR catalytic activity in both alkaline $(0.1 \mathrm{M} \mathrm{KOH})$ and acidic $\left(0.1 \mathrm{M} \mathrm{HClO}_{4}\right)$ electrolytes (see Fig. 4G and $\mathrm{H}$ ). High onset and half-wave potentials of 0.97 and $0.86 \mathrm{~V}$ were obtained in $0.1 \mathrm{M} \mathrm{KOH}$ electrolyte, which are comparable to those of commercial $\mathrm{Pt} / \mathrm{C}(1.00 \mathrm{~V}$ and $0.85 \mathrm{~V})$. And in $0.1 \mathrm{M} \mathrm{HClO}_{4}$ electrolyte, the $\mathrm{Co}_{9} \mathrm{~S}_{8} / \mathrm{NHCS}-900$ catalyst showed only a $76 \mathrm{mV}$ difference in half-wave potential when compared with commercial $\mathrm{Pt} / \mathrm{C}$. The average value of the electron number $(n)$ is 3.95 and 3.65 for alkaline and acidic 
electrolytes respectively. The durability of $\mathrm{Co}_{9} \mathrm{~S}_{8} / \mathrm{NHCS}-900$ is much better than that of $\mathrm{Pt} / \mathrm{C}$ in both electrolytes. The highdensity $\mathrm{Co}_{9} \mathrm{~S}_{8}$ NPs with small particle size provide abundant active sites and high catalytic activity. The synchronous carbonization of CoAl-LDHs makes the $\mathrm{Co}_{9} \mathrm{~S}_{8}$ NPs embedded within the carbon nanoflakes, leading to strong anchoring force and outstanding stability. ${ }^{85}$

Carbide-based electrocatalysts (e.g., tungsten carbide, WC) have been intensively studied because of their Pt-like behavior and intrinsic catalytic activity for chemical catalysis. ${ }^{86}$ Especially, bimetallic carbides showed more enhanced electrocatalytic activity for the ORR due to their special electronic structure and the synergistic effect of the dual metal species. ${ }^{87}$ Recently, $\mathrm{Li}$ and co-workers proposed a composite of cobalt-tungsten bimetallic carbide NPs and N/P co-doped graphitized carbon $\left(\mathrm{Co}_{3} \mathrm{~W}_{3} \mathrm{C} / \mathrm{NPG}\right)$ as a highly active and stable non-noble-metal catalyst for the acidic ORR (see Fig. 4I-P). ${ }^{88}$ Obviously, extremely high-density $\mathrm{Co}_{3} \mathrm{~W}_{3} \mathrm{C}$ NPs of about $20 \mathrm{~nm}$ size were loaded onto the graphitized carbon support (see Fig. 4I-L). The carbon content of $\mathrm{Co}_{3} \mathrm{~W}_{3} \mathrm{C} / \mathrm{NPG}$ was determined to be $39.8 \%$ by TGA; in other words, the $\mathrm{Co}_{3} \mathrm{~W}_{3} \mathrm{C}$ loading onto the NPG support was up to $60.2 \%$. The newly $\mathrm{Co}_{3} \mathrm{~W}_{3} \mathrm{C} / \mathrm{NPG}$ catalyst presented a high onset potential of $0.92 \mathrm{~V}$, a large limiting current $\left(5.3 \mathrm{~mA} \mathrm{~cm}^{-2}\right)$ and an especially high half-wave potential $(0.79 \mathrm{~V})$ in $0.1 \mathrm{M}$ $\mathrm{HClO}_{4}$ electrolyte (see Fig. 4M-P). The slightly decreased halfwave potential of $5 \mathrm{mV}$ and the high electron transfer number of 3.95 after 8000 cycles indicated that the catalyst undergoes a steady four-electron process in acidic medium. The excellent performances can be attributed to two factors: (i) the Co element in the carbide endows it with $\mathrm{Co} / \mathrm{N} / \mathrm{C}$ and $\mathrm{Co} / \mathrm{P} / \mathrm{C}$ double active sites; and (ii) the $\mathrm{W}$ species in the carbide is a synergistic component that boosts the activity of the hybrid catalyst system. ${ }^{88}$

4.1.5 Metal compound-promoted metal (or its alloy) nanoparticles. Some transition metal compounds (e.g., carbides) were found to have synergistic promoting effects on noble metals (or their alloys) for the ORR.$^{89-91}$ For example, a WC$\mathrm{PdFe} / \mathrm{C}$ electrocatalyst showed superior activity comparable with that of $\mathrm{Pt} / \mathrm{C}$ towards the ORR in acidic electrolyte due to the synergistic effect of $\mathrm{Pd}-\mathrm{Fe}$ and $\mathrm{WC} .{ }^{89}$ The $\mathrm{Co}_{6} \mathrm{Mo}_{6} \mathrm{C}_{2}$ promoted $\mathrm{Pt} / \mathrm{C}$ showed much higher activity and stability than $\mathrm{Pt} / \mathrm{C}$ for the ORR in acidic electrolyte. ${ }^{90}$ The synergistic effect is proved to be based on the close-range interface interaction between the carbide (co-catalyst) and noble metal NPS (catalyst). ${ }^{91}$ The electron metal-support interaction (EMSI) can elucidate the synergistic effect, by which electron transfers from the carbide to noble metal adjust its binding energy to an optimized level. ${ }^{92}$ Therefore, the high-density and uniform distribution of the two components on carbon supports is a prerequisite for the formation of close-contact interfaces and prominent EMSI due to the synergistic effect.

Recently, He et al. utilized large-surface-area graphene as a support to load high-density WC and Pt NPs, which showed high activity and high stability for the ORR in $0.1 \mathrm{M} \mathrm{HClO}_{4}$ (see Fig. 5A-C). ${ }^{93}$ A microwave-assisted method was used to synthesize truncated hexagonal pyramid (THP) WC with $5 \mathrm{~nm}$ in size on graphene $\left(\mathrm{WC}_{\mathrm{THP}} / \mathrm{G}\right)$ first, then Pt NPs on the $\mathrm{WC}_{\mathrm{THP}} / \mathrm{G}$ composite with close-contact $\mathrm{Pt}-\mathrm{WC}$ interfaces were prepared by a chemical adsorption/reduction method (see Fig. 5A). Pt$\mathrm{WC}_{\mathrm{THP}} / \mathrm{G}$ showed much higher ORR onset potential (1.052 vs. $0.993 \mathrm{~V})$, half-wave potential (0.942 vs. $0.900 \mathrm{~V})$ and mass activity (528 vs. $137 \mathrm{~mA} \mathrm{mg}_{\mathrm{Pt}}^{-1}$ ) values compared with commercial Pt/C (see Fig. 5B and C). The enhancement of ORR activity on $\mathrm{Pt}-\mathrm{WC}_{\mathrm{THP}} / \mathrm{G}$ is mainly due to the synergistic effect of $\mathrm{Pt}$ and WC, which correlates with the change in the Pt surface d-band center caused by the EMSI on the Pt-WC interfaces. Furthermore, the EMSI can also increase the binding energy of oxygen on $\mathrm{Pt}-\mathrm{WC}_{\mathrm{THP}} / \mathrm{G}$, thereby enhancing its catalytic activity toward the ORR. ${ }^{93}$

The development of multi-component hybrid catalysts offers great promise to enhance catalytic performance for the ORR. Li and co-workers reported a quaternary hybrid material composed of WC, FeS, FePt alloy and N-doped carbon (NC), i.e. $\mathrm{WC} / \mathrm{FeS} / \mathrm{FePt} / \mathrm{NC}$ hybrid architecture, as a high-performance electrocatalyst for the ORR (see Fig. 5D-F). ${ }^{94}$ Due to the efficient ternary promoting effects from WC, FeS and NC, the FePt alloy electrocatalyst exhibits an excellent mass activity of $317 \mathrm{~mA} \mathrm{mg}_{\mathrm{Pt}}{ }^{-1}$, which is much higher than that of $\mathrm{Pt} / \mathrm{C}$ catalyst (125 $\mathrm{mA} \mathrm{mg}{ }_{\mathrm{Pt}}{ }^{-1}$ ) (see Fig. 5E and F). Moreover, superior durability of the $\mathrm{WC} / \mathrm{FeS} / \mathrm{FePt} / \mathrm{NC}$ is also demonstrated for the ORR in acidic electrolyte $\left(0.1 \mathrm{M} \mathrm{HClO}_{4}\right)$. This hybrid catalyst has three structural advantages over previous reports: ${ }^{89-91}$ (i) ultrafine 1-D WC nanorods are prepared by an FeS-regulated strategy; (ii) FePt alloy is formed by in situ transformation on FeS without an external Fe source; and (iii) multiple synergistic effects on the FePt alloy might be in operation relying on the WC, FeS and NC components.

Recently, Pt-free electrocatalysts based on Pd have been proposed as promising candidates for the ORR in acidic electrolyte, due to the inherent catalytic activity and lower cost of Pd compared to Pt. For example, Li and co-workers synthesized a high-performance $\mathrm{Pd}$ electrocatalyst $\left(\mathrm{Pd} / \mathrm{Co}_{3} \mathrm{~W}_{3} \mathrm{C} / \mathrm{GC}\right)$ for the ORR, which was synergistically enhanced using $\mathrm{Co}_{3} \mathrm{~W}_{3} \mathrm{C}$ and graphitic carbon (GC) (see Fig. 5G-N). ${ }^{95}$ The GC nanosheet was uniformly decorated with the ultrahigh-density and wellproportioned $\mathrm{Co}_{3} \mathrm{~W}_{3} \mathrm{C}$ NPs $(\sim 20 \mathrm{~nm}$ ) and Pd NPs $(\sim 3 \mathrm{~nm}$ ) (see Fig. 5A and B). The Pd NPs were deposited not only onto the carbon substrate but also onto $\mathrm{Co}_{3} \mathrm{~W}_{3} \mathrm{C}$, indicating a strong interaction between the $\mathrm{Co}_{3} \mathrm{~W}_{3} \mathrm{C}$ and Pd NPs (see Fig. $5 \mathrm{C}$ and D). It was estimated that more than $30 \%$ of the Pd NPs were deposited onto or closely around the $\mathrm{Co}_{3} \mathrm{~W}_{3} \mathrm{C}$, which provided necessary conditions for interface synergistic effects. ${ }^{91}$ Due to the synergistic effects of $\mathrm{Co}_{3} \mathrm{~W}_{3} \mathrm{C}$ and acceleration by $\mathrm{GC}$, the $\mathrm{Pd} / \mathrm{Co}_{3} \mathrm{~W}_{3} \mathrm{C} / \mathrm{GC}$ electrocatalyst showed much higher activity than $\mathrm{Pd} / \mathrm{GC}$ and $\mathrm{Pd} / \mathrm{C}$ in a $0.1 \mathrm{M} \mathrm{HClO}_{4}$ electrolyte, and the mass activity of $\mathrm{Pd} / \mathrm{Co}_{3} \mathrm{~W}_{3} \mathrm{C} / \mathrm{GC}\left(110 \mathrm{~mA} \mathrm{mg}{ }_{\mathrm{Pd}}{ }^{-1}\right)$ was comparable to that of commercial $\mathrm{Pt} / \mathrm{C}\left(107 \mathrm{~mA} \mathrm{mg}_{\mathrm{Pt}}{ }^{-1}\right.$ ) (see Fig. $5 \mathrm{~K}$ and $\mathrm{L}$ ). After the 1000th cycle, a high activity retention of $93 \%$ was achieved for $\mathrm{Pd} / \mathrm{Co}_{3} \mathrm{~W}_{3} \mathrm{C} / \mathrm{GC}$, which was higher than that of commercial Pt/C (82\%) (see Fig. 5M and N). These excellent properties make it a highly active and stable Pt-free acidic ORR electrocatalyst. For the sake of convenience, the comparison 

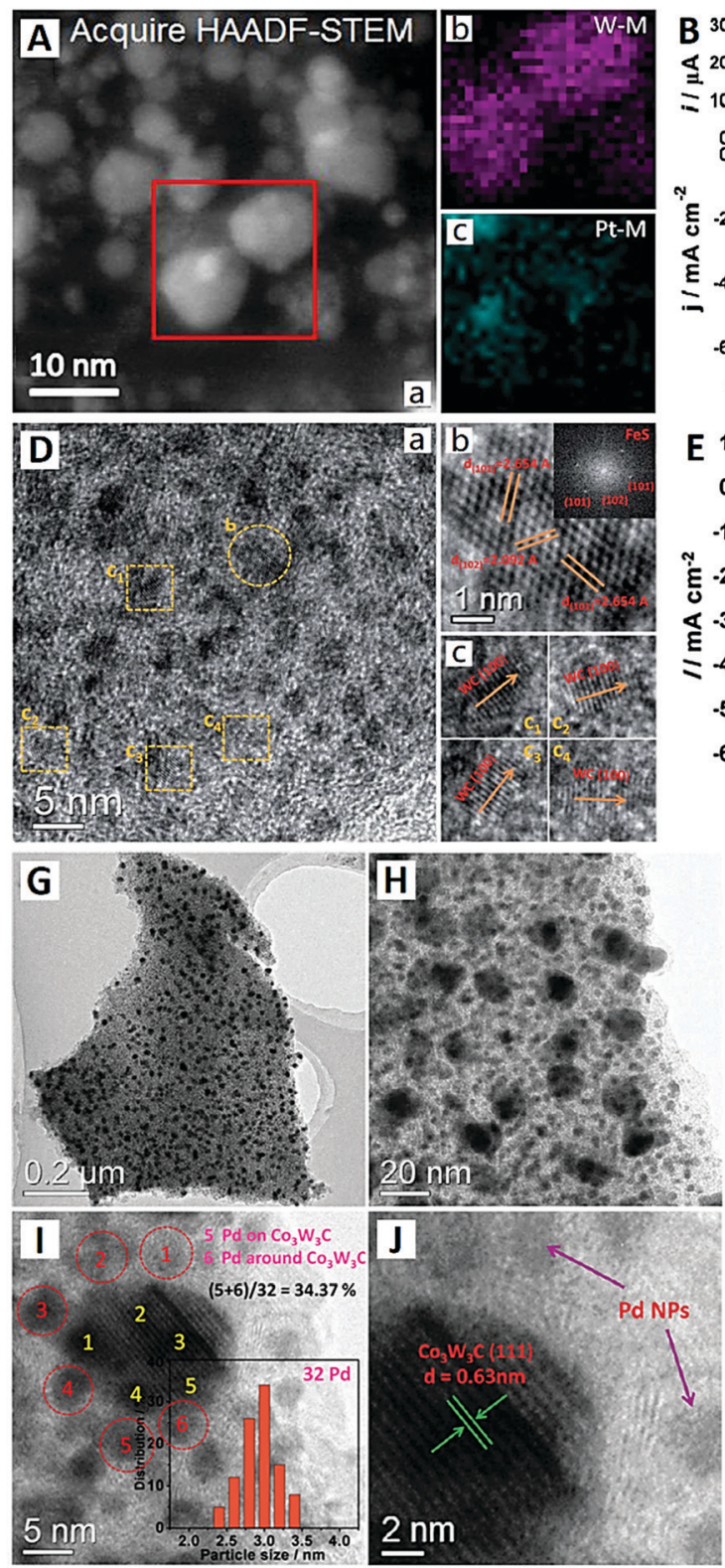
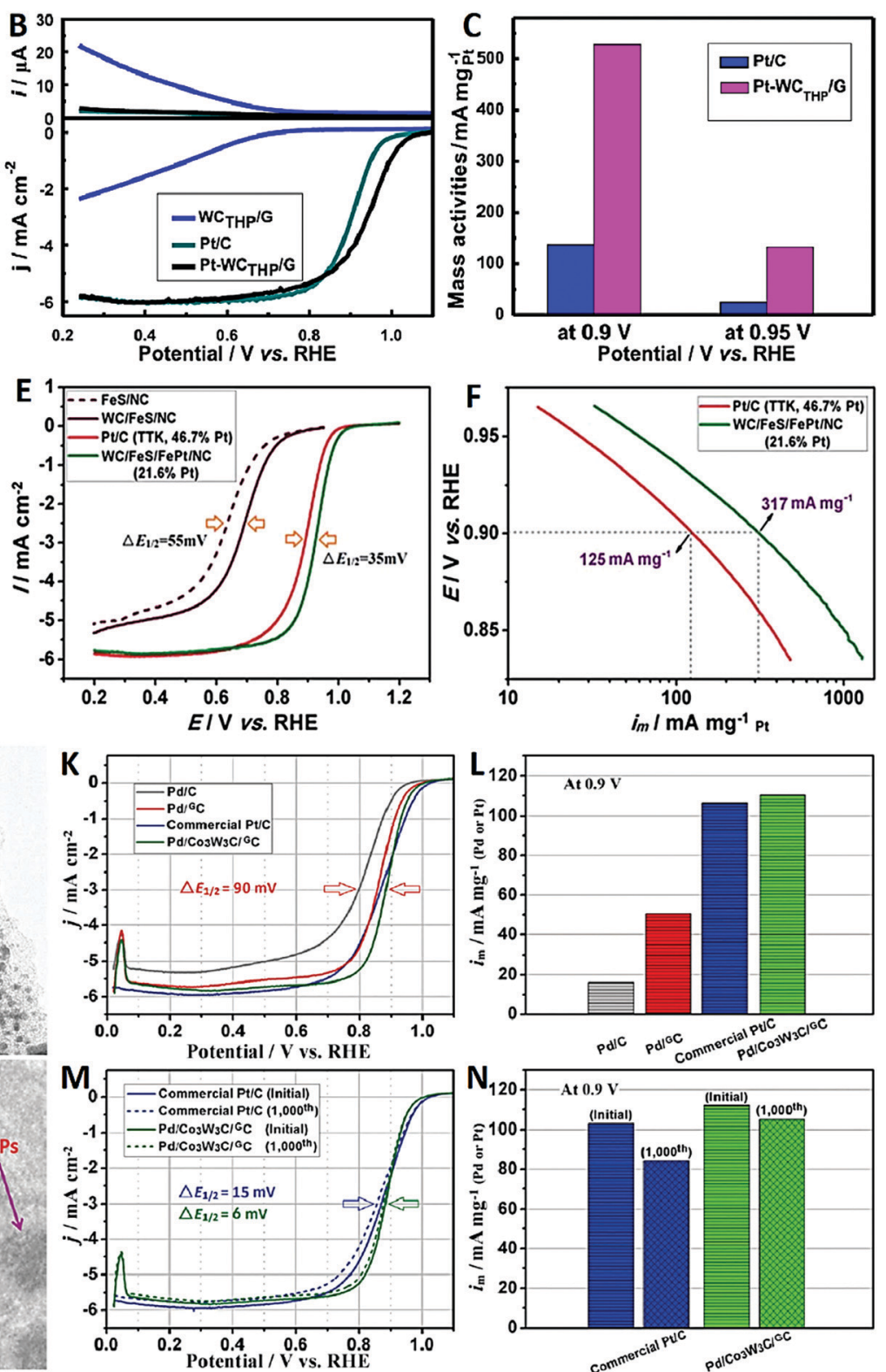

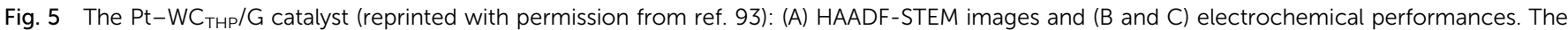

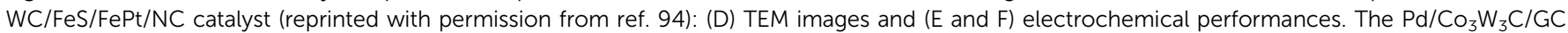
catalyst (reprinted with permission from ref. 95): (G-J) TEM images and $(K-N)$ electrochemical performances.

parameters of different nanoscale ORR electrocatalysts are summarized in Table 1.

\subsection{Atomic-level ORR electrocatalysts}

\subsubsection{Single-atom catalysts}

4.2.1.1 Origin of carbon-supported single-atom catalysts (Me/ $N / C$ ) for the ORR. Noble metal Pt catalysts are still the most efficient ORR electrocatalysts, but their scarcity, high price and unsatisfactory stability badly hinder their large-scale application. ${ }^{6-8}$ Therefore, on the premise of guaranteeing high performance, it is of great importance to develop cost-effective low-Pt, Pt-free, or even non-noble metal electrocatalysts. The introduction of heterogeneous element nitrogen $(\mathrm{N})$ and active transition metal (Me) components on carbon materials is an extensive and efficient strategy for the engineering of nonnoble metal (including $\mathrm{Me} / \mathrm{N} / \mathrm{C}$ and $\mathrm{M}-\mathrm{N}_{4} / \mathrm{C}$ single-atom catalysts) ORR electrocatalysts. ${ }^{22,96}$

The initially developed non-noble metal ORR electrocatalysts are $\mathrm{Me} / \mathrm{N} / \mathrm{C}$ catalysts (where Me includes transition metals, such as $\mathrm{Fe}, \mathrm{Co}, \mathrm{Ni}$ and $\mathrm{Cu}, \mathrm{N}$ is chelating atomic nitrogen, and $\mathrm{C}$ is $\mathrm{sp}^{2}$ carbon). ${ }^{97}$ The earliest non-noble metal electrocatalysts were macrocyclic compounds containing nitrogen transition metals, such as phthalocyanines and porphyrins. The common structure of these macrocyclic compounds is their planar configuration $\mathrm{MeN}_{4}$ structure, which is also the most likely active site in the $\mathrm{Me} / \mathrm{N} / \mathrm{C}$ catalyst. Some of the studies have 
Table 1 Comparison parameters of different ORR electrocatalysts

\begin{tabular}{|c|c|c|c|c|c|c|c|c|}
\hline Ref. & $\begin{array}{l}\text { Name of the } \\
\text { catalyst }\end{array}$ & Type of catalyst & $\begin{array}{l}\text { Content of } \\
\text { metals }\end{array}$ & Electrolyte & $\begin{array}{l}\text { Onset } \\
\text { potential }\end{array}$ & $\begin{array}{l}\text { Half-wave } \\
\text { potential }\end{array}$ & $\begin{array}{l}\text { Limited diffu- } \\
\text { sion } \\
\text { current density }\end{array}$ & $\begin{array}{l}\text { Specific activity/electron } \\
\text { transfer number }(n) / \mathrm{H}_{2} \mathrm{O}_{2} \\
\text { yield/Tafel slope }\end{array}$ \\
\hline [50] & Pt/GNP500 & Single metal NPs & $39.2 \mathrm{wt} \% \mathrm{Pt}$ & $5 \mathrm{M} \mathrm{H}_{2} \mathrm{SO}_{4}$ & $0.91 \mathrm{~V}$ & $0.80 \mathrm{~V}$ & $5.9 \mathrm{~mA} \mathrm{~cm}^{-1}$ & $80 \mathrm{~mA} \mathrm{mg}{ }^{-1} \mathrm{Pt} @ 0.8 \mathrm{~V}$ \\
\hline$[54]$ & Pt dendrites/C & Single metal NPs & $37.5 \mathrm{wt} \% \mathrm{Pt}$ & $0.1 \mathrm{M} \mathrm{HClO}_{4}$ & $1.02 \mathrm{~V}$ & $0.92 \mathrm{~V}$ & $6.0 \mathrm{~mA} \mathrm{~cm}^{-1}$ & $251 \mathrm{~mA} \mathrm{mg}{ }^{-1} \mathrm{Pt} @ 0.9 \mathrm{~V}$ \\
\hline [63] & $\mathrm{FePt} / \mathrm{rGO}$ & Metal alloy NPs & $37.0 \mathrm{wt} \% \mathrm{Pt}$ & $0.5 \mathrm{M} \mathrm{H}_{2} \mathrm{SO}_{4}$ & $1.00 \mathrm{~V}$ & $0.93 \mathrm{~V}$ & $5.6 \mathrm{~mA} \mathrm{~cm}^{-1}$ & $1960 \mathrm{~mA} \mathrm{mg}{ }^{-1} \mathrm{Pt} @ 0.9 \mathrm{~V}$ \\
\hline$[70]$ & PtAg/3DMGS & Metal alloy NPs & 49.6 wt\% PtAg & $0.1 \mathrm{M} \mathrm{HClO}_{4}$ & $1.02 \mathrm{~V}$ & $0.93 \mathrm{~V}$ & $6.0 \mathrm{~mA} \mathrm{~cm}^{-1}$ & $392 \mathrm{~mA} \mathrm{mg}{ }^{-1} \mathrm{Pt} @ 0.9 \mathrm{~V}$ \\
\hline$[76]$ & Pt-Ni@Pt $/ \mathrm{G}$ & Metal core-shell NPs & - & $0.1 \mathrm{M} \mathrm{HClO}_{4}$ & $0.94 \mathrm{~V}$ & $0.83 \mathrm{~V}$ & $6.3 \mathrm{~mA} \mathrm{~cm}^{-1}$ & 610 mA mg ${ }^{-1} \mathrm{Pt} @ 0.9 \mathrm{~V}$ \\
\hline$[79]$ & $\mathrm{Pd}_{10} \mathrm{Pt}_{1} / \mathrm{AGNs}$ & Metal core-shell NPs & $32.0 \mathrm{wt} \% \mathrm{PdPt}$ & $0.1 \mathrm{M} \mathrm{HClO}_{4}$ & $1.00 \mathrm{~V}$ & $0.89 \mathrm{~V}$ & $5.7 \mathrm{~mA} \mathrm{~cm}^{-1}$ & 1185 mA mg ${ }^{-1} \mathrm{Pt} @ 0.9 \mathrm{~V}$ \\
\hline$[81]$ & $\mathrm{Pd}_{9} \mathrm{Au}_{1} @ \mathrm{Pt} / \mathrm{C}$ & Metal core-shell NPs & 19.6 wt $\%$ PdAuPt & $0.1 \mathrm{M} \mathrm{HClO}_{4}$ & $0.94 \mathrm{~V}$ & $0.89 \mathrm{~V}$ & $6.1 \mathrm{~mA} \mathrm{~cm}^{-1}$ & 239 mA mg ${ }^{-1} \mathrm{Pt} @ 0.9 \mathrm{~V}$ \\
\hline$[84]$ & $\mathrm{Co}_{3} \mathrm{O}_{4} / \mathrm{N}-\mathrm{rmGO}$ & Metal compound NPs & $70.0 \mathrm{wt} \% \mathrm{Co}_{3} \mathrm{O}_{4}$ & $0.1 \mathrm{M} \mathrm{KOH}$ & $0.93 \mathrm{~V}$ & $0.83 \mathrm{~V}$ & $5.0 \mathrm{~mA} \mathrm{~cm}^{-1}$ & $n=3.90$ \\
\hline [85] & $\mathrm{Co}_{9} \mathrm{~S}_{8} / \mathrm{NHCS}$ & Metal compound NPs & $19.6 \mathrm{wt} \% \mathrm{Co}_{9} \mathrm{~S}_{8}$ & $\begin{array}{l}0.1 \mathrm{M} \mathrm{KOH} / \\
0.1 \mathrm{M} \mathrm{HClO}_{4}\end{array}$ & $\begin{array}{l}0.97 \mathrm{~V} / \\
0.78 \mathrm{~V}\end{array}$ & $\begin{array}{l}0.86 \mathrm{~V} / \\
0.63 \mathrm{~V}\end{array}$ & $\begin{array}{l}6.0 \mathrm{~mA} \mathrm{~cm}^{-1} / \\
5.0 \mathrm{~mA} \mathrm{~cm}^{-1}\end{array}$ & $n=3.95 / n=3.65$ \\
\hline$[88]$ & $\mathrm{Co}_{3} \mathrm{~W}_{3} \mathrm{C} / \mathrm{NPG}$ & Metal compound NPs & $\begin{array}{l}60.2 \mathrm{wt} \% \\
\mathrm{Co}_{3} \mathrm{~W}_{3} \mathrm{C}\end{array}$ & $0.1 \mathrm{M} \mathrm{HClO}_{4}$ & $0.92 \mathrm{~V}$ & $0.79 \mathrm{~V}$ & $5.3 \mathrm{~mA} \mathrm{~cm}^{-1}$ & $n=3.95$ \\
\hline [93] & $\mathrm{Pt}-\mathrm{WC}_{\mathrm{THP}} / \mathrm{G}$ & $\begin{array}{l}\text { Synergistic hybrid } \\
\text { NPs }\end{array}$ & - & $0.1 \mathrm{M} \mathrm{HClO}_{4}$ & $1.05 \mathrm{~V}$ & $0.94 \mathrm{~V}$ & $6.0 \mathrm{~mA} \mathrm{~cm}^{-1}$ & $528 \mathrm{~mA} \mathrm{mg}{ }^{-1} \mathrm{Pt} @ 0.9 \mathrm{~V}$ \\
\hline$[94]$ & $\mathrm{WC} / \mathrm{FeS} / \mathrm{FePt} / \mathrm{NC}$ & $\begin{array}{l}\text { Synergistic hybrid } \\
\text { NPs }\end{array}$ & $28.4 \mathrm{wt} \% \mathrm{Pt}$ & $0.1 \mathrm{M} \mathrm{HClO}_{4}$ & $1.03 \mathrm{~V}$ & $0.92 \mathrm{~V}$ & $6.0 \mathrm{~mA} \mathrm{~cm}^{-1}$ & 317 mA mg ${ }^{-1} \mathrm{Pt} @ 0.9 \mathrm{~V}$ \\
\hline [95] & $\mathrm{Pd} / \mathrm{Co}_{3} \mathrm{~W}_{3} \mathrm{C} / \mathrm{GC}$ & $\begin{array}{l}\text { Synergistic hybrid } \\
\text { NPs }\end{array}$ & $30.0 \mathrm{wt} \% \mathrm{Pd}$ & $0.1 \mathrm{M} \mathrm{HClO}_{4}$ & $0.98 \mathrm{~V}$ & $0.87 \mathrm{~V}$ & $5.6 \mathrm{~mA} \mathrm{~cm}^{-1}$ & $110 \mathrm{~mA} \mathrm{mg}{ }^{-1} \mathrm{Pd} @ 0.9 \mathrm{~V}$ \\
\hline [118] & $\mathrm{Fe}-\mathrm{N}-\mathrm{C} / \mathrm{N}-\mathrm{OMC}$ & Single-atom catalysts & $2.9 \mathrm{wt} \% \mathrm{Fe}$ & $0.1 \mathrm{M} \mathrm{KOH}$ & $1.08 \mathrm{~V}$ & $0.93 \mathrm{~V}$ & $8.1 \mathrm{~mA} \mathrm{~cm}^{-1}$ & $n=3.93$ \\
\hline$[120]$ & SA-Fe-NHPC & Single-atom catalysts & $1.25 \mathrm{wt} \% \mathrm{Fe}$ & $0.1 \mathrm{M} \mathrm{KOH}$ & $1.04 \mathrm{~V}$ & $0.93 \mathrm{~V}$ & $5.9 \mathrm{~mA} \mathrm{~cm}^{-1}$ & $n=3.92$ \\
\hline$[121]$ & $\begin{array}{l}\text { Commercial } \mathrm{Fe}-\mathrm{N}- \\
\mathrm{C}\end{array}$ & Single-atom catalysts & - & $0.1 \mathrm{M} \mathrm{KOH}$ & $0.97 \mathrm{~V}$ & $0.85 \mathrm{~V}$ & $7.1 \mathrm{~mA} \mathrm{~cm}^{-1}$ & $n=3.97$ \\
\hline$[123]$ & $\mathrm{Fe}-\mathrm{N}_{4} \mathrm{SACs}$ & Single-atom catalysts & $8.02 \mathrm{wt} \% \mathrm{Fe}$ & $0.1 \mathrm{M} \mathrm{KOH}$ & $1.00 \mathrm{~V}$ & $0.84 \mathrm{~V}$ & $5.8 \mathrm{~mA} \mathrm{~cm}^{-1}$ & $1570 \mathrm{~mA} \mathrm{mg}{ }^{-1} \mathrm{Fe} @ 0.85 \mathrm{~V}$ \\
\hline$[124]$ & Fe-N-C SACs & Single-atom catalysts & 1.5 at $\% \mathrm{Fe}$ & $0.5 \mathrm{M} \mathrm{H}_{2} \mathrm{SO}_{4}$ & $1.03 \mathrm{~V}$ & $0.88 \mathrm{~V}$ & $4.0 \mathrm{~mA} \mathrm{~cm}^{-1}$ & $\mathrm{H}_{2} \mathrm{O}_{2}<1 \%$ \\
\hline$[125]$ & $\mathrm{Fe}-\mathrm{N}-\mathrm{C}$ SACs & Single-atom catalysts & $2.5 \mathrm{wt} \% \mathrm{Fe}$ & $0.5 \mathrm{M} \mathrm{H}_{2} \mathrm{SO}_{4}$ & $0.94 \mathrm{~V}$ & $0.82 \mathrm{~V}$ & $5.4 \mathrm{~mA} \mathrm{~cm}^{-1}$ & $0.047 \mathrm{~A} \mathrm{~cm}^{-2}$ at $0.88 \mathrm{~V}_{\mathrm{iR}-}$ \\
\hline [128] & $\mathrm{Co}-\mathrm{N}_{4}$ SACs & Single-atom catalysts & 1.0 at $\%$ Co & $0.5 \mathrm{M} \mathrm{H}_{2} \mathrm{SO}_{4}$ & $0.93 \mathrm{~V}$ & $0.82 \mathrm{~V}$ & $4.0 \mathrm{~mA} \mathrm{~cm}^{-1}$ & $\mathrm{H}_{2} \mathrm{O}_{2}<1.5 \%$ \\
\hline$[129]$ & $\mathrm{Fe}_{2} \mathrm{~N}_{6}$ DACs & Dual-atom catalysts & $4.9 \mathrm{wt} \% \mathrm{Fe}$ & $0.5 \mathrm{M} \mathrm{H}_{2} \mathrm{SO}_{4}$ & $0.92 \mathrm{~V}$ & $0.82 \mathrm{~V}$ & $5.0 \mathrm{~mA} \mathrm{~cm}^{-1}$ & $n=3.96$ \\
\hline$[130]$ & $\mathrm{Co}_{2} \mathrm{~N}_{5}$ DACs & Dual-atom catalysts & - & $0.1 \mathrm{M} \mathrm{HClO}_{4}$ & $0.90 \mathrm{~V}$ & $0.79 \mathrm{~V}$ & $6.0 \mathrm{~mA} \mathrm{~cm}^{-1}$ & $n=3.97 ; 7468 \mathrm{~mA} \mathrm{mg}_{\mathrm{Co}_{2}}-1$ \\
\hline$[131]$ & $\mathrm{Fe}, \mathrm{Co} \mathrm{N}-\mathrm{C}$ DACs & Dual-atom catalysts & - & $0.1 \mathrm{M} \mathrm{HClO}_{4}$ & $1.06 \mathrm{~V}$ & $0.86 \mathrm{~V}$ & $6.0 \mathrm{~mA} \mathrm{~cm}^{-1}$ & $n=3.98$ \\
\hline$[132]$ & $\mathrm{FeCoN}_{6} \mathrm{DACs}$ & Dual-atom catalysts & 10 wt $\%$ FeCo & $\begin{array}{l}0.1 \mathrm{M} \mathrm{KOH} / \\
0.1 \mathrm{M} \mathrm{HClO}_{4}\end{array}$ & $\begin{array}{l}0.95 \mathrm{~V} / \\
0.91 \mathrm{~V}\end{array}$ & $\begin{array}{l}0.89 \mathrm{~V} / \\
0.81 \mathrm{~V}\end{array}$ & $\begin{array}{l}5.7 \mathrm{~mA} \mathrm{~cm}^{-1} / \\
5.0 \mathrm{~mA} \mathrm{~cm}^{-1}\end{array}$ & $n=3.97$ \\
\hline [133] & $\mathrm{Fe}-\mathrm{N}_{4} \mid \mathrm{Co}-\mathrm{N}_{4}$ DACs & Dual-atom catalysts & 3.27 wt\% FeCo & $\begin{array}{l}0.1 \mathrm{M} \mathrm{KOH} / \\
0.5 \mathrm{M} \mathrm{H}_{2} \mathrm{SO}_{4}\end{array}$ & $\begin{array}{l}0.98 \mathrm{~V} / \\
0.91 \mathrm{~V}\end{array}$ & $\begin{array}{l}0.86 \mathrm{~V} / \\
0.75 \mathrm{~V}\end{array}$ & $\begin{array}{l}5.7 \mathrm{~mA} \mathrm{~cm}^{-1} / \\
5.2 \mathrm{~mA} \mathrm{~cm}^{-1}\end{array}$ & $n=3.97 ; 52 \mathrm{mV} \mathrm{dec}{ }^{-1}$ \\
\hline [136] & $\mathrm{Co} / \mathrm{PC} \mathrm{SCCs}$ & Atom cluster catalysts & - & $0.1 \mathrm{M} \mathrm{KOH}$ & $1.00 \mathrm{~V}$ & $0.92 \mathrm{~V}$ & $6.0 \mathrm{~mA} \mathrm{~cm}^{-1}$ & $66 \mathrm{mV} \mathrm{dec}{ }^{-1}$ \\
\hline$[137]$ & CuZn/NC SCCs & Atom cluster catalysts & 0.77 wt\% CuZn & $0.1 \mathrm{M} \mathrm{KOH}$ & $1.00 \mathrm{~V}$ & $0.89 \mathrm{~V}$ & $5.2 \mathrm{~mA} \mathrm{~cm}^{-1}$ & $45 \mathrm{mV} \mathrm{dec}-1$ \\
\hline$[138]$ & $\mathrm{Fe}_{\mathrm{AC}} @ \mathrm{Fe}_{\mathrm{SA}}-\mathrm{N}-\mathrm{C}$ & SACs + SCCs & $4.0 \mathrm{wt} \% \mathrm{Fe}$ & $0.1 \mathrm{M} \mathrm{KOH}$ & $1.00 \mathrm{~V}$ & $0.91 \mathrm{~V}$ & $6.1 \mathrm{~mA} \mathrm{~cm}^{-1}$ & $61 \mathrm{mV} \mathrm{dec}{ }^{-1}$ \\
\hline [139] & $\mathrm{Fe}-\mathrm{N}-\mathrm{C}$ & SACs + SCCs & $2.9 \mathrm{wt} \% \mathrm{Fe}$ & $0.1 \mathrm{M} \mathrm{KOH}$ & $0.98 \mathrm{~V}$ & $0.90 \mathrm{~V}$ & $3.8 \mathrm{~mA} \mathrm{~cm}^{-1}$ & $n=3.85$ \\
\hline$[140]$ & $\mathrm{Fe}_{\mathrm{SA}} / \mathrm{FeO}_{\mathrm{NC}} / \mathrm{NSC}$ & SACs + SCCs & $0.25 \mathrm{wt} \% \mathrm{Fe}_{\mathrm{SA}}$ & $0.1 \mathrm{M} \mathrm{KOH}$ & $0.95 \mathrm{~V}$ & $0.85 \mathrm{~V}$ & $4.5 \mathrm{~mA} \mathrm{~cm}^{-1}$ & $n=3.87$ \\
\hline$[142]$ & Co-SAC/SNPs@NC & SACs + NPs & 5.8 wt $\%$ Co & $0.1 \mathrm{M} \mathrm{KOH}$ & $0.97 \mathrm{~V}$ & $0.90 \mathrm{~V}$ & $6.0 \mathrm{~mA} \mathrm{~cm}^{-1}$ & $n=3.96$ \\
\hline$[143]$ & CoNPs@Fe-N ${ }_{4}-\mathrm{C}$ & SACs + NPs & $0.1 \mathrm{wt} \%$ Co & $0.1 \mathrm{M} \mathrm{KOH}$ & $1.01 \mathrm{~V}$ & $0.92 \mathrm{~V}$ & $5.0 \mathrm{~mA} \mathrm{~cm}^{-1}$ & $n=3.95$ \\
\hline$[144]$ & FeCo-N-C & SACs + NPs & 6.6 wt $\%$ FeCo & $0.1 \mathrm{M} \mathrm{KOH}$ & $0.98 \mathrm{~V}$ & $0.85 \mathrm{~V}$ & $4.8 \mathrm{~mA} \mathrm{~cm}^{-1}$ & $n=3.97$ \\
\hline
\end{tabular}

shown that the structures of $\mathrm{MeN}_{2}$ and $\mathrm{MeN}_{2+2}$ may also be the active sites for oxygen reduction. Therefore, the structure formula of the active sites of $\mathrm{Me} / \mathrm{N} / \mathrm{C}$ non-noble metal electrocatalysts can be expressed as: $\mathrm{Me} / \mathrm{N}_{x} / \mathrm{C}(x=2$ and 4 , or $2+2) \cdot{ }^{98}$ The early $\mathrm{Me} / \mathrm{N} / \mathrm{C}$ non-noble metal catalysts were usually in the form of composites with transition metal NPs and N-doped carbon, laying more emphasis on the pyrolytic synthesis of catalysts, as well as the effect of the size of metal NPs, the content of $\mathrm{N}$, and the thickness of the graphited layer on ORR performances.

In recent years, since the original concept of "single-atom catalysts (SACs)" (noble metal Pt single atoms on oxide supports) was proposed by the Zhang group, ${ }^{23}$ numerous noble metal (Pt, Pd, Ag, Ir, etc.) and transition metal (Fe, Co, Ni, Cu, etc.) SACs on carbon supports have been discovered in different electrocatalytic fields. ${ }^{22,99}$ The formation of $\mathrm{M}-\mathrm{N}_{4}$ active moieties (where $\mathrm{M}$ includes noble or transition metals) from atomically dispersed metal (M) atoms and the coordination $\mathrm{N}$ atoms doped onto carbon supports is the main reason for the stabilization and high ORR activity of these carbon-supported SACs. $^{25,100}$ In general, the research priorities of carbonsupported SACs $\left(\mathrm{M}-\mathrm{N}_{4}\right)$ ORR electrocatalysts are as follows: (i) adjusting the coordination environment and electronic structures of $\mathrm{M}$ centers, (ii) optimizing the nanoscale morphology and pore structures of carbon supports, (iii) increasing the number of metal active centers by increasing the metal density, and (iv) investigating the atomic interaction and synergistic effect of single atoms with different metal densities.

\subsubsection{Synergistic effect of high-density single-atom catalysts} on carbon supports. In the field of catalysis, when the distance between the two catalytically active centers is reduced to the atomic scale, the interaction between the active centers will greatly affect the catalytic performance of the catalyst (including catalytic selectivity and conversion). ${ }^{101}$ Due to the high surface energy of single atoms, the metal loading in 
carbon-supported SACs is generally low $(<1.5 \mathrm{wt} \%)$ in order to avoid the agglomeration of single metal atoms. Therefore, the distance between two adjacent active sites is relatively far ( $\gg 1 \mathrm{~nm}$ ), and the interaction between two single atoms is basically ignored. ${ }^{102}$ In fact, in order to improve the practicability of SACs, it is necessary to fix more metal atoms per unit area to realize the design of high-density single-atom active sites, which will make the metal atoms come close together, and the interaction between adjacent sites cannot be ignored. ${ }^{99}$ If the metal loading in carbon-supported SACs can be increased so that it not only maintains the feature of high dispersion of single atoms, but also increases the interaction between adjacent atoms, it is highly expected to realize the synergistic effect between these adjacent single atoms. ${ }^{103}$ The synergistic effect between metal atoms may exist in single or dual atom systems with the same metal or different metals, which plays roles in enhancing the adsorption of reaction substrates, reducing the reaction potential barrier, changing the reaction path, etc. ${ }^{104}$ Therefore, it is a very important topic to study the synergistic effect of single atoms. It enriches the regulation means of SACs, emphasizes the importance of site interaction, and has positive guiding significance for the design of carbon-supported SACs with high dispersion and high metal density.

However, some of the current carbon-supported SACs cannot provide enough reaction sites in ORR catalytic reactions due to their low metal loading. ${ }^{4-46}$ Generally, at least two adjacent metal atoms (i.e., two adjacent active centers) need to cooperate effectively to promote the efficient four-electron mechanism. Therefore, the existing noble metal SACs with low metal loading usually exhibit oxygen reduction by the twoelectron mechanism because they cannot cooperate with each other. ${ }^{105}$ Many carbon nanocomposites with a M/N/C structure, especially those in atomically-dispersed $\mathrm{M}-\mathrm{N}_{4}$ (where $\mathrm{M}=\mathrm{Fe}$, $\mathrm{Co}, \mathrm{Ni}$, etc.) moieties, exhibit ORR catalytic properties that are even comparable to commercial Pt based catalysts. ${ }^{25,99,100}$ The latest research shows that in $\mathrm{M} / \mathrm{N} / \mathrm{C}$ catalyst, when the dispersed $\mathbf{M}-\mathrm{N}_{4}$ single sites are close enough (i.e., when the metal density is large enough), there will be strong interaction between two adjacent single atoms, so as to form the synergetic paired active centers of $\mathrm{M}-\mathrm{N}_{4}$ and significantly improve the ORR catalytic performances. ${ }^{104,106}$ The specific reasons can be attributed to the following aspects: (i) adjacent metal atoms may change the adsorption energy and adsorption state of catalytic species; (ii) the synergistic effect may be conducive to the activation of chemical bonds and reduce the reaction energy barrier; and (iii) the adjacent paired active centers may also change the reaction route of the intermediate and lead to fast kinetics.

4.2.1.3 Preparation strategies of high-density single-atom catalysts on carbon supports. In recent years, carbon-supported SACs have become the hotspot due to their high atomic utilization, definite active centers, and high catalytic performances. So far, various synthesis strategies have been developed to prepare carbon-supported SACs: ${ }^{107}$ (i) SACs can be synthesized by impregnation in aqueous dispersion, where the metal precursors are anchored onto carbon by physical adsorption or chemical coordination; ${ }^{22}$ (ii) because bulk metal can be changed into gaseous species by high-temperature treatment, the thermal emission and atom trapping method has been developed to prepare sintering-resistant SACs on pyrolytic carbon supports; ${ }^{99}$ (iii) atomic layer deposition (ALD) and chemical vapor deposition (CVD) technologies are powerful and effective strategies for controllable synthesis of SACs and cluster catalysts; ${ }^{26}$ and (iv) some other physical and chemical synthesis methods are used to prepare SACs, such as ball milling and electrochemical deposition. ${ }^{107}$

However, due to the easy migration and aggregation of active atoms in the preparation process, the high loading of SACs onto carbon supports is still a great challenge. ${ }^{25}$ Common synthesis methods of $\mathrm{M}-\mathrm{N}-\mathrm{C}$ (in $\mathrm{M}-\mathrm{N}_{4}$ moieties) SACs include the process of high-temperature pyrolysis. Increasing the density of active sites only by increasing the concentration of metals usually leads to inevitable metal clusters and metal NPs. ${ }^{99}$ Researchers have achieved some impressive results by using the following methods to achieve highly-dispersed and high-density SACs on carbon supports: (i) using a large number of complexing agents to form coordination bonds with metal ions to physically isolate the metal sources at the molecular scale, ensuring the formation of highly-dispersed single atom sites by subsequent pyrolysis; ${ }^{108}$ (ii) nanoscale carbon supports with high specific surface area and rich functional groups are used to realize the high-density loading of metal complexes relying on their high pore volume and rich coordinated groups; ${ }^{26}$ and (iii) high-density $\mathrm{M}-\mathrm{N}_{4}$ moieties can be generated by the synchronous pyrolysis of $\mathrm{N}$-containing precursors and metal complexing compounds, where a porous carbon network is generated as an effective cascaded anchoring carrier. ${ }^{99} \mathrm{~N}$ Doped carbon $(\mathrm{N}-\mathrm{C})$ is an ideal support for the preparation of high-metal-density SACs, where the $\mathrm{N}$ with lone pair electrons can form a $\mathrm{M}-\mathrm{N}_{4}$ coordination bond with metal species, which greatly improves the thermal and chemical stability of SACs. The synthetic strategies of $\mathrm{N}-\mathrm{C}$ materials mainly include: use of (1) nitrogen-containing organic compounds (such as phenanthroline, porphyrin and phthalocyanine); (2) MOFs and their derivatives; (3) N-doped graphene and CNTs; (4) g- $\mathrm{C}_{3} \mathrm{~N}_{4}$ with high nitrogen content; and (5) rich, cheap and renewable nitrogen-containing biomass. ${ }^{34}$

In the following, we will introduce the design strategies and preparation methods of high-density SACs on carbon supports through several typical cases according to the "physical synthesis" and "chemical synthesis" categories. For the physical synthesis, ALD and CVD synthetic strategies are analyzed contrastively. Recently, Yan et al. devised a reliable ozone-assisted multicycle ALD technique for the preparation of high-metalloading $\mathrm{Co}_{1} / \mathrm{G}$ SACs, which allows the precise tuning of the density of isolated Co single atoms $\left(\mathrm{Co}_{1}\right)$ on the graphene $(\mathrm{G})$ support (see Fig. 6A-C). ${ }^{109}$ During ALD cycles, the self-limiting surface reaction ensures that each Co precursor molecule is anchored onto a single active site of the graphene, and the active site (epoxy groups) can be re-generated by the secondary reaction between ozone and the graphene surface (see Fig. 6A). 
A
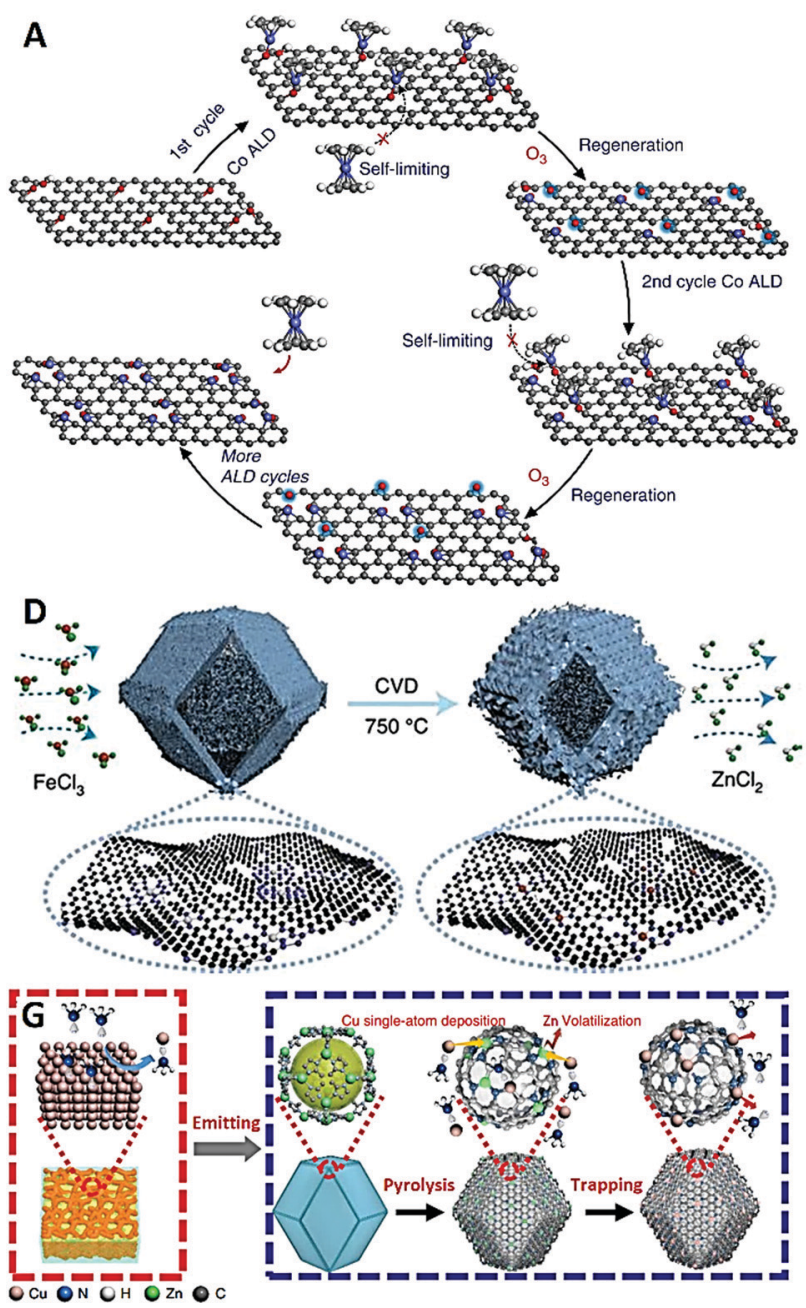
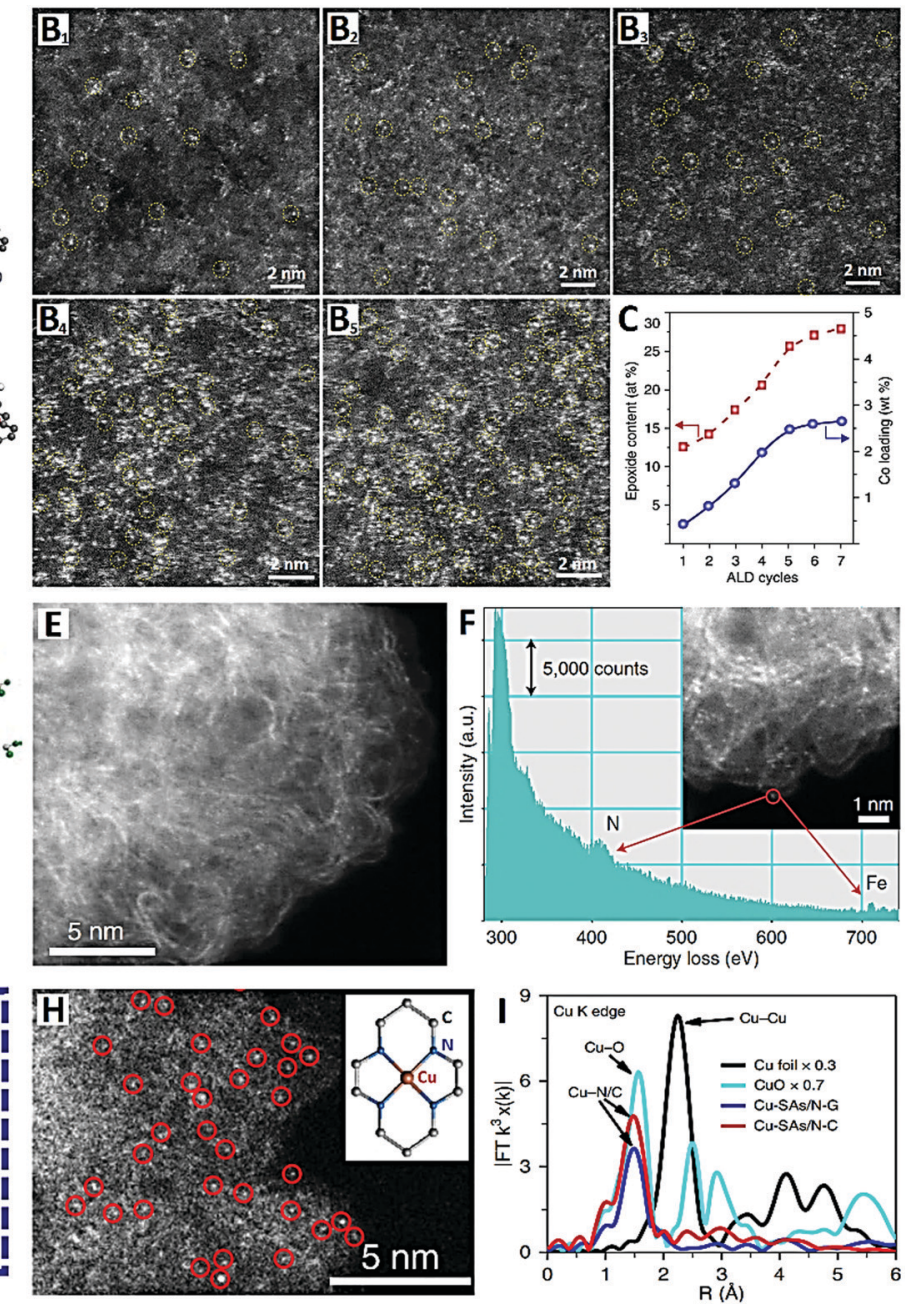

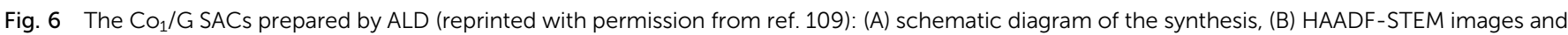

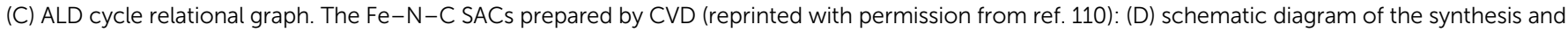

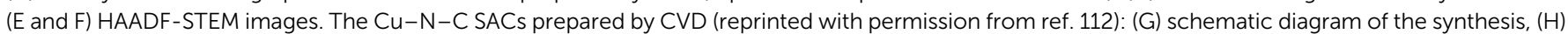
HAADF-STEM image and (I) EXAFS spectra.

The expected result is that the ALD in different cycles can be used to accurately control the synthesis of SACs with different metal loadings. A series of $\mathrm{Co}_{1} / \mathrm{G}$ catalysts with Co loadings of $0.4,0.8,1.3,2.0$, and $2.5 \mathrm{wt} \%$ (see Fig. 6B1-B5) were synthesized by performing 1, 2, 3, 4, and 5 cycles of ozone-assisted Co ALD respectively (see Fig. 5C). The density of Co single atoms loaded onto graphene is closely correlated with the amount of epoxy groups on the support, which further supports the idea that the epoxy groups act as anchor sites for the Co precursors. The ozone-assisted multicycle ALD not only completes a single cycle of ALD, but also regenerates the active sites of chelating single atoms, conducive to the precise tuning of the density of Co single atoms. ${ }^{109}$

In order to increase active site density and site utilization, Jiao et al. proposed a metal-transferred CVD technique to synthesize $\mathrm{Fe}-\mathrm{N}-\mathrm{C}$ by flowing iron chloride $\left(\mathrm{FeCl}_{3}\right)$ vapor over a $\mathrm{Zn}-\mathrm{N}-\mathrm{C}$ substrate at $750{ }^{\circ} \mathrm{C}$, leading to in situ trans-metalation of $\mathrm{Zn}-\mathrm{N}_{4}$ sites into $\mathrm{Fe}-\mathrm{N}_{4}$ sites (see Fig. $6 \mathrm{D}-\mathrm{F}$ ). ${ }^{110}$ Zeolite imidazole framework (ZIF-8) nanocrystals with a uniform size of about $80 \mathrm{~nm}$ were first prepared to obtain a $\mathrm{Zn}-\mathrm{N}-\mathrm{C}$ substrate with high-density $\mathrm{Zn}-\mathrm{N}_{4}$ sites (see Fig. 6D). After the in situ CVD trans-metalation, carbon-supported Fe-based SACs with high-density $\mathrm{Fe}-\mathrm{N}_{4}$ sites were readily achieved (see Fig. 6E and $\mathrm{F}$ ). These $\mathrm{Fe}-\mathrm{N}_{4}$ sites formed by this transformation approach were in the gas-phase and electrochemically accessible, and the catalyst had a high active site density of $\mathrm{Fe}-\mathrm{N}_{4}(1.92$ $\times 10^{20}$ sites $\mathrm{g}^{-1}$ ) with $100 \%$ site utilization. ${ }^{110}$ Wang et al. lately reported $\mathrm{Fe}-\mathrm{N}-\mathrm{C}$ SACs $\left(\mathrm{Fe}-\mathrm{N}_{4}\right.$ sites) obtained by pyrolysis of ferric $\left(\mathrm{Fe}^{3+}\right)$ ion-adsorbed porous $\mathrm{N}$-doped carbon derived from ZIF-8, which also showed a high density of accessible surface Fe- $\mathrm{N}_{4}$ sites $\left(2.63 \times 10^{20}\right.$ sites $\left.\mathrm{g}^{-1}\right) .{ }^{111}$ The high porosity of the ZIF-8-derived N-doped carbon support is a key factor in building $\mathrm{Fe}-\mathrm{N}-\mathrm{C}$ SACs with a high density of accessible-sites.

Because bulk copper can be changed into gaseous species of $\mathrm{Cu}\left(\mathrm{NH}_{3}\right)_{x}$ at high temperature and in an ammonia environment, a thermal emitting and atom trapping strategy was developed to prepare $\mathrm{Cu}-\mathrm{N}-\mathrm{C}$ SACs $\left(\mathrm{Cu}-\mathrm{N}_{4}\right.$ sites) on a pyrolytic carbon support from ZIF-8 (see Fig. 6G-I) by the Li group. ${ }^{112}$ In 
the $\mathrm{NH}_{3}$ atmosphere, $\mathrm{Cu}\left(\mathrm{NH}_{3}\right)_{x}$ species were trapped by $\mathrm{Zn}$ vaporized defects in the $\mathrm{N}$-doped carbon, forming isolated $\mathrm{Cu}$ sites, and then forming $\mathrm{Cu}-\mathrm{N}_{4}$ catalysts (see Fig. 6G). Relatively high metal density and close atomic distance $(\sim 1 \mathrm{~nm})$ were demonstrated for these $\mathrm{Cu}-\mathrm{N}_{4}$ catalysts (see Fig. $6 \mathrm{H}$ and I). Overall, this work developed an $\mathrm{NH}_{3}$-assisted gas migration strategy (i.e., facile CVD strategy) that enabled the direct conversion of bulk metal to $\mathrm{M}-\mathrm{N}_{4}$ single atoms, bringing new hope for large-scale preparation and industrial applications of SACs on carbon supports.

For the chemical synthesis of carbon-supported SACs, the wet-chemistry and pyrolysis synthetic strategies are widely investigated. $^{23}$ The wet-chemistry method usually includes impregnation, co-precipitation, and electrochemical deposition, and belongs to the "top-down approach" based on ready-made carbon supports with vacancy modification (see Fig. 7A-(1)). This synthetic approach can easily lead to inevitable metal clusters or metal NPs when increasing the concentration of metals, and the subsequent acid treatment is therefore a necessary step. ${ }^{113}$ On the other hand, the pyrolysis method belongs to the "bottom-up approach”, where SACs are directly prepared from metal nodecontaining nitrogen and carbon precursors (such as MOFs and COFs) by pyrolysis (see Fig. 7A-(2)). For example, Jiang and coworkers ${ }^{114}$ recently reported atomically-dispersed Ni metal on $\mathrm{N}$ doped carbon nanotubes (CNTs) with a high Ni loading (20 wt\%) via the direct pyrolysis "bottom-up approach" with $\mathrm{Ni}(\mathrm{acac})_{2}$ and $\mathrm{C}_{2} \mathrm{H}_{8} \mathrm{~N}_{2}$ as precursors (see Fig. 7B). Wu and co-workers ${ }^{115}$ also reported high-density Fe SACs $(<1 \mathrm{~nm}$ in distance) supported on N-doped carbon nanosheets by a Phen-molecule-confined pyrolysis "top-down approach" with $\mathrm{FeCl}_{2}$, polyetherimide (PI) and $g-\mathrm{C}_{3} \mathrm{~N}_{4}$ as precursors (see Fig. 7C and D). Importantly, during pyrolysis, the closed Fe ions are directly reduced by carbonization
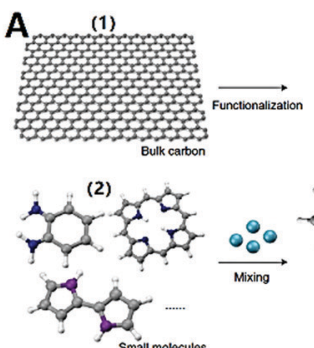

(3)
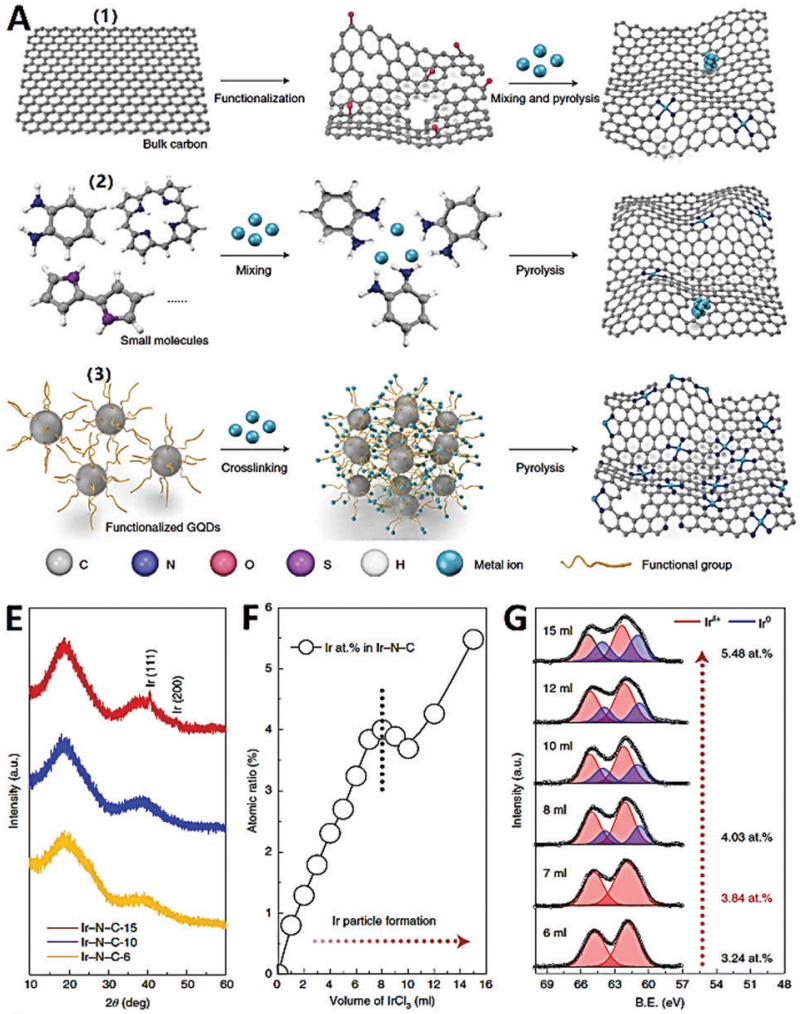

I Elranoo
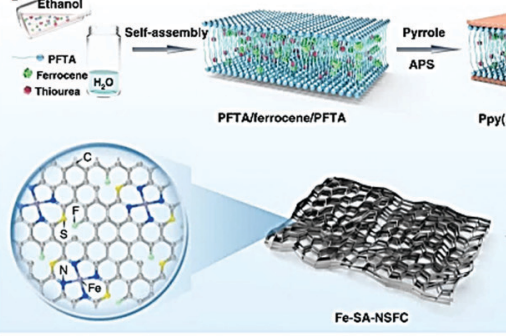

Fe-SA-NSFC
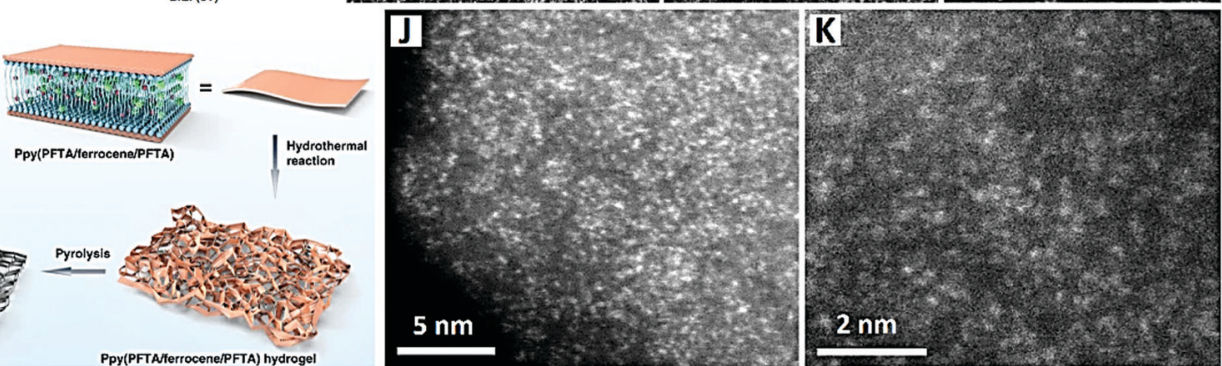

Fig. 7 (A) Schematic diagram of carbon-supported SACs by chemical synthesis; (B) HAADF-STEM images of Ni-N-C SACs prepared by pyrolysis (reprinted with permission from ref. 114); (C) schematic diagram and (D) HAADF-STEM images of Fe-N-C SACs obtained by pyrolysis (reprinted with permission from ref. 115); (E) XRD patterns, (F) atomic ratios, (G) XPS spectra, and (H) HAADF-STEM images of Fe-N-C SACs obtained by pyrolysis (see (A) for the schematic diagram) (reprinted with permission from ref. 116); (I) schematic diagram of the synthesis and (J and K) HAADF-STEM images of M-SANSFC (reprinted with permission from ref. 117). 
of PEI to form isolated $\mathrm{Fe}$ atoms without additional acid treatment.

Noble metal SACs have high catalytic activity per metal site, but it is usually difficult to achieve a high density of SACs (usually less than $3 \mathrm{wt} \%$ ), so the overall catalytic activity is limited. Therefore, developing a general synthesis strategy to greatly improve the atom density of noble metal SACs and make the metal loading close to or even exceed the commercial benchmark (e.g., $20 \mathrm{wt} \% \mathrm{Ir} / \mathrm{C})$ will play a key role in the field of electrocatalysis. In view of this, Xia and co-workers ${ }^{116}$ developed a universal method lately for synthesizing record highmetal-loading (41.6 wt\%) Ir SACs on graphene quantum dots (GQDs) (see Fig. 7A-(3) and E-H). Specifically, when functionalized with amine groups and mixed with $\mathrm{IrCl}_{3}$, GQDs can stably and uniformly diffuse and limit $\operatorname{Ir}^{3+}$ on their surfaces $\left(\mathrm{Ir}^{3+} /\right.$ GQDs- $\mathrm{NH}_{2}$ ) due to the strong chelation effect between $\mathrm{Ir}^{3+}$ and amine groups (see Fig. 7A-(3)). This strong interaction helps GQDs connect with each other and crosslink into a 3-D network structure during the freeze-drying process (see Fig. $7 \mathrm{H}_{1}$ ). Then pyrolysis was carried out in an ammonia rich atmosphere to obtain a GQD-supported Ir SAC (3.84 at\% or $41.6 \mathrm{wt} \%$ ) with $8 \mathrm{ml}$ of $\mathrm{IrCl}_{3}$ (see Fig. 7E-G). The GQD-supported Ir SAC (Ir-N sites) reveals an extremely-uniform and highly-dense distribution of Ir atoms ( $0.5 \mathrm{~nm}$ in distance) on GQDs (see Fig. $7 \mathrm{H}_{2}-\mathrm{H}_{4}$ ).

Starting from amine-group functional graphene quantum dots (GQDs- $\mathrm{NH}_{2}$ ), the authors had the following motives: (i) compared with the carbon support in the "top-down approach", GQDs are small enough to provide many N-doped active sites for anchoring a large number of isolated metal atoms; and (ii) compared with the organic precursors in the "bottom-up approach", GQDs, as an intermediate carbon support, do not undergo significant structural evolution during pyrolysis, providing stable and large spacings between metal atoms to avoid aggregation. ${ }^{116}$ The authors also obtained other noble metal (Pt) SACs or transition metal (Ni) SACs with similarly high metal loadings (32.3 wt\% and $15.0 \mathrm{wt} \%$ respectively) on GQDs, demonstrating the favorable universality and generality of this GQD- $\mathrm{NH}_{2}$-guided synthetic strategy for highloading metal single-atom architectures.

Furthermore, the design of tunable coordination environments (e.g., second coordination regulation) for carbonsupported SACs with high metal loading has special significance for catalytic performance regulation. Recently, Zhou et al. reported a multilayer stabilization strategy for constructing $\mathrm{M}-\mathrm{N}_{4}$ (where $\mathrm{M}=\mathrm{Fe}, \mathrm{Co}, \mathrm{Ru}$, Ir and Pt) SACs with high metal loading ( $\sim 16 \mathrm{wt} \%$ ) on $\mathrm{N}, \mathrm{S}$ and $\mathrm{F}$ co-doped porous graphitized carbons (i.e., M-SA-NSFC) (see Fig. 7I-K). ${ }^{117}$ The metal precursors (ferrocene) are embedded into perfluorotetradecanoic acid (PFTA) multilayers and further coated with polypyrrole (Ppy) prior to hydrothermal reaction and pyrolysis (see Fig. 7I). The confinement by the PFTA and Ppy multilayers can efficiently prevent metal precursors from migrating during the pyrolysis process, resulting in the efficient coordination of high-density metal atoms $(\sim 0.5 \mathrm{~nm}$ in distance) with $\mathrm{N}$ atoms in graphitized carbon (see Fig. 7J and K). This multilayer stabilization bottomup strategy coupled with the N, S and F co-doping conception is very promising, in terms of abundant metal species, the control of metal loading and second coordination regulation by $\mathrm{S}$ (or long-range regulation by $\mathrm{F}$ ), to explore the potential of highloading M-SACs and their diversified catalytic applications. ${ }^{117}$

4.2.1.4 Application of high-density single-atom catalysts on carbon supports for the ORR. Among many transition metal SACs, Fe-N-C catalyst has the most outstanding ORR performance. In alkaline electrolyte, the performance of $\mathrm{Fe}-\mathrm{N}-\mathrm{C}$ catalyst is even better than that of $\mathrm{Pt} / \mathrm{C}$ catalyst. ${ }^{97} \mathrm{Fe}-\mathrm{N}-\mathrm{C}$ catalysts are mainly prepared by pyrolysis of precursors containing $\mathrm{Fe}, \mathrm{N}$ and $\mathrm{C}$, where $\mathrm{C}$ and $\mathrm{N}$ precursors are transformed into an $\mathrm{N}$-doped carbon skeleton, and $\mathrm{Fe}$ atoms coordinate with $\mathrm{N}$ atoms to obtain $\mathrm{FeN}_{4}$ active sites. ${ }^{100}$ The N-doped carbon skeleton obtained by direct pyrolysis contains many disordered micropores, which results in low utilization of $\mathrm{FeN}_{4}$ active sites due to the low mass transfer kinetics in the micropores. In addition, the activity of the catalyst depends on the intrinsic activity of single metal sites and the number of accessible active sites. ${ }^{118}$ Therefore, increasing the metal loading of $\mathrm{Fe}-\mathrm{N}-\mathrm{C}$ SACs and improving the accessibility of $\mathrm{FeN}_{4}$ active sites is an effective way to further improve the ORR performance of $\mathrm{Fe}-\mathrm{N}-$ C catalyst.

Because ORR activity is controlled by kinetics and mass transfer processes, in order to better mass diffusion, optimizing the pore structure of catalysts can effectively affect their ORR activity. The rapid transfer of $\mathrm{O}_{2}$ from bulk solution to active centers is a key step in providing high current density. ${ }^{70}$ The three types of pore structures that can promote the mass transfer of $\mathrm{O}_{2}$ in porous catalysts are macropores $(>50 \mathrm{~nm})$, mesopores $(2-50 \mathrm{~nm})$ and micropores $(<2 \mathrm{~nm}) .{ }^{69}$ Each type of pore has a unique function to improve ORR activity: (i) macropores are designed to ensure that reactants quickly pass through the entire dense catalyst layer; (ii) mesopores ensure that electrolytes and reactants enter the active centers (e.g., $\mathrm{FeN}_{4}$ active sites) deeply buried under the surface of the catalyst; and (iii) micropores help in increasing the number of active sites and the total surface area of the catalyst. ${ }^{119}$

Recently, Feng and co-workers ${ }^{120}$ designed a novel N-doped hierarchical micro/meso-porous carbon (NHPC)-supported Fe$\mathrm{N}-\mathrm{C}$ SAC with densely available $\mathrm{FeN}_{4}$ species by a $\mathrm{Zn}$-mediated silica-template strategy, and applied it to a high-performance alkaline ORR (see Fig. 8A-E). Firstly, the DAP/ZnFe/SiO ${ }_{2}$ composite was prepared by drying colloidal silica containing 2,6-diaminopyridine (DAP), zinc nitrate and iron nitrate. The obtained $\mathrm{DAP} / \mathrm{ZnFe} / \mathrm{SiO}_{2}$ was heat treated at $900{ }^{\circ} \mathrm{C}$ under nitrogen for 2 hours, then etched in HF followed by secondary pyrolysis in nitrogen to obtain the final SA-Fe-NHPC SAC (see Fig. 8A). There are many mesopores on the Fe-NHPC SAC, with an average diameter of about $12 \mathrm{~nm}$, which is consistent with the size of the silica template (see Fig. 8B). In addition, the HAADF-STEM image of the Fe-NHPC SAC shows that the dense single Fe atoms are well dispersed on the carbon matrix with rich micropores by $\mathrm{Zn}$ vaporization (see Fig. 8C). The Fe-NHPC SAC showed unprecedentedly high ORR activity in $0.1 \mathrm{M} \mathrm{KOH}$ electrolyte, and the half wave potential was $0.93 \mathrm{~V}$ 
A<smiles>Nc1cccc(N)n1</smiles>
$+$

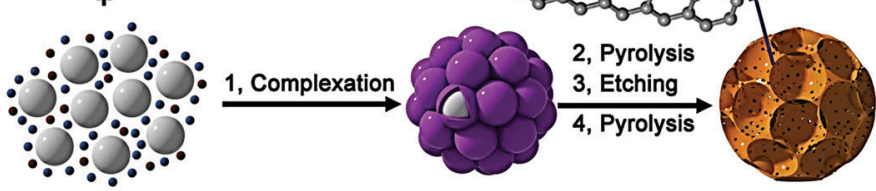

Silica colloid $\bullet \mathrm{Zn}^{2+} \bullet \mathrm{Fe}^{3+}$

DAP/ZnFe/SiO ${ }_{2}$ complex

SA-Fe-NHPC
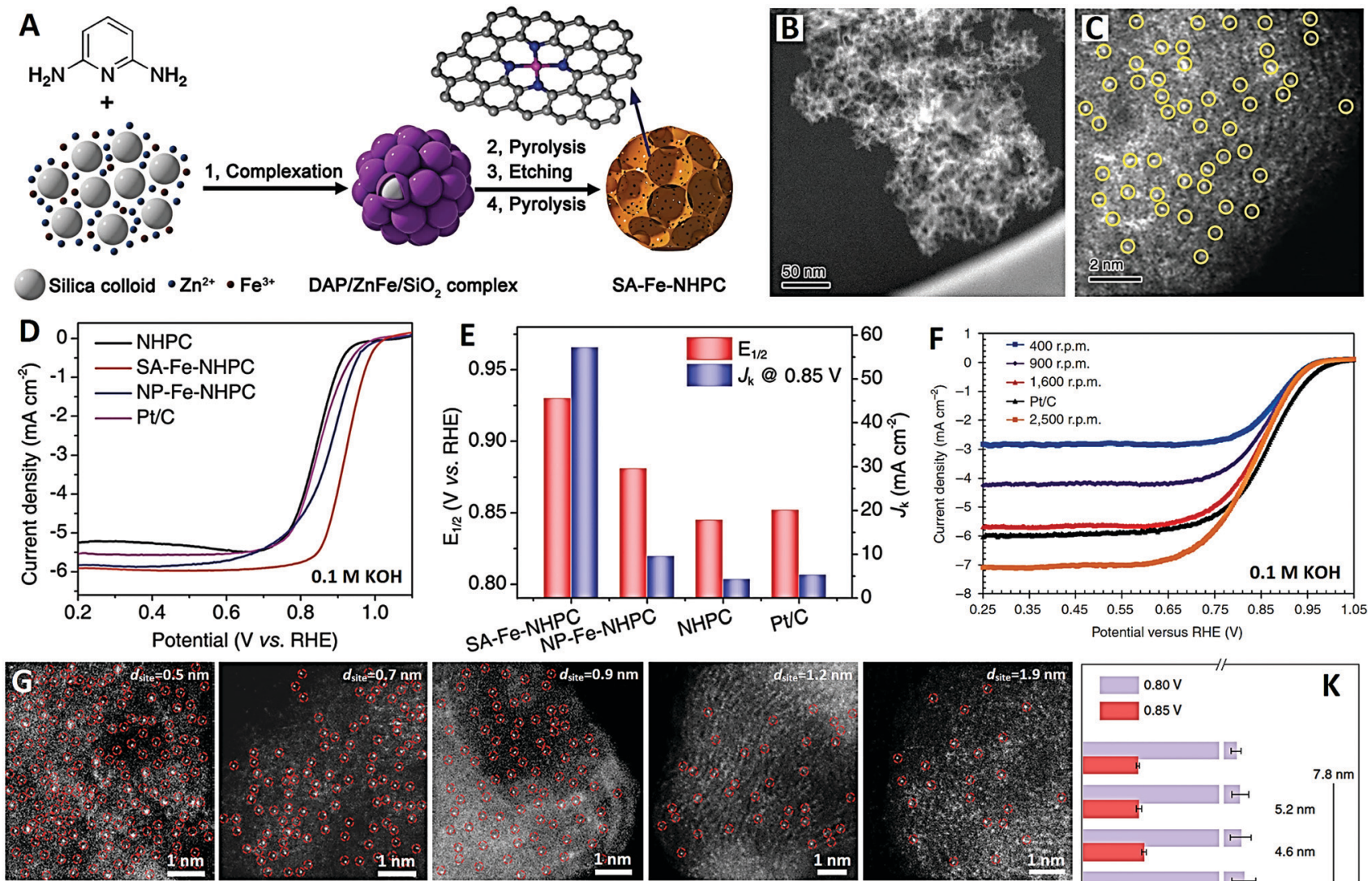

Potential versus RHE (V)
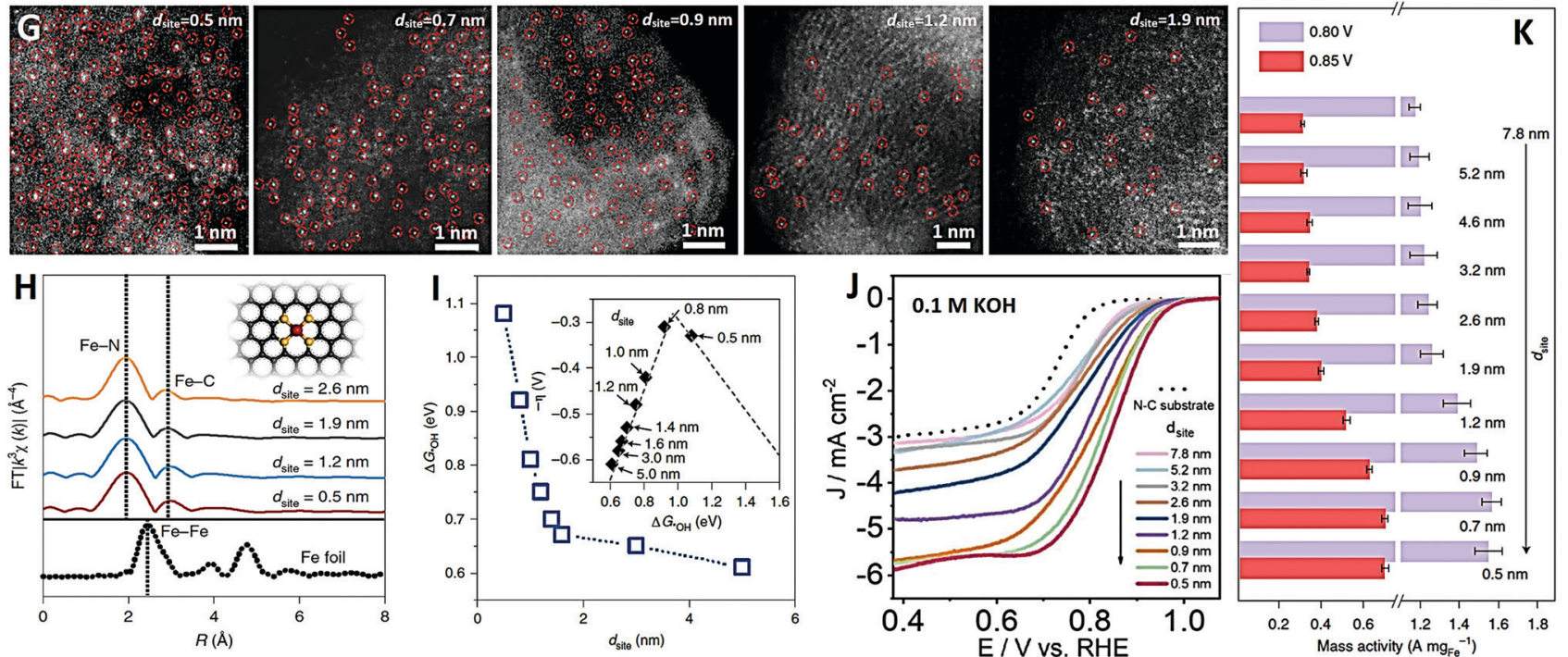

Fig. 8 The SA-Fe-NHPC catalyst (reprinted with permission from ref. 120): (A) schematic diagram of synthesis, (B and C) HAADF-STEM images and (D and E) electrochemical performances. (F) ORR curves of commercial Fe-N-C catalyst (reprinted with permission from ref. 121). The Fe- $\mathrm{N}_{4} \mathrm{SACs}$ with various site distances $\left(d_{\text {site }}\right.$ ) (reprinted with permission from ref. 123): (G) HAADF-STEM images, (H) EXAFS spectra, (I) Gibbs free energy, (J) ORR curves and $(K)$ mass activity for various $d_{\text {site }}$ values.

(see Fig. 8D and E), which is much better than those of $\mathrm{Pt} / \mathrm{C}$ catalyst $(0.82 \mathrm{~V})$ and commercial $\mathrm{Fe}-\mathrm{N}-\mathrm{C}$ catalyst $(0.85 \mathrm{~V})$ (see Fig. 8F). ${ }^{121}$ This work opens a new way to improve the density and accessibility of $\mathrm{FeN}_{4}$ species and develop high-performance $\mathrm{Fe}-\mathrm{N}-\mathrm{C}$ ORR catalysts. In addition, $\mathrm{Fe}-\mathrm{N}-\mathrm{C} / \mathrm{N}-\mathrm{OMC}$ catalysts with $\mathrm{N}$-doped ordered mesoporous carbon (N-OMC) can also provide highly accessible $\mathrm{FeN}_{4}$ active sites and reduce mass transfer resistance. ${ }^{118}$ Therefore, the $\mathrm{Fe}-\mathrm{N}-\mathrm{C} / \mathrm{N}-\mathrm{OMC}$ catalysts show extremely high ORR activity in $0.1 \mathrm{M} \mathrm{KOH}$ electrolyte, with a half wave potential of $0.93 \mathrm{~V}$ and a limited current density of $8.14 \mathrm{~mA} \mathrm{~cm}^{-2}$. To sum up, the design of mesoporous carbon and high metal loading provide double guarantee for high-performance SACs.
When the density of single-atom active sites increases to a certain extent, the distance between single atoms will become very small, and the interaction between adjacent active sites becomes a key factor affecting intrinsic activity. And the adjacent single-atom active sites can cooperate to produce an optimized electronic structure, which affects the catalytic activity and catalytic path of SACs in heterogeneous catalysis. ${ }^{122}$ Previous studies have shown that adjusting the active site density of SACs can significantly improve the electrocatalytic performance of the ORR due to the synergistic effect. ${ }^{104-106} \mathrm{At}$ the same time, the recent breakthrough in the synthesis method of SACs has helped the metal loading to exceed $10 \mathrm{wt} \%$, which exceeds the performance of $\mathrm{Pt} / \mathrm{C}(20 \mathrm{wt} \%)^{23}$ 
Although high-density SACs have better overall activity for the ORR, the catalytic behavior controlled by the distance between single active sites has not been deeply studied.

With that in mind, $\mathrm{Yu}$ and Xiao recently studied and revealed the origin of the enhancement of ORR activity (in $0.1 \mathrm{M} \mathrm{KOH}$ electrolyte) of isolated $\mathrm{Fe}-\mathrm{N}_{4}$ SACs with the different intersite distances at the sub-nanometer level, by integrating the experimental and theoretical methods (see Fig. 8G-K). ${ }^{123}$ Atomically-dispersed $\mathrm{Fe}-\mathrm{N}_{4}$ sites with controllable density and various site distances $\left(d_{\text {site }}\right)$ were prepared on an $\mathrm{N}$-doped carbon substrate via the hydrogel anchoring strategy (see Fig. 8G). When the $d_{\text {site }}$ was controlled at 0.5-2.6 nm, favorable $\mathrm{Fe}-\mathrm{N}_{4}$ moieties were obtained without Fe clusters or nanoparticles (see Fig. 8H). The theoretical and experimental results indicate that, when the $d_{\text {site }}$ value is less than $1.2 \mathrm{~nm}$, the strong interaction between adjacent $\mathrm{Fe}-\mathrm{N}_{4}$ sites changes the electronic structure and improves the inherent activity of the ORR. This distance-dependent enhanced activity could be maintained until the $d_{\text {site }}$ value was close to $0.7 \mathrm{~nm}$; when the $d_{\text {site }}$ was further reduced, the ORR activity decreased slightly (see Fig. 8I$\mathrm{K})$. This study determined in detail the kinetic behavior of a single active site and the site distance effect of adjacent single metal atoms, which provides an important opportunity to further understand the inherent catalytic behavior of carbonsupported SACs. And understanding the site distance effect of $\mathrm{Fe}-\mathrm{N}_{4}$ catalyst is of great significance to the mechanism of the ORR, which is helpful to realize the full potential of densely distributed SACs in electrocatalysis. ${ }^{123}$

Platinum group metal-free (PGM-free) catalysts for the ORR with atomically-dispersed $\mathrm{Fe}-\mathrm{N}_{4}$ sites have emerged as potential catalysts for acidic polymer electrolyte fuel cells (PEFCs). ${ }^{26}$ Therefore, it is very important to study the acidic ORR performance (in $\mathrm{H}_{2} \mathrm{SO}_{4}$ or $\mathrm{HClO}_{4}$ ) of carbon-supported $\mathrm{Fe}$ $\mathrm{N}-\mathrm{C}$ SACs with high $\mathrm{Fe}-\mathrm{N}_{4}$ site density. Previously, polyaniline/ cyanamide-based $\mathrm{Fe}-\mathrm{N}-\mathrm{C}$ SACs with rich $\mathrm{Fe}-\mathrm{N}_{4}$ sites at graphene edges exhibited a half-wave potential of $0.80 \mathrm{~V}$ and a limited current density of $3 \mathrm{~mA} \mathrm{~cm}{ }^{-2}$ in $0.5 \mathrm{M} \mathrm{H}_{2} \mathrm{SO}_{4}$ electrolyte. ${ }^{100}$ The Fe-N-C catalyst with the highest density of Fe- $\mathrm{N}_{4}$ active sites achieved from ZIF-8 precursors also showed respectable ORR activity with a half-wave potential of 0.88 and a limited current density of $4 \mathrm{~mA} \mathrm{~cm}{ }^{-2}$ in $0.5 \quad \mathrm{M} \mathrm{H}_{2} \mathrm{SO}_{4}$ electrolyte. ${ }^{124}$ Mesoporous silica coated ZIF-8 derived $\mathrm{Fe}-\mathrm{N}-\mathrm{C}$ with dense active sites and efficient mass transport exhibited a desirable half-wave potential of $0.82 \mathrm{~V}$ and a larger limited current density of $5.4 \mathrm{~mA} \mathrm{~cm}{ }^{-2}$ in $0.5 \mathrm{M} \mathrm{H}_{2} \mathrm{SO}_{4}$ electrolyte. ${ }^{125}$ Compared with ZIF-8-derived $\mathrm{Fe}-\mathrm{N}-\mathrm{C}$ prepared via wet chemical synthesis, the CVD method can reduce the pore size of the Kat-Zn (MeIm) $)_{2}$ (Kat) phase to reduce the formation of inert metal aggregates, resulting in a much higher density of $\mathrm{Fe}-\mathrm{N}_{4}$ active sites and excellent catalytic performance in $0.5 \mathrm{M}$ $\mathrm{H}_{2} \mathrm{SO}_{4}$ electrolyte. ${ }^{126}$ Besides, previously mentioned highdensity Fe SACs on porous carbon nanosheets presented a half-wave potential of $0.80 \mathrm{~V}$ and a larger limited current density of $5.5 \mathrm{~mA} \mathrm{~cm}{ }^{-2}$ in $0.1 \mathrm{M} \mathrm{HClO}_{4}$ electrolyte. $^{115}$ In general, it is difficult for the ORR half-wave potential of $\mathrm{Fe}-\mathrm{N}-\mathrm{C}$ in acidic electrolyte to reach $0.9 \mathrm{~V}$ as in alkaline electrolyte, ${ }^{118,121}$ so the development of acidic PEFCs with PGM-free catalysts is a challenging task.

On the other hand, carbon-supported Co-N-C SACs with a high-density of $\mathrm{Co}-\mathrm{N}_{4}$ active sites are also promising candidates for PGM-free catalysts, by virtue of their high intrinsic activity and immunity to Fenton reactions (for Fe-N-C SACs) that occurred in the proton exchange membrane of fuel cells. $^{26,96}$ The research on the relationship between the site density of Co- $\mathrm{N}_{4}$ moieties and the activity of Co-N-C SACs is also very necessary for achieving optimized performances in fuel cells. In view of this, the Shui team synthesized a series of Co-N-C SACs with different densities of Co- $\mathrm{N}_{4}$ active sites for a quantitative study of the structure-property relationship. ${ }^{127}$ It was found that in the low-density region, the battery power density increased slowly and linearly with the Co- $\mathrm{N}_{4}$ site density, while in the high-density region, an accelerated growth trend in terms of power density was observed. These results confirm the fact that M-N-C SACs with limited intrinsic activity can effectively improve the performance of batteries by increasing the density of $\mathrm{M}-\mathrm{N}_{4}$ active sites. ${ }^{97,100}$

More recently, the Shao team synthesized a highperformance atomically-dispersed $\mathrm{Co}(\mathrm{mIm})-\mathrm{NC}$ catalyst by means of a microporous encapsulation-ligand exchange strategy, where ZIF-8, Co(acac) ${ }_{3}$, and 2-methylimidazole (mIm) were used as precursors. ${ }^{128}$ This strategy greatly increases the density of $\mathrm{Co}-\mathrm{N}_{4}$ sites and therefore greatly increases ORR catalytic activity in $0.5 \mathrm{M} \mathrm{H}_{2} \mathrm{SO}_{4}$ electrolyte. The mass activity of the catalyst increased with the increase of Co content (0.28-1.0 at\%), in which the $E_{\text {onset }}$ and $E_{1 / 2}$ values of $\mathrm{Co}(\mathrm{mIm})-\mathrm{NC}(1.0 \mathrm{at} \% \mathrm{Co})$ were $0.93 \mathrm{~V}$ and $0.82 \mathrm{~V}$, which are only $25 \mathrm{mV}$ and $35 \mathrm{mV}$ lower than those of Pt/C catalyst, respectively. In addition, the catalytic activity of this $\mathrm{Co}-\mathrm{N}-\mathrm{C}$ $\mathrm{SAC}$ is comparable to that of the $\mathrm{Fe}-\mathrm{N}-\mathrm{C}$ SACs, but the durability is increased by four times. This study provides a promising method to develop high activity and durable Fe-free and PGM-free ORR electrocatalysts (i.e., high-density single atom $\mathrm{Co}-\mathrm{N}_{4} / \mathrm{C}$ ) for PEM fuel cells. ${ }^{128}$

4.2.2 Dual-atom catalysts. Metal-nitrogen-carbon (M-NC) SACs (such as $\mathrm{Fe}-\mathrm{N}-\mathrm{C}$ and $\mathrm{Co}-\mathrm{N}-\mathrm{C}$ ) with atomicallydispersed metal sites $\left(\mathrm{M}-\mathrm{N}_{4}\right)$ have very high atomic utilization efficiency and considerable ORR performances. However, in the ORR process, the $\mathrm{O}-\mathrm{O}$ bond dissociation is limited by the adsorption mode (side or end mode) of $\mathrm{O}_{2}$ on the single metal site, which is not conducive to its direct four-electron transfer process. $^{4,5}$ Recently, some transition metal dual-atom catalysts (DACs) with paired active sites (e.g., homonuclear $\mathrm{Fe}-\mathrm{Fe}$ or Co-Co and heteronuclear Fe-Co DACs) have stronger $\mathrm{O}_{2}$ adsorption capacity than SACs, which can effectively reduce the energy barrier of the $\mathrm{O}-\mathrm{O}$ bond, with higher ORR activity and higher selectivity for the four-electron mechanism (see Fig. 9). ${ }^{129-133}$ The development of dense $M_{1} M_{2} N_{x}$ dual-atom sites $^{134}$ will be an effective strategy to optimize the ORR catalytic path and reaction kinetics, to improve the catalytic efficiency of atomic-level ORR electrocatalysts.

For example, $\mathrm{Wu}$ and co-workers unraveled planar-like $\mathrm{Fe}_{2} \mathrm{~N}_{6}$ active sites (homonuclear DACs) as a highly efficient 


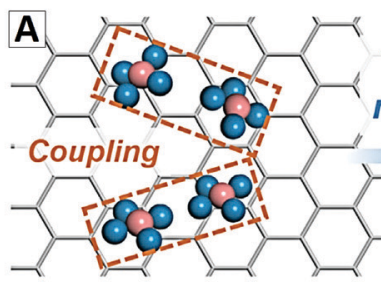

Isolated

$\mathrm{FeN}_{4}$ sites
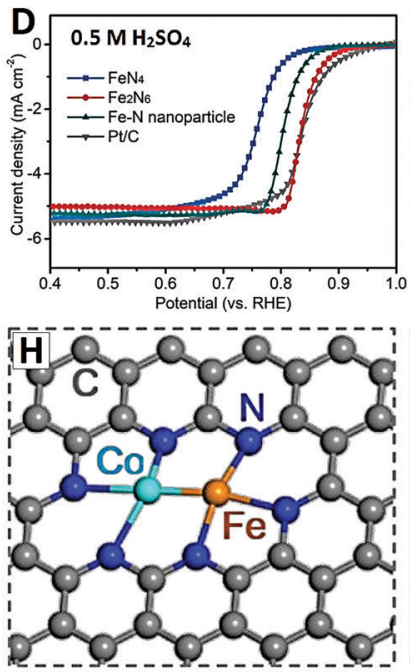

L Fe/Co-N $=1.9 \AA \quad \mathrm{Fe} / \mathrm{Co}-\mathrm{C}=2.7 \AA$

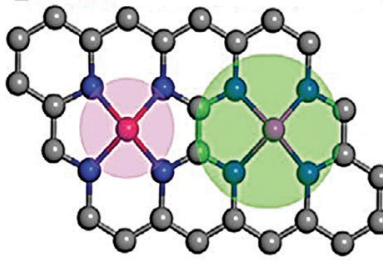

First shell

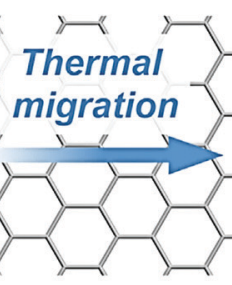

migration

Fig. 9 The $\mathrm{Fe}_{2} \mathrm{~N}_{6}$ DACs (reprinted with permission from ref. 129): (A) structural schematic diagram, (B and C) HAADF-STEM images and (D-G) electrochemical performances; the FeCoN 6 DAC (reprinted with permission from ref. 132): (H) structural schematic diagram, (I) HAADF-STEM image and ( $\mathrm{J}$ and K) ORR curves in different electrolytes; and the $\mathrm{FeN}_{4} \mid \mathrm{CON}_{4} \mathrm{DAC}$ (reprinted with permission from ref. 133): (L) structural schematic diagram, (M) HAADF-STEM image and ( $\mathrm{N}$ and $\mathrm{O}$ ) ORR curves in different electrolytes.

ORR catalyst, which showed greatly improved catalytic activity and excellent stability compared to isolated $\mathrm{Fe}-\mathrm{N}_{4}$ sites (see Fig. 9A-G). ${ }^{129}$ The formation of planar-like $\mathrm{Fe}_{2} \mathrm{~N}_{6}$ structures results from the thermal migration of isolated $\mathrm{Fe}-\mathrm{N}_{4}$ sites in hemin molecules (see Fig. 9A). The planar-like $\mathrm{Fe}_{2} \mathrm{~N}_{6}$ structure presents a high-density and homogeneous distribution of $\mathrm{Fe}$ atoms on the carbon framework (see Fig. 9B), and most of the $\mathrm{Fe}$ atoms get together to form many $\mathrm{Fe}_{2}$ dimer structures (see Fig. 9C). The planar-like $\mathrm{Fe}_{2} \mathrm{~N}_{6}$ structure exhibits the highest catalytic activity with a high half-wave potential of $0.84 \mathrm{~V}$ (see Fig. 9D) and a small Tafel slope of $82 \mathrm{mV} \mathrm{dec}^{-1}$ (see Fig. 9E) in $0.5 \mathrm{M} \mathrm{H}_{2} \mathrm{SO}_{4}$ electrolyte. The $\mathrm{Fe}_{2} \mathrm{~N}_{6}$ structure shows much enhanced mass activity and half-wave potential compared to single $\mathrm{Fe}-\mathrm{N}_{4}$ and Fe NPs (see Fig. 9F). The electron transfer number of the $\mathrm{Fe}_{2} \mathrm{~N}_{6}$ structure reaches 3.98 below $0.75 \mathrm{~V}$, indicating an efficient four-electron reduction pathway (see
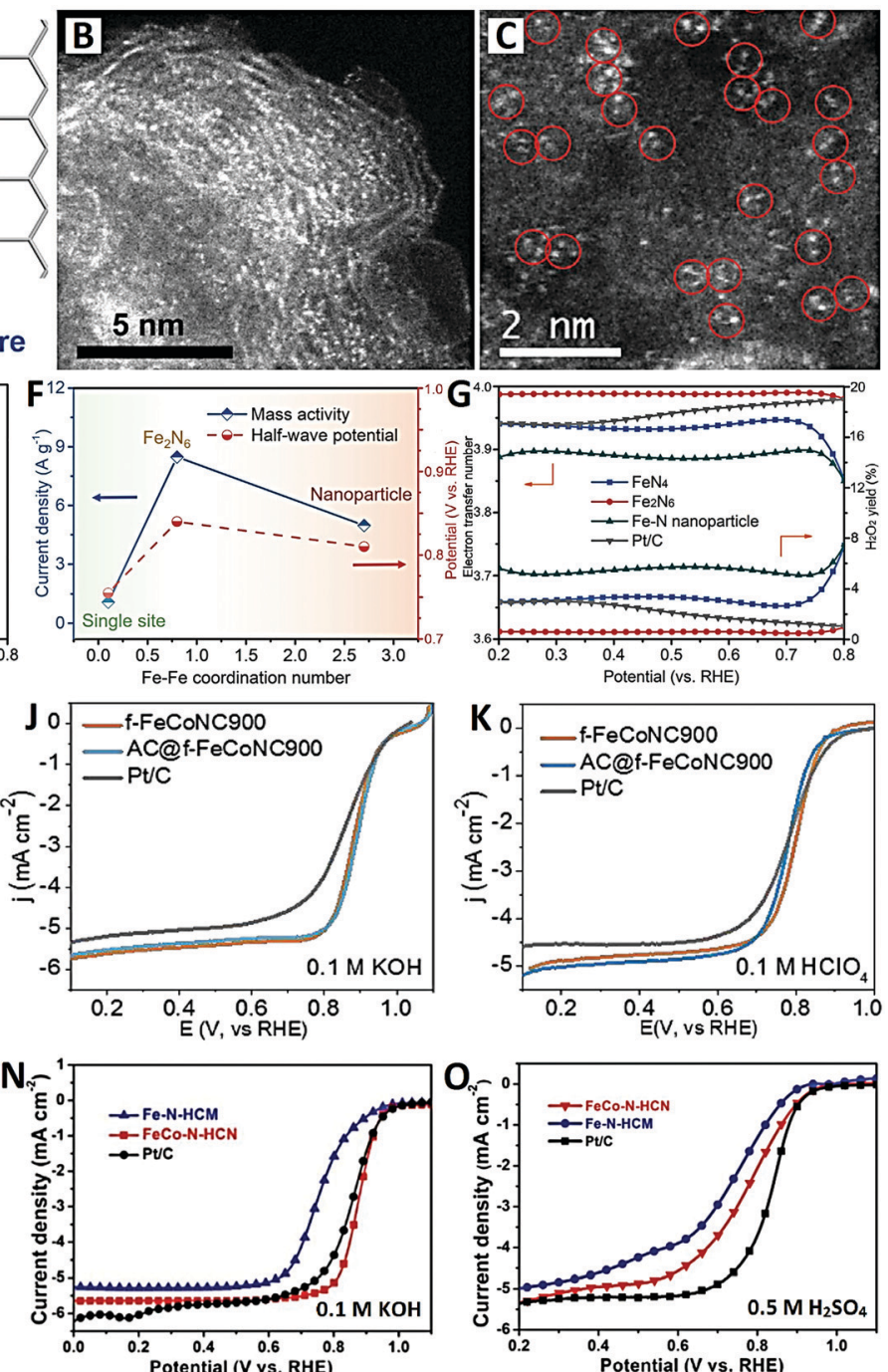
that this novel $\mathrm{Co}_{2} \mathrm{~N}_{5}$ site exhibits a greatly reduced thermodynamic barrier towards the ORR, thus contributing to the much higher intrinsic activity. This finding opens up a new opportunity to design high-performance $\mathrm{M}-\mathrm{N}-\mathrm{C}$ catalysts, thus pushing the fuel cell industry one step ahead possibly. ${ }^{130}$

Recently, $\mathrm{Wu}$ and co-workers ${ }^{131}$ reported a host-guest synthesis of a high-density heteronuclear $(\mathrm{Fe}, \mathrm{Co}) / \mathrm{N}-\mathrm{C}$ DAC (with $\mathrm{FeCoN}_{6}$ dual sites) on $\mathrm{N}$-doped porous carbon from a $\mathrm{Zn} / \mathrm{Co}$ bimetallic MOF (ZnCo-ZIF8) with adsorbed $\mathrm{FeCl}_{3}$ molecules. The bonding ( $\mathrm{Fe}-\mathrm{Co}$ ) between the Co nodes (host) and adsorbed $\mathrm{Fe}$ ions (guest) can be precisely controlled within ZnCo-ZIF8 by a double-solvent method. Compared with Fe SAs/ $\mathrm{N}-\mathrm{C}$, Co SAs/N-C, commercial $\mathrm{Pt} / \mathrm{C}$ and those previously reported, ${ }^{129,130}$ this well-defined $(\mathrm{Fe}, \mathrm{Co}) / \mathrm{N}-\mathrm{C}$ DAC exhibits a considerably high ORR activity with a record halfwave potential of $0.86 \mathrm{~V}$, an onset potential of $1.06 \mathrm{~V}$ and a limited current density of $6.0 \mathrm{~mA} \mathrm{~cm}{ }^{-2}$ in $0.1 \mathrm{M} \mathrm{HClO}_{4}$ electrolyte. ${ }^{131}$ Just like the catalytic behavior of $\mathrm{Pt} / \mathrm{C}$, the $\mathrm{H}_{2} \mathrm{O}_{2}$ yield of the $(\mathrm{Fe}, \mathrm{Co}) / \mathrm{N}-\mathrm{C}$ DAC is below $1.17 \%$, demonstrating the efficient four-electron mechanism $(n=3.98)$. Besides, excellent power density and long-term stability are also obtained in $\mathrm{H}_{2}$ /air fuel cells, suggesting its great potential in shortening the gap between non-noble metal catalysts and commercial $\mathrm{Pt} / \mathrm{C}$ catalyst.

Considering the high price of MOF-based precursors, it is of great significance to prepare bimetallic $(\mathrm{Fe}, \mathrm{Co}) / \mathrm{N}-\mathrm{C}$ catalysts with cheap and extensive raw materials. Back in 2011, Wu et al. ${ }^{10}$ used commercial carbon black and polyaniline (PANI) as low-cost precursors for the high-temperature synthesis of (Fe,Co NPs)/N-C catalysts, which showed desirable activity with an onset potential of $0.93 \mathrm{~V}$ and a halfwave potential of $0.78 \mathrm{~V}$ in $0.5 \mathrm{M} \mathrm{H}_{2} \mathrm{SO}_{4}$ electrolyte. Recently, Zhang et al. ${ }^{132}$ reported an efficient synthesis of $(\mathrm{Fe}, \mathrm{Co}) / \mathrm{N}-\mathrm{C}$ DACs (with $\mathrm{FeCoN}_{6}$ dual sites) based on a cost-effective route by condensation and carbonization of inexpensive formamide (FA) (see Fig. 9H-K). This general method can be used for mass production $(16 \mathrm{~g})$ of DACs with high-loading ( $\sim 10 \mathrm{wt} \%$ for $\mathrm{Fe}$ and $\mathrm{Co})$ and atomically-dispersed $\mathrm{FeCoN}_{6}$ sites (see Fig. $9 \mathrm{H}$ and I). Under the same catalyst load, the ORR activity in alkaline $(0.1 \mathrm{M} \mathrm{KOH})$ and acidic $\left(0.1 \mathrm{M} \mathrm{HClO}_{4}\right)$ electrolytes is outstanding, and is better than that of commercial Pt/C (see Fig. 9J and K). The halfwave potential in alkaline and acidic electrolytes is $0.89 \mathrm{~V}$ and $0.81 \mathrm{~V}$, respectively. More importantly, the extraordinary ORR activity was preserved when these $\mathrm{FeCoN}_{6}$ sites were deposited on inexpensive activated carbon (AC), presenting broad application prospects for implantable electrocatalysts or heterogeneous catalysts. ${ }^{132}$

The controllable preparation of adjacent dual active centers $\left(\mathrm{M}_{1}-\mathrm{N}_{4} \mid \mathrm{M}_{2}-\mathrm{N}_{4}\right)$ is also a very promising approach to highactivity DACs for the ORR due to synergetic effects. ${ }^{134}$ More recently, Zhang et al. ${ }^{133}$ reported FeCo-N-doped hollow carbon nanocages (FeCo-N-HCN) with adjacent $\mathrm{Fe}-\mathrm{N}_{4}$ and $\mathrm{Co}-\mathrm{N}_{4}$ dual active centers as an efficient ORR electrocatalyst (see Fig. 9L-O). The theoretical calculations show that the $\mathrm{Fe}-\mathrm{Co}$ distance in adjacent $\mathrm{M}_{1}-\mathrm{N}_{4} \mid \mathrm{M}_{2}-\mathrm{N}_{4}$ active centers is $0.49 \mathrm{~nm}$, which is very close to the value $(\sim 0.5 \mathrm{~nm})$ obtained by experimental observation (see Fig. 9L and M). In $0.1 \mathrm{M} \mathrm{KOH}$ electrolyte, FeCo-N-HCN shows much higher ORR activity than $\mathrm{Fe}-\mathrm{N}-$ HCN, even better than Pt/C, with halfwave potentials of 0.86 $\mathrm{V}, 0.76 \mathrm{~V}$ and $0.85 \mathrm{~V}$, respectively. And the corresponding halfwave potentials are $0.75 \mathrm{~V}, 0.70 \mathrm{~V}$ and $0.84 \mathrm{~V}$ in $0.5 \mathrm{M}$ $\mathrm{H}_{2} \mathrm{SO}_{4}$ electrolyte on FeCo-N-HCN, Fe-N-HCN and Pt/C. The synergistic effect of adjacent $\mathrm{Fe}-\mathrm{N}_{4}$ and $\mathrm{Co}-\mathrm{N}_{4}$ dual active centers reduces the energy barrier for the ORR by largely increasing the $\mathrm{O}-\mathrm{O}$ bond on $\mathrm{Fe}-\mathrm{N}_{4} \mid \mathrm{Co}-\mathrm{N}_{4}$ DACs. This work provides new insights into and understandings about adjacent dual-active-centers at the atomic level. ${ }^{133}$

4.2.3 Atom cluster catalysts. SACs with isolated metal atoms dispersed on carbon supports can maximize the utilization efficiency of metal atoms in an unsaturated coordination environment and have great potential in achieving high performances for various reactions. ${ }^{22}$ However, the isolated and single active sites in SACs may bring a risk that a single active atom cannot drive the catalytic process to achieve the expected results for the reactions requiring continuous active sites. ${ }^{104} \mathrm{As}$ described above, designing high-density SACs or SACs supported on carbon supports can largely solve this problem. Besides, atom cluster catalysts (SCCs) with ultra-small particle size $(<1.0 \mathrm{~nm})$ and controllable dimensions (e.g., monolayer clusters or multilayer clusters) have unique electronic states between dense atoms and adjacent active sites, which can exhibit improved electrocatalytic performances compared to low-density SACs. ${ }^{135}$ For ORR electrocatalysis, with the increase of the number of atoms in SCCs, the adsorption mode of $\mathrm{O}_{2}$ in the catalytic center can be changed from superoxide adsorption to peroxy adsorption, which provides high catalytic efficiency for the ORR. ${ }^{43}$

Recently, Zhou et al. devised porous carbon limited Co SCCs (Co/PC SCCs) as an efficient electrocatalyst for the ORR in alkaline electrolyte via a "top-down approach" from carbon black. ${ }^{136}$ Typically, $\mathrm{Co}\left(\mathrm{NO}_{3}\right)_{2}$ and phenanthroline were dissolved in ethanol and then a porous carbon black material (Ketjenblak) was added. Because this carbon black has a rich porous structure and $\Pi-\Pi$ interaction with metal macrocyclic molecules, the Co-phenanthroline intermediate can be adsorbed in the nanopores. After sintering in an inert atmosphere at $750{ }^{\circ} \mathrm{C}$ for $2 \mathrm{~h}$, Co clusters $(0.5-1.0 \mathrm{~nm})$ can be confined to the nanopores to form Co/PC SCCs (see Fig. 10A). The as-prepared Co/PC SCCs showed an extremely high initial potential $(1.0 \mathrm{~V})$, a half-wave potential $(0.92 \mathrm{~V})$, and a remarkable limited current density of $6.0 \mathrm{~mA} \mathrm{~cm}{ }^{-2}$ in $0.1 \mathrm{M} \mathrm{KOH}$ electrolyte (see Fig. 10B). The Tafel slope of $\mathrm{Co} / \mathrm{PC}$ was as low as $66 \mathrm{mV} \mathrm{dec}{ }^{-1}$, indicating that the ORR kinetics was significantly enhanced, which was closely related to the rich active sites and higher $\mathrm{O}_{2}$ mass transfer effect (see Fig. 10C). In addition, the stability of $\mathrm{Co} / \mathrm{PC}$ can be significantly improved by the nonporous confinement, where the attenuation of the half-wave potential and the limiting current density of the Co/PC catalyst can be ignored after $10000 \mathrm{CV}$ cycles. Thanks to the waterresistance effect of the nanopores, the highly active Co clusters are confined in specific nanopores and have a stable gas-solidliquid three-phase reaction region, which enhances the mass 

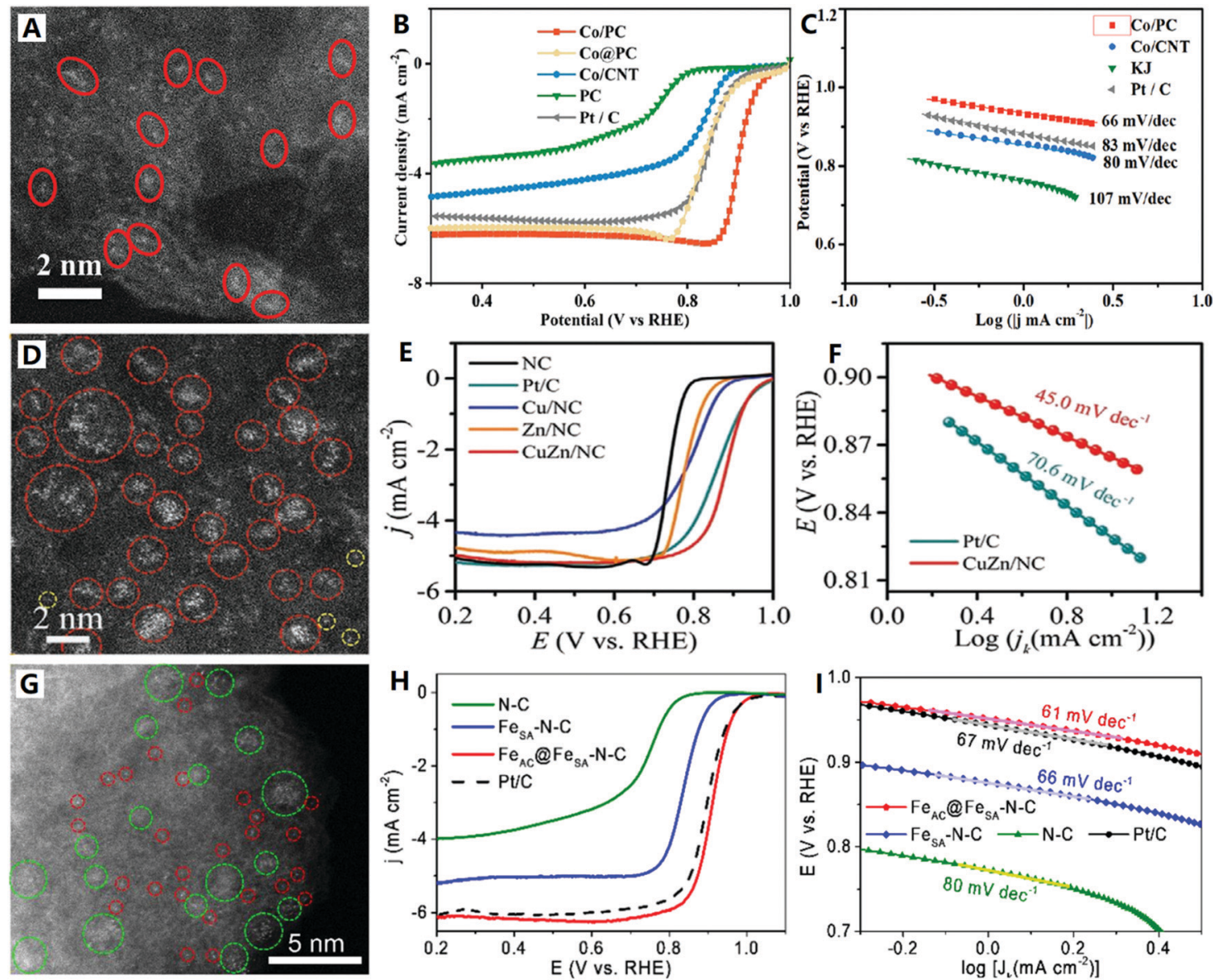

Fig. 10 The Co/PC SCCs (reprinted with permission from ref. 136): (A) HAADF-STEM image and (B and C) electrochemical performances; the CuZn/NC SCCs (reprinted with permission from ref. 137): (D) HAADF-STEM image and (E and F) electrochemical performances; and the Fe $e_{A C} @ F_{S A}-N-C$ (reprinted with permission from ref. 138): (G) HAADF-STEM image and (H and I) electrochemical performances.

transfer capacity, makes full use of the active sites, and also has strong stability due to confinement. ${ }^{136}$

Zhou et al. also reported a simple one-step pyrolysis method (so-called "bottom-up approach") for the preparation of bimetallic CuZn sub-nanoclusters (0.8 $\mathrm{nm}$ in mean size) anchored onto N-doped carbon (denoted CuZn/NC SCCs) with rhamnose $\left(\mathrm{C}_{6} \mathrm{H}_{12} \mathrm{O}_{5}\right)$ as a carbon source. ${ }^{137}$ The formation of abundant homogeneous $\mathrm{Cu}$ and $\mathrm{Zn}$ sub-nanoclusters and a spot of single $\mathrm{Cu} / \mathrm{Zn}$ sites on carbon carriers can be clearly observed in HAADF-STEM images (see Fig. 10D). An X-ray absorption fine structure test showed that the $\mathrm{M}-\mathrm{N}$ bond $(\mathrm{M}=\mathrm{Cu}$ or $\mathrm{Zn})$ and $\mathrm{M}-$ $\mathrm{M}$ bond existed simultaneously in the catalyst. These $\mathrm{N}$ coordinated $\mathrm{Cu}$ and $\mathrm{Zn}$ bimetallic structures make CuZn/NC SCCs exhibit high ORR activity in alkaline solution (0.1 M $\mathrm{KOH}$ ), showing a half wave potential of $0.89 \mathrm{~V}$ (see Fig. 10E) and a Tafel slope of $45 \mathrm{mV} \mathrm{dec}^{-1}$ (see Fig. 10F). The ORR activity of CuZn/NC SCCs is even higher than that of commercial Pt/C catalyst. After a $30000 \mathrm{~s}$ continuous electrolysis, CuZn/NC SCCs showed a smaller current drop of $12.3 \%$ than $\mathrm{Pt} / \mathrm{C}(49.4 \%)$, indicating a very high durability of these SCCs. Comprehensive experiments and theoretical calculations approved that the excellent performances of this catalyst can be attributed to the collaboration of the $\mathrm{Cu} / \mathrm{Zn}-\mathrm{N}_{4}$ sites with $\mathrm{CuZn}$ moieties on N-doped carbons. ${ }^{137}$

4.2.4 Single-atom and atom cluster mixed catalysts. $\mathrm{M}-\mathrm{N}-$ $\mathrm{C}$ (where $\mathrm{M}$ is noble metal or transition metal) SACs have been widely studied in ORR electrocatalysis, where the coordination environment of metal sites plays a key role in catalytic activity and stability. ${ }^{122}$ At present, most studies focus on the coordination atoms and numbers of metal atoms, while the effect of adjacent sub-nanoclusters on single atom active sites is ignored. Due to thermodynamic instability, the metal atoms can easily migrate and agglomerate into high-density atom clusters during the pyrolysis. Importantly, several studies have shown that the presence of homogeneous atom clusters (including metallic elements and their oxides) can also significantly enhance the ORR activity of SACs. ${ }^{138-140}$

For example, Ao et al. recently designed and fabricated a multi-scale $\mathrm{Fe}-\mathrm{N}-\mathrm{C}$ ORR electrocatalyst, where abundant Fe atomic clusters and $\mathrm{Fe}-\mathrm{N}_{4}$ single-atom sites are both embedded in an $\mathrm{N}$-doped carbon support $\left(\mathrm{Fe}_{\mathrm{AC}} @ \mathrm{Fe}_{\mathrm{SA}}-\mathrm{N}-\mathrm{C}\right)$, by using a covalent organic framework (COF) as the precursor. ${ }^{138}$ The coexistence of $\mathrm{Fe}$ single atoms and Fe nanoclusters was realized by a spatial isolation strategy based on COFs (see Fig. 10G). The 
$\mathrm{Fe}_{\mathrm{AC}} @ \mathrm{Fe}_{\mathrm{SA}}-\mathrm{N}-\mathrm{C}$ catalyst exhibits excellent electrocatalytic performance for the ORR with a half-wave potential of $0.912 \mathrm{~V}$ in $0.1 \mathrm{M} \mathrm{KOH}$ electrolyte, which is 68 and $15 \mathrm{mV}$ higher than those of the single-atom $\mathrm{Fe}-\mathrm{N}_{4}$ catalyst $\left(\mathrm{Fe}_{\mathrm{SA}}-\mathrm{N}-\mathrm{C}\right)(0.844 \mathrm{~V})$ and commercial Pt/C (0.897 V), respectively (see Fig. 10H). The Tafel slope of $\mathrm{Fe}_{\mathrm{AC}} @ \mathrm{Fe}_{\mathrm{SA}}-\mathrm{N}-\mathrm{C}$ was as low as $61 \mathrm{mV} \mathrm{dec}^{-1}$ (see Fig. 10I), which is slightly lower than that of Co/PC SCCs (see Fig. 10C). The DFT calculation showed that $\mathrm{Fe}-\mathrm{N}_{4}$ sites are the main active sites, and Fe nanoclusters could further enhance its activity. In addition to the formation of $\mathrm{Fe}-\mathrm{N}$ bonds, $\mathrm{Fe}$ nanoclusters also promote the conversion of pyrrole nitrogen and nitrogen oxide to graphitic nitrogen and pyridine nitrogen due to metal catalysis, which is beneficial for improving the performance of the ORR. ${ }^{138}$

Lee and Yang also reported an $\mathrm{Fe}-\mathrm{N}-\mathrm{C}$ ORR electrocatalyst with $\mathrm{Fe}$ single atoms and $\mathrm{Fe}$ nanoclusters co-embedded in $\mathrm{N}$ doped porous carbon by pyrolysis of metal-organic precursors and NaCl. ${ }^{139}$ The geometric structures of catalytic sites in $\mathrm{Fe}-\mathrm{N}-\mathrm{C}$ are revealed, where the isolated distribution of $\mathrm{Fe}-\mathrm{N}_{4}$ sites and $\mathrm{Fe}$ nanoclusters with sizes less than $0.5 \mathrm{~nm}$ are well deposited on NC. The synergistic enhancement effect of Fe single atoms and $\mathrm{Fe}$ nanoclusters results in excellent ORR performances with a halfwave potential of $0.895 \mathrm{~V}$ in $0.1 \mathrm{M} \mathrm{KOH}$ electrolyte. The DFT calculation showed that, compared with the Fe- $\mathrm{N}_{4}$ site with single structures, the coexistence of Fe nanoclusters on the carbon layer will supply electrons to the $\mathrm{Fe}-\mathrm{N}_{4}$ system. Therefore, both the dband center of the Fe active site and the Fermi level of the system are adjusted, and the neighboring Fe nanoclusters are shown to weaken the binding energies of the ORR intermediates on $\mathrm{Fe}-\mathrm{N}_{4}$ sites, hence enhancing both catalytic kinetics and thermodynamics. This study provides new insights into the understanding of the synergies of single atoms and clusters on N-doped carbon ORR electrocatalysts. ${ }^{139}$

More recently, Lei and co-workers reported a hybrid catalyst $\left(\mathrm{Fe}_{\mathrm{SA}} / \mathrm{FeO}_{\mathrm{NC}} / \mathrm{NSC}\right)$ with $\mathrm{Fe}$ single atoms $\left(\mathrm{Fe}-\mathrm{N}_{4}\right.$ sites $)$ and $\mathrm{Fe}_{2} \mathrm{O}_{3}$ clusters (only a few Fe atomic centers) on N,S-co-doped porous carbon, which was obtained by the in situ transformation of Fedistributed biomass (Spirulina platensis) based on a small molecular nitrogen source-mediated co-pyrolysis strategy. ${ }^{140}$ Due to the coupling effect with ultra-small $\mathrm{Fe}_{2} \mathrm{O}_{3}$ clusters and the favorable reaction site provided by the ultra-thin $\mathrm{N}, \mathrm{S}$-codoped porous carbon skeleton, the $\mathrm{Fe}_{\mathrm{SA}} / \mathrm{FeO}_{\mathrm{NC}} / \mathrm{NSC}$ catalyst showed excellent ORR activity and catalytic stability comparable to $\mathrm{Pt} / \mathrm{C}$ and. $\mathrm{Fe}_{\mathrm{SA}} / \mathrm{FeO}_{\mathrm{NC}} / \mathrm{NSC}$ has high $E_{\text {onset }}(0.99 \mathrm{~V})$ and $E_{1 / 2}(0.86 \mathrm{~V})$ values, which are better than those of $\mathrm{Pt} / \mathrm{C}\left(E_{\text {onset }}=\right.$ $\left.0.98 \mathrm{~V} ; E_{1 / 2}=0.85 \mathrm{~V}\right)$. The ultra-thin porous structure of $\mathrm{Fe}_{\mathrm{SA}} /$ $\mathrm{FeO}_{\mathrm{NC}} / \mathrm{NSC}$ is rich in edge defects, which not only provides a favorable site for the ORR, but also contributes to enhancing ORR activity. Crucially, the high ORR activity is mainly caused by the interaction between the atomic-level dispersed $\mathrm{Fe}-\mathrm{N}_{4}$ sites and $\mathrm{Fe}_{2} \mathrm{O}_{3}$ clusters embedded in the N,S-mediated porous carbon layers. In this study, a highly efficient catalyst coupled with metal single atoms and homologous oxide clusters was obtained directly from biomass by in situ conversion, which provided inspiration for the synthesis of newly non-noble metal electrocatalysts. ${ }^{140}$
4.2.5 Single-atom and nanoparticle mixed catalysts. Generally, the metal-support interaction can change the charge state of SACs through the electron transfer between SACs and supports, which leads to the formation of active intermediates and enhancement of the catalytic activity. Inspired by this, it is necessary to add some synergistic components to accurately adjust the interaction and make SACs have an optional local environment, hence improving their catalytic performances. ${ }^{141}$ The introduction of synergistic components (such as homogeneous $\mathrm{NPs}^{142}$ and heterogeneous $\mathrm{NPs}^{143}$ ) can controllably adjust the electronic and geometric structures of SACs and improve the graphitization of carbon supports, hence improving the activity, selectivity, and stability of SACs for the ORR. ${ }^{144}$ In contrast, some transition metal SACs ( $\mathrm{MN}_{4}$ sites) can also promote noble metal NPs for the ORR due to their synergistic effects. ${ }^{145,146}$

Recently, Wang et al. ${ }^{142}$ reported a mixed ORR catalyst with atomically-dispersed $\mathrm{Co}-\mathrm{N}_{4}$ sites (Co SAC) and small Co NPs (Co SNPs) co-anchored in N-doped porous carbon nanocages (denoted Co-SAC/SNPs@NC). Co SNPs promote the formation of a graphited layer, which also acts as the support of Co- $\mathrm{N}_{4}$ sites without affecting the highly porous structure of the carbon nanocages. The synergy between Co SAC and Co SNPs and the enhanced graphitization matrix of carbon endowed this mixed catalyst with a high half-wave potential of $0.898 \mathrm{~V}$ and a high dynamic current density $\left(J_{\mathrm{K}}\right)$ of $60.7 \mathrm{mV} \mathrm{cm}^{-2}$ at $0.85 \mathrm{~V}$ in alkaline medium. After 20000 cycles, the negative shift in halfwave potential was only $7 \mathrm{mV}$, which was better than that of CoSAC@NC with only Co- $\mathrm{N}_{4}$ sites and commercial Pt/C. It may be a feasible method to solve the stability problem, by appropriately introducing metal small NPs into carbon-supported SACs. The small NPs and SCAs can work together to not only improve the activity of the ORR, but also improve the graphitization (high stability) of carbon supports. ${ }^{142}$

Recently, Jiang et al. ${ }^{143}$ also reported an $\mathrm{Fe}-\mathrm{N}-\mathrm{C}$ ORR catalyst (with $\mathrm{Fe}-\mathrm{N}_{4}$ sites) enhanced by heterogeneous Co NPs

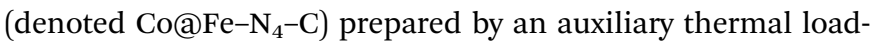
ing method. The characteristics showed that the Co@Fe- $\mathrm{N}_{4}-\mathrm{C}$ catalyst had larger specific surface area and higher graphitic $\mathrm{N}$ content than single $\mathrm{Fe}-\mathrm{N}_{4}-\mathrm{C}$. The $\mathrm{Co@Fe}-\mathrm{N}_{4}-\mathrm{C}$ catalyst showed strong ORR activity in $0.1 \mathrm{M} \mathrm{KOH}$ electrolyte, where the halfwave potential $\left(E_{1 / 2}\right)$ was $0.92 \mathrm{~V}$, which was much higher than those of single $\mathrm{Fe}-\mathrm{N}_{4}-\mathrm{C}\left(E_{1 / 2}=0.85 \mathrm{~V}\right)$ and $\mathrm{Pt} / \mathrm{C}\left(E_{1 / 2}=0.90 \mathrm{~V}\right)$. In $0.1 \mathrm{M} \mathrm{HClO}_{4}$ electrolyte, the $E_{1 / 2}$ of the catalyst was $0.79 \mathrm{~V}$, which was only $30 \mathrm{mV}$ lower than that of $\mathrm{Pt} / \mathrm{C}\left(E_{1 / 2}=0.82 \mathrm{~V}\right)$. The DFT calculations confirmed that the strong synergistic effect between Co NPs and $\mathrm{Fe}-\mathrm{N}_{4}$ sites provided $\mathrm{Co} @ \mathrm{Fe}-\mathrm{N}_{4}-\mathrm{C}$ with favorable electronic structures and a local coordination environment. The introduction of Co NPs onto the surfaces of $\mathrm{Fe}-\mathrm{N}_{4}-\mathrm{C}$ materials plays a key role in improving the catalytic activity and stability of the ORR, which provides a new way to prepare efficient $\mathrm{Fe}-\mathrm{N}-\mathrm{C}$ ORR catalysts. ${ }^{143}$

More recently, Sun and co-workers ${ }^{144}$ developed a bimetallic FeCo-N-C catalyst with highly active $\mathrm{M}-\mathrm{NPs}$ and $\mathrm{MN}_{4}$ composite sites $(\mathrm{M}=\mathrm{FeCo})$ on $\mathrm{N}$-doped porous carbon (denoted $\mathrm{M}$ / FeCo-SA-N-C). This FeCo-N-C catalyst showed the coexistence 
of $\mathrm{Fe} / \mathrm{Co}$ NPs and $\mathrm{Fe} / \mathrm{Co}$ single atoms, indicating that $\mathrm{M} / \mathrm{MN}_{4}$ composite sites were successfully constructed. The M/FeCo-SA$\mathrm{N}-\mathrm{C}$ catalyst exhibited superior catalytic activity in terms of superhigh onset potential $(0.981 \mathrm{~V})$ and half-wave potential $(0.851 \mathrm{~V})$ in $0.1 \mathrm{M} \mathrm{HClO}_{4}$ electrolyte, which surpassed those of most M-N-C electrocatalysts in an acidic ORR. ${ }^{88,115,130,132,143} \mathrm{It}$ was also successfully proved that the $\mathrm{M} / \mathrm{MN}_{4}$ composite sites provided excellent stability to the $\mathrm{M} / \mathrm{FeCo}-\mathrm{SA}-\mathrm{N}-\mathrm{C}$ catalyst in acidic electrolyte. The synergistic effect between M-NPs and $\mathrm{MN}_{4}$ may play a crucial role in the boosted ORR performance through the construction of $\mathrm{M} / \mathrm{MN}_{4}$ composite sites. The DFT calculations indicated that the M-NPs can increase the local charge density of $\mathrm{MN}_{4}$, and subsequently enhance $\mathrm{O}_{2}$ adsorption and elongate $\mathrm{O}-\mathrm{O}$ bonds, resulting in the facile cleavage of the $\mathrm{O}-\mathrm{O}$ bond. This work may present new highly active $\mathrm{M} / \mathrm{MN}_{4}$ composite sites for catalyzing the ORR in acidic medium. ${ }^{144}$

On the other hand, transition metal SACs with $\mathrm{MN}_{4}$ sites can synergistically promote single noble metal (or its alloy) NPs for the ORR in acidic medium. ${ }^{145,146}$ For example, $\mathrm{He}$ and $\mathrm{Mu}^{145}$ reported a Pt@Co SAs-ZIF-NC catalyst by isolation of Pt NPs with $\mathrm{CoN}_{4}$ sites on ZIF-based N-doped carbon. In $0.1 \mathrm{M} \mathrm{HClO}_{4}$ electrolyte, the Pt@Co SAs-ZIF-NC showed a half wave potential $(0.917 \mathrm{~V})$ that is better than that of commercial Pt/C $(0.868 \mathrm{~V})$, and its mass activity $\left(480 \mathrm{~mA} \mathrm{mg}_{\mathrm{Pt}}{ }^{-1}\right)$ at $0.9 \mathrm{~V}$ is three times that of $\mathrm{Pt} / \mathrm{C}\left(160 \mathrm{~mA} \mathrm{mg}_{\mathrm{Pt}}{ }^{-1}\right)$. More recently, $\mathrm{Wu}$ and co-workers ${ }^{146}$ also reported that Fe SACs with $\mathrm{FeN}_{4}$ sites on N-doped carbon can significantly promote the ORR activity of Pt NPs and $\mathrm{Pt}_{3} \mathrm{Co}$ alloy NPs. Pt/FeN ${ }_{4}-\mathrm{C}$ and $\mathrm{Pt}_{3} \mathrm{Co} / \mathrm{FeN}_{4}-\mathrm{C}$ showed mass activities of $451 \mathrm{~mA} \mathrm{mg}_{\mathrm{Pt}}{ }^{-1}$ and $720 \mathrm{~mA} \mathrm{mg}{ }_{\mathrm{Pt}}{ }^{-1}$ at $0.9 \mathrm{~V}$, respectively. The DFT calculation predicted that the synergy between Pt NPs and the surrounding $\mathrm{FeN}_{4}$ sites can weaken the adsorption of $\mathrm{O}_{2}$ on the Pt plane, thus enhancing the intrinsic activity of the $\mathrm{Pt}$ catalyst. In general, transition metal single atoms can improve the activity of noble metal catalysts, and finally achieve the goal of reducing the use of noble metal. For the sake of convenience, the comparison parameters of different atomic-level ORR electrocatalysts are also summarized in Table 1.

\section{Proposed evaluation methods and site interaction rules for high-metal- density electrocatalysts}

At present, "high dispersion" and "high density" are just general adjectives, and it is difficult to establish a unified evaluation standard for this type of high-metal-density electrocatalyst. Usually, the smaller particle size and the higher degree of dispersion can endow catalytic materials with larger surface catalytic activity. Meanwhile, it is of great significance to develop high-loading (i.e., high metal density of small NPs or atomic sites) electrocatalysts for the sake of high-mass-activity catalytic systems in practical industrial applications. In order to better elucidate the relationship between the metal density and electrocatalytic performance of catalysts, we propose two methods to calculate or identify the metal density or site density on the surface of the support: (i) the method based on the relative distance of metal particles or atomic sites (i.e., the ratio of actual distance to particle diameter or atom diameter) and (ii) that based on the average number of particles or atomic sites per unit area (i.e., particle number per $100 \mathrm{~nm}^{2}$ and atom number per $1 \mathrm{~nm}^{2}$ ) (see Fig. 11A for the schematic diagram).

For nanoparticle catalysts, method (i) (relative distance method) is more objective and convenient to calculate or evaluate the metal density, due to their different particle diameters and easily distinguishable structures. Based on the previous case analysis, it can be found that when the relative distance is close to or less than 1 , the distribution of nanoparticles on the carbon support is very close, and these catalysts also show high mass catalytic activity (see Fig. 2-5 for details). For atomic-level catalysts, both method (i) (relative distance method) and method (ii) (average number method) can be used under high resolution HAADF-STEM. Particularly, considering that the site sizes of metal atoms are very close, we can use the actual site distance to evaluate the metal density of atomic-level catalysts. In general, when the average distance of atomic sites is equal to or less than $1 \mathrm{~nm}$, the distribution of metal atoms in the carbon carrier is very dense (see Fig. 7 for details) and the catalytic performance is obviously dependent on the site distance (see Fig. 8 for details).

For nanoparticle systems, high-metal-density electrocatalysts can lead to distinctive ion diffusion characteristics in extensive electrochemical processes. Fig. 11B shows the surface-density-dependent diffusion models of nanoparticle arrays at different potential sweep rates: (left) high sweep rate, (middle) medium sweep rate and (right) very low sweep rate. ${ }^{147}$ For the high sweep rate, the diffusion layer thickness is much smaller than the average distance between adjacent particles; for the medium sweep rate the diffusion layers of adjacent particles overlap for a high particle density; and for the very low sweep rate steady-state diffusion is reached for all density samples. These electrochemical characteristics have positive guiding significance in the design of highperformance electrocatalysis, where the overlap effect of the diffusion layer thickness of adjacent particles may induce unexpected electrocatalytic synergistic effects for high-metaldensity electrocatalysts.

For atomic-level systems, high-metal-density electrocatalysts can also lead to distinctive electronic properties and catalytic activity. Fig. 11C-E show the structural model and surfacedensity-dependent atomic site electrostatic interaction of $\mathrm{Pd}_{1}$ / $\mathrm{CeO}_{2}$ single atom catalyst. ${ }^{148}$ Due to the cumulative enhancement of $\mathrm{CeO}_{2}$ reducibility, the specific activity of a single Pd atom supported by $\mathrm{CeO}_{2}$ increases linearly with the increase of Pd atom density. With the increase of surface Pd density, the long-range electrostatic footprints $(\sim 1.5 \mathrm{~nm})$ around each $\mathrm{Pd}$ site overlap each other, resulting in a deviation from the constant specific activity observed. The results show that the specific catalytic activity of reducible oxide supported single atom catalysts can be adjusted by changing the surface density of a single metal atom. These theoretical models provide help with the development of high specific activity and high metal density atomic-level catalysts. 


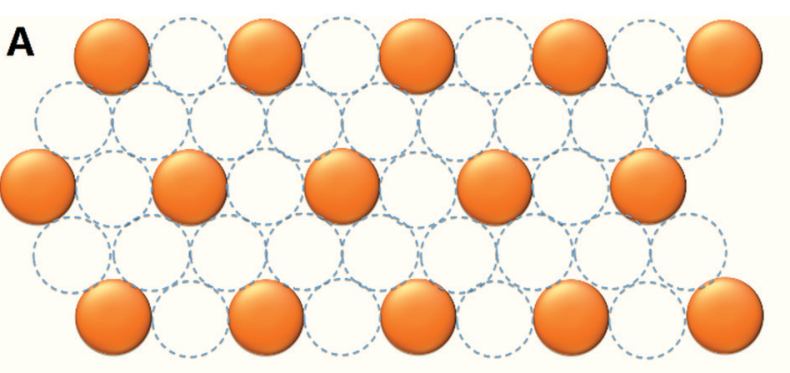

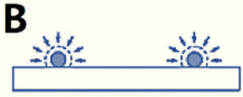
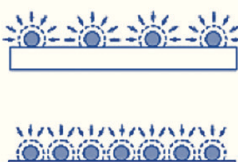

high sweep rate
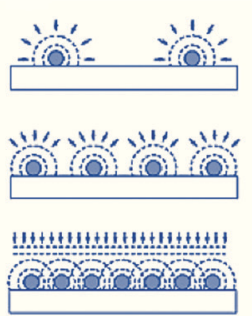

medium sweep rate
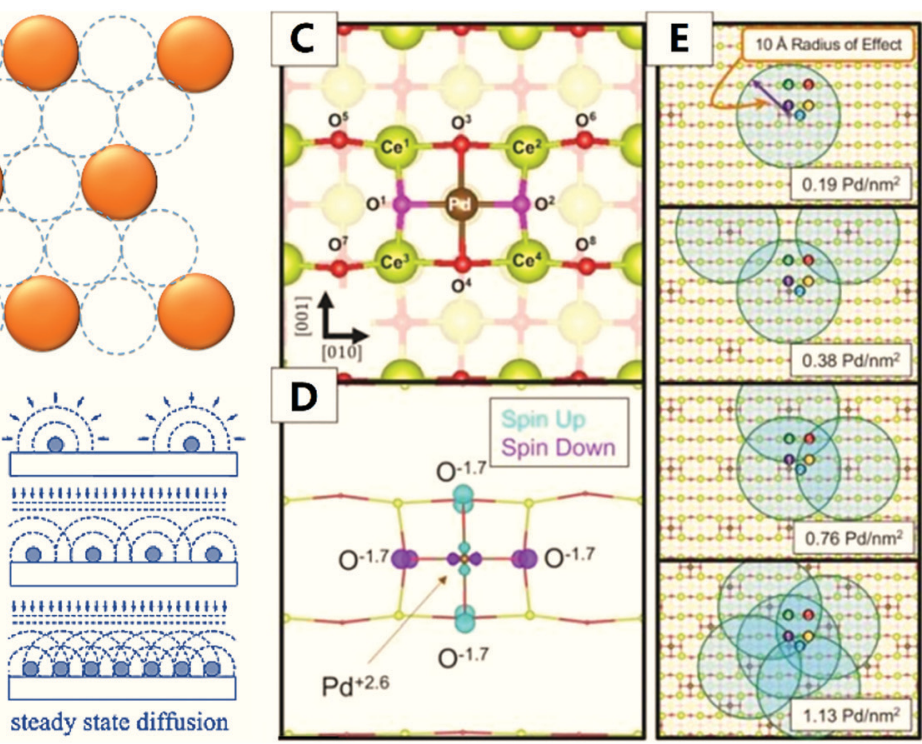

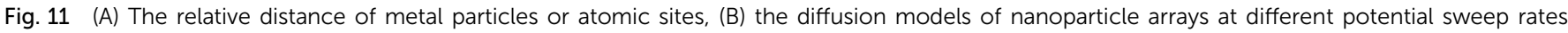

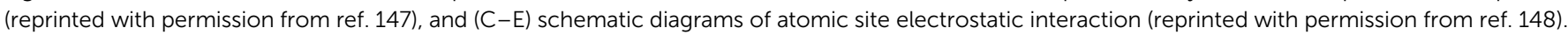

\section{Conclusions and prospects}

\subsection{Conclusions}

In summary, carbon-supported noble metal Pt NP (including their alloy and core-shell structure) catalysts with high loading and high dispersity are very beneficial to constructing ultra-thin catalyst layers for fast-diffusion-dynamics MEA application in PEMFCs. The easily available commercial carbon black supports and state-of-the-art graphene supports with moderately graphited structures and mesoporous structures are the best choices for structuring high-metal-loading ORR electrocatalysts. The densely-distributed NPs of transition metal compounds on carbon supports are also critical for designing non-noble metal ORR electrocatalysts, where the high metal content can be obtained by a synchronous pyrolysis process. Metal carbide-promoted noble metal NPs with a high-density dispersion of two components on carbon supports are conducive to the formation of close-contact synergistic interfaces. Therefore, the two-step synthesis by loading single noble metal (or its alloy) NPs onto a carbon-supported carbide is often adopted, where the highly-proportioned noble metal NPs can be grown tightly on or around the carbide component. Highdensity carbides synergistically enhanced low-Pt or Pd ORR electrocatalysts are of special importance due to the fact that strong EMSI can be easily formed on the dense interface of $\mathrm{Pt} / \mathrm{Pd}$ and carbides.

When the distance between two active metal atom centers is reduced to the subnanometer level, the catalytic behavior will be significantly affected because of the site interaction effect. High-density atomically-dispersed metal catalysts (including SACs, DACs, and SCCs) often exhibit more significant catalytic properties than the sparse counterparts due to the synergistic effect of dense atomic sites. $\mathrm{M}-\mathrm{N}-\mathrm{C}$ (where $\mathrm{M}$ includes transition metals and noble metals) ORR catalysts with high active site density can generate higher activity by exposing the inaccessible $\mathrm{M}-\mathrm{N}_{4}$ active sites and strengthening the mass transport. In order to ensure the mass transport and high activity of highmetal-density SACs, it is very necessary to develop carbon supports with high surface area and mesoporous structure, which facilitates ion transfer and improves their catalytic performances. Besides, the high-density bimetal sites dispersed on $\mathrm{N}$-doped carbon $\left(\mathrm{M}_{1} \mathrm{M}_{2} \mathrm{~N}_{x}\right.$ DACs) can form different adjacent active sites and improve the activity and stability of the catalyst through synergistic catalysis. The construction of dual active sites provides a new opportunity for high-performance ORR catalysts, which can not only develop more combinations of coordination environments, but also lead to the enhancement of two different metal sites of high-density atomically-dispersed catalysts. Preparation of cluster catalysts (SCCs) and the combination of SACs with SCCs/ NPs are the significant complement strategies for the design of high-density ORR catalysts with improved catalytic performances.

\subsection{Prospects}

Usually, the low metal loading of catalysts will increase the thickness and impedance of the catalyst layer in the MEA, which causes more serious mass transfer loss, and reduces the performances of fuel cells at high current density. ORR electrocatalysts based on noble metal NPs with high metal loading ( $\sim 40 \mathrm{wt} \%)$ have attracted great attention, which can well solve the above technical problems of fuel cells. However, many studies ignore the loss of mass activity caused by high loading (such as the decrease of activity caused by dense stacking), and the electrochemical oxidation of carbon supports under high potentials (resulting in a decrease of catalyst stability). Therefore, in future work, one should strive to find effective methods to prepare high-loading catalysts and develop high stability support materials, to ensure the mass activity of the ORR and the stability of catalysts while improving the metal 
density on supports. At the same time, the as-prepared catalysts with high-loadings of noble metal NPs should be applied to the MEA, and the feasibility of high-metal-density catalysts should be confirmed by the measurement of impedance, maximum power density and other parameters in fuel cells, which will in turn guide the optimized preparation of high-loading ORR electrocatalysts and further improve the device performances of fuel cells.

The ORR performance of high-metal-density $\mathrm{M}-\mathrm{N}-\mathrm{C}(\mathrm{M}=\mathrm{Fe}$, $\mathrm{Co}, \mathrm{Ni}$, etc.) catalysts (including SACs, DACs, and SCCs) in the kinetic region is very close to that of Pt-based catalysts, but there are still great challenges for these non-noble metal catalysts, especially under acidic conditions. Because of their sensitive physical and chemical properties, especially in acidic environments, these transition metal elements have poor corrosion resistance. Therefore, high-density transition metal $\mathrm{M}-\mathrm{N}-\mathrm{C}$ catalysts (especially $\mathrm{Fe}-\mathrm{N}_{4} \mathrm{SACs}$ ) still face great challenges in the practical application of PEMFCs, due to their under-stable characteristic and potential Fenton oxidation. More catalytic systems with high activity, high stability and four-electron selectivity still need to be found. Rational design of metal cluster catalysts, including dimers, trimers, and larger metal clusters, is also an important research direction to overcome the defects of SACs. At present, the central metal atom of most high-density atomically-dispersed metal catalysts only coordinates with the $\mathrm{N}$ atom in the carbon substrates. In the subsequent research, the coordination effect of other elements such as S, P, B and O can be considered to adjust the electronic structure of the central metal atom, so as to obtain a more efficient and stable ORR electrocatalyst. Particularly, some reliable synthesis strategies (e.g., mechanochemistry and heat migration strategies) need to be explored to realize the batch production of SACs with high metal density and high stability on different supports.

Carbon-supported ORR electrocatalysts (including nanoparticles and atomic-level architectures) are always faced with problems of carbon corrosion of the support and the resultant catalyst instability in practical application. Especially under the catalysis of ultrafine metal species and high-potential or acidic oxidation conditions, the amorphous component in conventional carbon supports (e.g., porous carbon and acetylene black) shows a fast electrochemical corrosion rate in the operating state of fuel cells. Based on this, it is necessary to develop new-type highcrystallinity carbon with or without ceramic support materials (e.g., conducting metal oxides, carbides, and borides) with high electrochemical and thermodynamic stability, in order to accelerate the progress of both nano-structured and atomic-level ORR electrocatalysts in practical application of fuel cells.

\section{Conflicts of interest}

There are no conflicts to declare.

\section{Acknowledgements}

This research was supported by the National Natural Science Foundation of China (22078071, 21777034), the Natural Science
Foundation of Guangdong Province (2021A1515010125, 2020A1515010344), Maoming Science and Technology Project (mmkj2020032), the Science and Technology Innovation Project of Guangdong Province College Students (733330, 733336), Guangdong Province Universities and Colleges Pearl River Scholar Funded Scheme (2019), Guangdong Basic and Applied Basic Research Foundation (2019A1515011249), the Key Research Project of Natural Science of Guangdong Provincial Department of Education (2019KZDXM010), and the Program for Innovative Research Team of Guangdong University of Petrochemical Technology.

\section{References}

1 D. F. Dominković, I. Bačeković, A. S. Pedersen and G. Krajačić, The future of transportation in sustainable energy systems: Opportunities and barriers in a clean energy transition, Renewable Sustainable Energy Rev., 2018, 82, 1823-1838.

2 X. X. Wang, M. T. Swihart and G. Wu, Achievements, challenges and perspectives on cathode catalysts in proton exchange membrane fuel cells for transportation, Nat. Catal., 2019, 2(7), 578-589.

3 E. H. Majlan, D. Rohendi, W. R. W. Daud, T. Husaini and M. A. Haque, Electrode for proton exchange membrane fuel cells: A review, Renewable Sustainable Energy Rev., 2018, 89, 117-134.

4 A. Kulkarni, S. Siahrostami, A. Patel and J. K. Nørskov, Understanding catalytic activity trends in the oxygen reduction reaction, Chem. Rev., 2018, 118, 2302-2312.

5 L. Zhang, L. Fan, P. Yang, M. Li, H. Zhang, Y. Tang, Z. Kang, H. Guo, R. Wang and D. Sun, Green synthesis of hierarchical carbon coupled with $\mathrm{Fe}_{3} \mathrm{O}_{4} / \mathrm{Fe}_{2} \mathrm{C}$ as an efficient catalyst for the oxygen reduction reaction, Materials Advances, 2020, 1, 2010-2018.

6 S. Ott, A. Orfanidi, H. Schmies, B. Anke, H. N. Nong, J. HAbner and P. Strasser, Ionomer distribution control in porous carbon-supported catalyst layers for high-power and low Pt-loaded proton exchange membrane fuel cells, Nat. Mater., 2020, 19(1), 77-85.

7 J. Hou, M. Yang, C. Ke, G. Wei, C. Priest, Z. Qiao and J. Zhang, Platinum-group-metal catalysts for proton exchange membrane fuel cells: From catalyst design to electrode structure optimization, Energy Chem., 2020, 2(1), 100023.

8 Z. Zhao, C. Chen, Z. Liu, J. Huang, M. Wu, H. Liu and Y. Huang, Pt-Based nanocrystal for electrocatalytic oxygen reduction, Adv. Mater., 2019, 31(31), 1808115.

9 G. Bampos, L. Sygellou and S. Bebelis, Oxygen reduction reaction activity of Pd-based bimetallic electrocatalysts in alkaline medium, Catal. Today, 2020, 355, 685-697.

10 G. Wu, K. L. More, C. M. Johnston and P. Zelenay, High-performance electrocatalysts for oxygen reduction derived from polyaniline, iron, and cobalt, Science, 2011, 332(6028), 443-447. 
11 L. Pan, S. Ott, F. Dionigi and P. Strasser, Current challenges related to the deployment of shape-controlled Pt alloy oxygen reduction reaction nanocatalysts into low Ptloaded cathode layers of proton exchange membrane fuel cells, Curr. Opin. Electrochem., 2019, 18, 61-71.

12 L. Huang, S. Zaman, X. Tian, Z. Wang, W. Fang and B. Y. Xia, Advanced platinum-based oxygen reduction electrocatalysts for fuel cells, Acc. Chem. Res., 2021, 54(2), 311-322.

13 L. Du, V. Prabhakaran, X. Xie, S. Park, Y. Wang and Y. Shao, Low-PGM and PGM-free catalysts for proton exchange membrane fuel cells: Stability challenges and material solutions, Adv. Mater., 2021, 33(6), 1908232.

14 U. Martinez, S. K. Babu, E. F. Holby and P. Zelenay, Durability challenges and perspective in the development of PGM-free electrocatalysts for the oxygen reduction reaction, Curr. Opin. Electrochem., 2018, 9, 224-232.

15 S. Song, Y. Wang and P. K. Shen, Pulse-microwave assisted polyol synthesis of highly dispersed high loading Pt/C electrocatalyst for oxygen reduction reaction, J. Power Sources, 2007, 170(1), 46-49.

16 Y. Xiong, L. Xiao, Y. Yang, F. J. DiSalvo and H. D. Abruña, High-loading intermetallic $\mathrm{Pt} 3 \mathrm{Co} / \mathrm{C}$ core-shell nanoparticles as enhanced activity electrocatalysts toward the oxygen reduction reaction (ORR), Chem. Mater., 2018, 30(5), 1532-1539.

17 M. Shao, Q. Chang, J. P. Dodelet and R. Chenitz, Recent advances in electrocatalysts for oxygen reduction reaction, Chem. Rev., 2016, 116(6), 3594-3657.

18 S. H. Joo, K. Kwon, D. J. You, C. Pak, H. Chang and J. M. Kim, Preparation of high loading Pt nanoparticles on ordered mesoporous carbon with a controlled Pt size and its effects on oxygen reduction and methanol oxidation reactions, Electrochim. Acta, 2009, 54(24), 5746-5753.

19 X. Xu, C. Tan, H. Liu, F. Wang, Z. Li, J. Liu and J. Ji, Carbon black supported ultra-high loading silver nanoparticle catalyst and its enhanced electrocatalytic activity towards oxygen reduction reaction in alkaline medium, J. Electroanal. Chem., 2013, 696, 9-14.

20 G. Han, Y. Zheng, X. Zhang, Z. Wang, Y. Gong, C. Du and $\mathrm{X}$. Sun, High loading single-atom $\mathrm{Cu}$ dispersed on graphene for efficient oxygen reduction reaction, Nano Energy, 2019, 66, 104088.

21 J. F. Huang, J. R. Sie and R. H. Zeng, Engineering sub-nano structures with highly jagged edges on the Pt surface of Pt/ C electrocatalysts to promote oxygen reduction reactions, Electrochim. Acta, 2021, 372, 137868.

22 L. Liu and A. Corma, Metal catalysts for heterogeneous catalysis: From single atoms to nanoclusters and nanoparticles, Chem. Rev., 2018, 118(10), 4981-5079.

23 S. Ji, Y. Chen, X. Wang, Z. Zhang, D. Wang and Y. Li, Chemical synthesis of single atomic site catalysts, Chem. Rev., 2020, 120(21), 11900-11955.

24 Y. Peng, B. Lu and S. Chen, Carbon-supported single atom catalysts for electrochemical energy conversion and storage, Adv. Mater., 2018, 30(48), 1801995.
25 J. Wang, Z. Li, Y. Wu and Y. Li, Fabrication of single-atom catalysts with precise structure and high metal loading, Adv. Mater., 2018, 30(48), 1801649.

26 U. Martinez, S. Komini Babu, E. F. Holby, H. T. Chung, $\mathrm{X}$. Yin and P. Zelenay, Progress in the development of Febased PGM-free electrocatalysts for the oxygen reduction reaction, Adv. Mater., 2019, 31(31), 1806545.

27 A. Bharti and G. Cheruvally, Influence of various carbon nano-forms as supports for Pt catalyst on proton exchange membrane fuel cell performance, J. Power Sources, 2017, 360, 196-205.

28 A. Pal, M. Palashuddin Sk and A. Chattopadhyay, Recent advances in crystalline carbon dots for superior application potential, Materials Advances, 2020, 1, 525-553.

29 C. Wei, H. Wang, K. Eid, J. Kim, J. H. Kim, Z. A. Alothman and L. Wang, A three-dimensionally structured electrocatalyst: Cobalt-embedded nitrogen-doped carbon nanotubes/nitrogen-doped reduced graphene oxide hybrid for efficient oxygen reduction, Chem. - Eur. J., 2017, 23(3), 637-643.

30 H. Fei, J. Dong, D. Chen, T. Hu, X. Duan, I. Shakir and $\mathrm{X}$. Duan, Single atom electrocatalysts supported on graphene or graphene-like carbons, Chem. Soc. Rev., 2019, 48(20), 5207-5241.

31 H. Tan, J. Tang, J. Kim, Y. V. Kaneti, Y. M. Kang, Y. Sugahara and Y. Yamauchi, Rational design and construction of nanoporous iron-and nitrogen-doped carbon electrocatalysts for oxygen reduction reaction, J. Mater. Chem. A, 2019, 7(4), 1380-1393.

32 Z. Li, L. Zhang, X. Chen, B. Li, H. Wang and Q. Li, Threedimensional graphene-like porous carbon nanosheets derived from molecular precursor for high-performance supercapacitor application, Electrochim. Acta, 2019, 296, 8-17.

33 X. F. Lu, B. Y. Xia, S. Q. Zang and X. W. Lou, Metal-organic frameworks based electrocatalysts for the oxygen reduction reaction, Angew. Chem., 2020, 132(12), 4662-4678.

34 N. Cheng, L. Ren, X. Xu, Y. Du and S. X. Dou, Recent development of zeolitic imidazolate frameworks (ZIFs) derived porous carbon based materials as electrocatalysts, Adv. Energy Mater., 2018, 8(25), 1801257.

35 J. F. Sun, Q. Q. Xu, J. L. Qi, D. Zhou, H. Y. Zhu and J. Z. Yin, Isolated single atoms anchored on N-doped carbon materials as a highly efficient catalyst for electrochemical and organic reactions, ACS Sustainable Chem. Eng., 2020, 8(39), 14630-14656.

36 Y. N. Chen, X. Zhang and Z. Zhou, Carbon-based substrates for highly dispersed nanoparticle and even singleatom electrocatalysts, Small Methods, 2019, 3(9), 1900050.

37 Y. X. Xiao, J. Ying, G. Tian, Y. Tao, H. Wei, S. Y. Fan and C. Janiak, Highly dispersed PtPd on graphitic nanofibers and its heavy d- $\pi$ effect, Appl. Catal., B, 2019, 259, 118080.

38 E. Zagoraiou, M. K. Daletou, L. Sygellou, S. Ballomenou and S. G. Neophytides, Highly dispersed platinum supported catalysts - Effect of properties on the electrocatalytic activity, Appl. Catal., B, 2019, 259, 118050. 
39 Y. T. Kim and T. Mitani, Surface thiolation of carbon nanotubes as supports: a promising route for the high dispersion of Pt nanoparticles for electrocatalysts, J. Cat., 2006, 238(2), 394-401.

40 J. E. Park, J. Lim, M. S. Lim, S. Kim, O. H. Kim, D. W. Lee and Y. E. Sung, Gas diffusion layer/flow-field unified membrane-electrode assembly in fuel cell using graphene foam, Electrochim. Acta, 2019, 323, 134808.

41 W. J. Lee, S. Bera, C. M. Kim, E. K. Koh, W. P. Hong, S. J. Oh and S. H. Kwon, Synthesis of highly dispersed Pt nanoparticles into carbon supports by fluidized bed reactor atomic layer deposition to boost PEMFC performance, NPG Asia Mater., 2020, 12(1), 1-13.

42 J. Zhang, Y. Yuan, L. Gao, G. Zeng, M. Li and H. Huang, Stabilizing Pt-based electrocatalysts for oxygen reduction reaction: Fundamental understanding and design strategies, Adv. Mater., 2021, 33(20), 2006494.

43 W. Ye, S. Chen, Y. Lin, L. Yang, S. Chen, X. Zheng and Y. Xiong, Precisely tuning the number of $\mathrm{Fe}$ atoms in clusters on $\mathrm{N}$-doped carbon toward acidic oxygen reduction reaction, Chem, 2019, 5(11), 2865-2878.

44 L. Zhang, T. Yang, W. Zang, Z. Kou, Y. Ma, M. Waqar and J. Wang, Quasi-paired Pt atomic sites on $\mathrm{Mo}_{2} \mathrm{C}$ promoting selective four-electron oxygen reduction, $A d v$. Sci., 2021, 2101344.

45 X. Lu, X. Zhu, X. Tan, K. H. Wu, S. C. Haw, C. W. Pao and R. Amal, Intrinsic ORR activity enhancement of Pt atomic sites by engineering d-band center via local coordination tuning, Angew. Chem., Int. Ed., 2021, 60, 21911-21917.

46 T. Zhang, X. Han, H. Yang, A. Han, E. Hu, Y. Li and B. Liu, Atomically dispersed nickel(i) on an alloy-encapsulated nitrogen-doped carbon nanotube array for highperformance electrochemical $\mathrm{CO}_{2}$ reduction reaction, Angew. Chem., 2020, 132(29), 12153-12159.

47 Y. C. Park, H. Tokiwa, K. Kakinuma, M. Watanabe and M. Uchida, Effects of carbon supports on Pt distribution, ionomer coverage and cathode performance for polymer electrolyte fuel cells, J. Power Sources, 2016, 315, 179-191.

48 V. Yarlagadda, M. K. Carpenter, T. E. Moylan, R. S. Kukreja, R. Koestner, W. Gu and A. Kongkanand, Boosting fuel cell performance with accessible carbon mesopores, ACS Energy Lett., 2018, 3(3), 618-621.

49 Z. Qiao, S. Hwang, X. Li, C. Wang, W. Samarakoon, $\mathrm{S}$. Karakalos and $\mathrm{G}$. Wu, 3D porous graphitic nanocarbon for enhancing the performance and durability of Pt catalysts: A balance between graphitization and hierarchical porosity, Energy Environ. Sci., 2019, 12(9), 2830-2841.

50 M. Sakthivel and J. F. Drillet, An extensive study about influence of the carbon support morphology on Pt activity and stability for oxygen reduction reaction, Appl. Catal., B, 2018, 231, 62-72.

51 B. Lim, M. Jiang, P. H. Camargo, E. C. Cho, J. Tao, X. Lu and Y. Xia, Pd-Pt bimetallic nanodendrites with high activity for oxygen reduction, Science, 2009, 324(5932), 1302-1305.

52 H. Tan, J. Kim, J. Lin, C. Li, S. M. Alsheri, T. Ahamad and Y. Yamauchi, A facile surfactant-assisted synthesis of carbon-supported dendritic Pt nanoparticles with high electrocatalytic performance for the oxygen reduction reaction, Microporous Mesoporous Mater., 2019, 280, 1-6.

53 C. Li, H. Tan, J. Lin, X. Luo, S. Wang, J. You and J. Kim, Emerging Pt-based electrocatalysts with highly open nanoarchitectures for boosting oxygen reduction reaction, Nano Today, 2018, 21, 91-105.

54 Z. Li, C. He, M. Cai, S. Kang and P. K. Shen, A strategy for easy synthesis of carbon supported Co@Pt core-shell configuration as highly active catalyst for oxygen reduction reaction, Int. J. Hydrogen Energy, 2012, 37(19), 14152-14160.

55 S. S. Li, J. N. Zheng, A. J. Wang, F. L. Tao, J. J. Feng, J. R. Chen and H. Yu, Branched platinum-on-palladium bimetallic heteronanostructures supported on reduced graphene oxide for highly efficient oxygen reduction reaction, J. Power Sources, 2014, 272, 1078-1085.

56 X. R. Li, X. L. Li, M. C. Xu, J. J. Xu and H. Y. Chen, Gold nanodendrities on graphene oxide nanosheets for oxygen reduction reaction, J. Mater. Chem. A, 2014, 2(6), 1697-1703.

57 X. X. Wang, J. Sokolowski, H. Liu and G. Wu, Pt alloy oxygen-reduction electrocatalysts: Synthesis, structure, and property, Chin. J. Cat., 2020, 41(5), 739-755.

58 V. Colic and A. S. Bandarenka, Pt alloy electrocatalysts for the oxygen reduction reaction: From model surfaces to nanostructured systems, ACS Catal., 2016, 6(8), 5378-5385.

59 Y. J. Wang, W. Long, L. Wang, R. Yuan, A. Ignaszak, B. Fang and D. P. Wilkinson, Unlocking the door to highly active ORR catalysts for PEMFC applications: polyhedronengineered Pt-based nanocrystals, Energy Environ. Sci., 2018, 11(2), 258-275.

60 S. Sankarasubramanian, N. Singh, F. Mizuno and J. Prakash, $A b$ initio investigation of the oxygen reduction reaction activity on noble metal (Pt, $\mathrm{Au}, \mathrm{Pd}), \mathrm{Pt} 3 \mathrm{M}(\mathrm{M}=\mathrm{Fe}$, $\mathrm{Co}, \mathrm{Ni}, \mathrm{Cu})$ and $\mathrm{Pd} 3 \mathrm{M}(\mathrm{M}=\mathrm{Fe}, \mathrm{Co}, \mathrm{Ni}, \mathrm{Cu})$ alloy surfaces, for $\mathrm{LiO}_{2}$ cells, J. Power Sources, 2016, 319, 202-209.

61 L. M. Guo, D. F. Zhang and L. Guo, ). Structure design reveals the role of $\mathrm{Au}$ for ORR catalytic performance optimization in PtCo-based catalysts, Adv. Funct. Mater., 2020, 30(22), 2001575.

62 K. Jayasayee, J. R. Van Veen, T. G. Manivasagam, S. Celebi, E. J. Hensen and F. A. De Bruijn, Oxygen reduction reaction (ORR) activity and durability of carbon supported PtM (Co, $\mathrm{Ni}, \mathrm{Cu})$ alloys: Influence of particle size and non-noble metals, Appl. Catal., B, 2012, 111, 515-526.

63 T. Y. Yoo, J. M. Yoo, A. K. Sinha, M. S. Bootharaju, E. Jung, H. S. Lee and T. Hyeon, Direct synthesis of intermetallic platinum-alloy nanoparticles highly loaded on carbon supports for efficient electrocatalysis, J. Am. Chem. Soc., 2020, 142(33), 14190-14200.

64 B. Zhang, G. Fu, Y. Li, L. Liang, N. S. Grundish, Y. Tang and Z. Cui, General strategy for synthesis of ordered Pt3M intermetallics with ultrasmall particle size, Angew. Chem., 2020, 132(20), 7931-7937.

65 W. Wang, B. Lei and S. Guo, Engineering multimetallic nanocrystals for highly efficient oxygen reduction catalysts, Adv. Energy Mater., 2016, 6(17), 1600236. 
66 Y. T. Liang, S. P. Lin, C. W. Liu, S. R. Chung, T. Y. Chen, J. H. Wang and K. W. Wang, The performance and stability of the oxygen reduction reaction on $\mathrm{Pt}-\mathrm{M}(\mathrm{M}=\mathrm{Pd}, \mathrm{Ag}$ and $\mathrm{Au})$ nanorods: An experimental and computational study, Chem. Commun., 2015, 51(30), 6605-6608.

67 X. Deng, S. Yin, X. Wu, M. Sun, Z. Li, Z. Xie and Q. Huang, Scalable preparation of PtPd/carbon nanowires in the form of membrane as highly stable electrocatalysts for oxygen reduction reaction, Int. J. Hydrogen Energy, 2019, 44(5), 2752-2759.

68 Y. Deng, H. Xue, S. Lu, Y. Song, X. Cao, L. Wang and H. Gu, Trimetallic Au@PtPd mesoporous nanorods as efficient electrocatalysts for the oxygen reduction reaction, ACS Appl. Energy Mater., 2018, 1(9), 4891-4898.

69 Y. Li, Z. Li and P. K. Shen, Simultaneous formation of ultrahigh surface area and three-dimensional hierarchical porous graphene-like networks for fast and highly stable supercapacitors, Adv. Mater., 2013, 25(17), 2474-2480.

70 Z. Li, Y. Li, C. He and P. K. Shen, Bimetallic PtAg alloyed nanoparticles and 3-D mesoporous graphene nanosheet hybrid architectures for advanced oxygen reduction reaction electrocatalysts, J. Mater. Chem. A, 2017, 5(44), 23158-23169.

71 Q. Zhao, C. Wang, H. Wang, J. Wang, Y. Tang, Z. Mao and K. Sasaki, Synthesis of a high-performance low-platinum $\mathrm{PtAg} / \mathrm{C}$ alloyed oxygen reduction catalyst through the gradual reduction method, N. J. Chem., 2020, 44(9), 3728-3736.

72 R. Wang, H. Wang, F. Luo and S. Liao, Core-shellstructured low-platinum electrocatalysts for fuel cell applications, Electrochem. Energy Rev., 2018, 1(3), 324-387.

73 R. Jiang, S. Tung, Z. Tang, L. Li, L. Ding, X. Xi and J. Zhang, A review of core-shell nanostructured electrocatalysts for oxygen reduction reaction, Energy Storage Mater., 2018, 12, 260-276.

74 K. Sasaki, K. A. Kuttiyiel and R. R. Adzic, Designing high performance Pt monolayer core-shell electrocatalysts for fuel cells, Curr. Opin. Electrochem., 2020, 21, 368-375.

75 L. Wang, Z. Zeng, C. Ma, Y. Liu, M. Giroux, M. Chi and C. Wang, Plating precious metals on nonprecious metal nanoparticles for sustainable electrocatalysts, Nano Lett., 2017, 17(6), 3391-3395.

76 X. Lyu, Y. Jia, X. Mao, D. Li, G. Li, L. Zhuang and X. Yao, Gradient-concentration design of stable core-shell nanostructure for acidic oxygen reduction electrocatalysis, $A d v$. Mater., 2020, 32(32), 2003493.

77 Y. T. Pan and H. Yang, Design of bimetallic catalysts and electrocatalysts through the control of reactive environments, Nano Today, 2020, 31, 100832.

78 K. Mayrhofer, V. Juhart, K. Hartl, M. Hanzlik and M. Arenz, Adsorbate-induced surface segregation for core-shell nanocatalysts, Angew. Chem., Int. Ed., 2009, 48, 3529-3531.

79 Z. Li, Y. Li, G. He and P. K. Shen, Novel graphene-like nanosheet supported highly active electrocatalysts with ultralow Pt loadings for oxygen reduction reaction, J. Mater. Chem. A, 2014, 2(40), 16898-16904.
80 Y. Zhang, Y. C. Hsieh, V. Volkov, D. Su, W. An, R. Si and R. R. Adzic, High performance Pt monolayer catalysts produced via core-catalyzed coating in ethanol, ACS Catal., 2014, 4(3), 738-742.

81 J. Kong, Y. H. Qin, T. L. Wang and C. W. Wang, Pd9Au1@Pt/C core-shell catalyst prepared via Pd9Au1catalyzed coating for enhanced oxygen reduction, Int. J. Hydrogen Energy, 2020, 45(51), 27254-27262.

82 M. Kiani, J. Zhang, Y. Luo, C. Jiang, J. Fan, G. Wang and R. Wang, Recent developments in electrocatalysts and future prospects for oxygen reduction reaction in polymer electrolyte membrane fuel cells, J. Energy Chem., 2018, 27(4), 1124-1139.

83 H. Tan, Y. Li, J. Kim, T. Takei, Z. Wang, X. Xu and Y. Yamauchi, Sub-50 nm iron-nitrogen-doped hollow carbon sphere-encapsulated iron carbide nanoparticles as efficient oxygen reduction catalysts, Adv. Sci., 2018, 5(7), 1800120.

84 Y. Liang, Y. Li, H. Wang, J. Zhou, J. Wang, T. Regier and $\mathrm{H}$. Dai, Co3O4 nanocrystals on graphene as a synergistic catalyst for oxygen reduction reaction, Nat. Mater., 2011, 10(10), 780-786.

85 J. Wang, L. Li, X. Chen, Y. Lu and W. Yang, Monodisperse cobalt sulfides embedded within nitrogen-doped carbon nanoflakes: An efficient and stable electrocatalyst for the oxygen reduction reaction, J. Mater. Chem. A, 2016, 4(29), 11342-11350.

86 R. B. Levy and M. Boudart, Platinum-like behavior of tungsten carbide in surface catalysis, Science, 1973, 181(4099), 547-549.

87 Z. Yan, M. Zhang, J. Xie, J. Zhu and P. K. Shen, A bimetallic carbide Fe2MoC promoted Pd electrocatalyst with performance superior to $\mathrm{Pt} / \mathrm{C}$ towards the oxygen reduction reaction in acidic media, Appl. Catal., B, 2015, 165, 636-641.

88 B. Li, J. Zhou, L. Zhang and Z. Li, Bimetallic carbide of Co3W3C enhanced non-noble-metal catalysts with high activity and stability for acidic oxygen reduction reaction, RSC Adv., 2018, 8(22), 12292-12299.

89 S. Yin, M. Cai, C. Wang and P. K. Shen, Tungsten carbide promoted $\mathrm{Pd}-\mathrm{Fe}$ as alcohol-tolerant electrocatalysts for oxygen reduction reactions, Energy Environ. Sci., 2011, 4(2), 558-563.

90 X. Ma, H. Meng, M. Cai and P. K. Shen, Bimetallic carbide nanocomposite enhanced Pt catalyst with high activity and stability for the oxygen reduction reaction, J. Am. Chem. Soc., 2012, 134(4), 1954-1957.

91 D. Göhl, A. Garg, P. Paciok, K. J. Mayrhofer, M. Heggen, Y. Shao-Horn and M. Ledendecker, Engineering stable electrocatalysts by synergistic stabilization between carbide cores and Pt shells, Nat. Mater., 2020, 19(3), 287-291.

92 J. Yang, W. Li, D. Wang and Y. Li, Electronic metal-support interaction of single-atom catalysts and applications in electrocatalysis, Adv. Mater., 2020, 32(49), 2003300.

93 C. He and P. K. Shen, Pt loaded on truncated hexagonal pyramid WC/graphene for oxygen reduction reaction, Nano Energy, 2014, 8, 52-61. 
94 Z. Li, B. Li, Z. Liu, Z. Liu and D. Li, A tungsten carbide/iron sulfide/FePt nanocomposite supported on nitrogen-doped carbon as an efficient electrocatalyst for oxygen reduction reaction, RSC Adv., 2015, 5(128), 106245-106251.

95 Z. Li, S. Ji, B. G. Pollet and P. K. Shen, $\mathrm{A} \mathrm{Co}_{3} \mathrm{~W}_{3} \mathrm{C}$ promoted Pd catalyst exhibiting competitive performance over Pt/C catalysts towards the oxygen reduction reaction, Chem. Commun., 2014, 50(5), 566-568.

96 G. Wu, A. Santandreu, W. Kellogg, S. Gupta, O. Ogoke, H. Zhang and L. Dai, Carbon nanocomposite catalysts for oxygen reduction and evolution reactions: From nitrogen doping to transition-metal addition, Nano Energy, 2016, 29, 83-110.

97 L. Osmieri, L. Pezzolato and S. Specchia, Recent trends on the application of PGM-free catalysts at the cathode of anion exchange membrane fuel cells, Curr. Opin. Electrochem., 2018, 9, 240-256.

98 M. Lefèvre, E. Proietti, F. Jaouen and J. P. Dodelet, Ironbased catalysts with improved oxygen reduction activity in polymer electrolyte fuel cells, Science, 2009, 324(5923), 71-74.

99 A. Wang, J. Li and T. Zhang, Heterogeneous single-atom catalysis, Nat. Rev. Chem., 2018, 2(6), 65-81.

100 H. T. Chung, D. A. Cullen, D. Higgins, B. T. Sneed, E. F. Holby, K. L. More and P. Zelenay, Direct atomiclevel insight into the active sites of a high-performance PGM-free ORR catalyst, Science, 2017, 357(6350), 479-484.

101 D. A. Reed, B. K. Keitz, J. Oktawiec, J. A. Mason, T. Runčevski, D. J. Xiao and J. R. Long, A spin transition mechanism for cooperative adsorption in metal-organic frameworks, Nature, 2017, 550(7674), 96-100.

102 Q. K. Li, X. F. Li, G. Zhang and J. Jiang, Cooperative spin transition of monodispersed FeN3 sites within graphene induced by CO adsorption, J. Am. Chem. Soc., 2018, 140(45), 15149-15152.

103 H. Li, L. Wang, Y. Dai, Z. Pu, Z. Lao, Y. Chen and J. Zeng, Synergetic interaction between neighbouring platinum monomers in $\mathrm{CO}_{2}$ hydrogenation, Nat. Nanotechnol., 2018, 13(5), 411-417.

104 J. Wu, L. Xiong, B. Zhao, M. Liu and L. Huang, Densely populated single atom catalysts, Small Methods, 2020, 4(2), 1900540.

105 W. Chen, W. Gao, P. Tu, T. Robert, Y. Ma, H. Shan and J. Wu, Neighboring Pt atom sites in an ultrathin FePt Nanosheet for the efficient and highly CO-tolerant oxygen reduction reaction, Nano Lett., 2018, 18(9), 5905-5912.

106 J. Wu, H. Zhou, Q. Li, M. Chen, J. Wan, N. Zhang and L. Huang, Densely populated isolated single CoN site for efficient oxygen electrocatalysis, Adv. Energy Mater., 2019, $\mathbf{9}(22), 1900149$.

107 J. Xi, H. S. Jung, Y. Xu, F. Xiao, J. W. Bae and S. Wang, Synthesis strategies, catalytic applications, and performance regulation of single-atom catalysts, Adv. Funct. Mater., 2021, 31(12), 2008318.

108 L. Zhao, Y. Zhang, L. B. Huang, X. Z. Liu, Q. H. Zhang, C. He and L. J. Wan, Cascade anchoring strategy for general mass production of high-loading single-atomic metal-nitrogen catalysts, Nat. Commun., 2019, 10(1), 1-11.

109 H. Yan, X. Zhao, N. Guo, Z. Lyu, Y. Du, S. Xi and J. Lu, Atomic engineering of high-density isolated Co atoms on graphene with proximal-atom controlled reaction selectivity, Nat. Commun., 2018, 9(1), 1-9.

110 L. Jiao, J. Li, L. L. Richard, Q. Sun, T. Stracensky, E. Liu and Q. Jia, Chemical vapour deposition of Fe-N-C oxygen reduction catalysts with full utilization of dense Fe-N4 sites, Nat. Mater., 2021, DOI: 10.1038/s41563-021-01030-2.

111 Q. Wang, Y. Yang, F. Sun, G. Chen, J. Wang, L. Peng and G. I. Waterhouse, Molten NaCl-assisted synthesis of porous $\mathrm{Fe}-\mathrm{N}-\mathrm{C}$ electrocatalysts with a high density of catalytically accessible FeN4 active sites and outstanding oxygen reduction reaction performance, Adv. Energy Mater., 2021, 2100219.

112 Y. Qu, Z. Li, W. Chen, Y. Lin, T. Yuan, Z. Yang and Y. Li, Direct transformation of bulk copper into copper single sites via emitting and trapping of atoms, Nat. Catal., 2018, 1(10), 781-786.

113 T. Zheng, K. Jiang, N. Ta, Y. Hu, J. Zeng, J. Liu and $\mathrm{H}$. Wang, Large-scale and highly selective CO2 electrocatalytic reduction on nickel single-atom catalyst, Joule, 2019, 3(1), 265-278.

114 Y. Cheng, S. Zhao, B. Johannessen, J. P. Veder, M. Saunders, M. R. Rowles and S. P. Jiang, Atomically dispersed transition metals on carbon nanotubes with ultrahigh loading for selective electrochemical carbon dioxide reduction, Adv. Mater., 2018, 30(13), 1706287.

115 Z. Yang, Y. Wang, M. Zhu, Z. Li, W. Chen, W. Wei and Y. Li, Boosting oxygen reduction catalysis with Fe-N4 sites decorated porous carbons toward fuel cells, ACS Catal., 2019, 9(3), 2158-2163.

116 C. Xia, Y. Qiu, Y. Xia, P. Zhu, G. King, X. Zhang and H. Wang, General synthesis of single-atom catalysts with high metal loading using graphene quantum dots, Nat. Chem., 2021, 13, 887-894.

117 Y. Zhou, X. Tao, G. Chen, R. Lu, D. Wang, M. X. Chen and K. MAllen, Multilayer stabilization for fabricating highloading single-atom catalysts, Nat. Commun., 2020, 11(1), 1-11.

118 J. Han, H. Bao, J. Q. Wang, L. Zheng, S. Sun, Z. L. Wang and C. Sun, 3D N-doped ordered mesoporous carbon supported single-atom Fe-NC catalysts with superior performance for oxygen reduction reaction and zinc-air battery, Appl. Catal., B, 2021, 280, 119411.

119 C. Wan, X. Duan and Y. Huang, Molecular design of singleatom catalysts for oxygen reduction reaction, Adv. Energy Mater., 2020, 10(14), 1903815.

120 G. Chen, P. Liu, Z. Liao, F. Sun, Y. He, H. Zhong and $\mathrm{X}$. Feng, Zinc-mediated template synthesis of $\mathrm{Fe}-\mathrm{N}-\mathrm{C}$ electrocatalysts with densely accessible $\mathrm{Fe}-\mathrm{Nx}$ active sites for efficient oxygen reduction, Adv. Mater., 2020, 32(8), 1907399.

121 H. Adabi, A. Shakouri, N. Ul Hassan, J. R. Varcoe, B. Zulevi, A. Serov and W. E. Mustain, High-performing commercial 
$\mathrm{Fe}-\mathrm{N}-\mathrm{C}$ cathode electrocatalyst for anion-exchange membrane fuel cells, Nat. Energy, 2021, 6, 834-843.

122 X. Wu, H. Zhang, S. Zuo, J. Dong, Y. Li, J. Zhang and Y. Han, Engineering the coordination sphere of isolated active sites to explore the intrinsic activity in single-atom catalysts, Nano-Micro Lett., 2021, 13(1), 1-28.

123 Z. Jin, P. Li, Y. Meng, Z. Fang, D. Xiao and G. Yu, Understanding the inter-site distance effect in single-atom catalysts for oxygen electroreduction, Nat. Catal., 2021, 4, 615-622.

124 H. Zhang, H. T. Chung, D. A. Cullen, S. Wagner, U. I. Kramm, K. L. More and G. Wu, High-performance fuel cell cathodes exclusively containing atomically dispersed iron active sites, Energy Environ. Sci., 2019, 12(8), 2548-2558.

125 X. Wan, X. Liu, Y. Li, R. Yu, L. Zheng, W. Yan and J. Shui, Fe-N-C electrocatalyst with dense active sites and efficient mass transport for high-performance proton exchange membrane fuel cells, Nat. Catal., 2019, 2(3), 259-268.

126 S. Liu, M. Wang, X. Yang, Q. Shi, Z. Qiao, M. Lucero and $\mathrm{G}$. $\mathrm{Wu}$, Chemical vapor deposition for atomically dispersed and nitrogen coordinated single metal site catalysts, Angew. Chem., Int. Ed., 2020, 59(48), 21698-21705.

127 L. Chen, X. Liu, L. Zheng, Y. Li, X. Guo, X. Wan and J. Shui, Insights into the role of active site density in the fuel cell performance of Co-NC catalysts, Appl. Catal., B, 2019, 256, 117849.

128 X. Xie, C. He, B. Li, Y. He, D. A. Cullen, E. C. Wegener and Y. Shao, Performance enhancement and degradation mechanism identification of a single-atom Co-N-C catalyst for proton exchange membrane fuel cells, Nat. Catal., 2020, 3(12), 1044-1054.

129 N. Zhang, T. Zhou, J. Ge, Y. Lin, Z. Du, W. Wang and Y. Xie, High-density planar-like Fe2N6 structure catalyzes efficient oxygen reduction, Matter, 2020, 3(2), 509-521.

130 M. Xiao, H. Zhang, Y. Chen, J. Zhu, L. Gao, Z. Jin and W. Xing, Identification of binuclear $\mathrm{Co}_{2} \mathrm{~N}_{5}$ active sites for oxygen reduction reaction with more than one magnitude higher activity than single atom $\mathrm{CoN}_{4}$ site, Nano Energy, 2018, 46, 396-403.

131 J. Wang, Z. Huang, W. Liu, C. Chang, H. Tang, Z. Li and Y. Li, Design of N-coordinated dual-metal sites: A stable and active Pt-free catalyst for acidic oxygen reduction reaction, J. Am. Chem. Soc., 2017, 139(48), 17281-17284.

132 G. Zhang, Y. Jia, C. Zhang, X. Xiong, K. Sun, R. Chen and H. Dai, A general route via formamide condensation to prepare atomically dispersed metal-nitrogen-carbon electrocatalysts for energy technologies, Energy Environ. Sci., 2019, 12(4), 1317-1325.

133 H. Li, Y. Wen, M. Jiang, Y. Yao, H. Zhou, Z. Huang and S. Luo, Understanding of neighboring Fe-N4-C and CoN4-C dual active centers for oxygen reduction reaction, Adv. Funct. Mater., 2021, 2011289.

134 W. Zhang, Y. Chao, W. Zhang, J. Zhou, F. Lv, K. Wang and S. Guo, Emerging dual-atomic-site catalysts for efficient energy catalysis, Adv. Mater., 2021, 2102576.

135 B. W. Zhang, L. Ren, Z. F. Xu, N. Y. Cheng, W. H. Lai, L. Zhang and S. X. Dou, Atomic structural evolution of single-layer Pt clusters as efficient electrocatalysts, Small, 2021, 2100732.

136 T. Zhou, H. Shan, H. Yu, C. A. Zhong, J. Ge, N. Zhang and Y. Xie, Nanopore confinement of electrocatalysts optimizing triple transport for an ultrahigh-power-density zinc-air fuel cell with robust stability, Adv. Mater., 2020, 32(47), 2003251.

137 D. Qi, Y. Liu, M. Hu, X. Peng, Y. Qiu, S. Zhang and X. Liu, Engineering atomic sites via adjacent dual-metal subnanoclusters for efficient oxygen reduction reaction and Zn-air battery, Small, 2020, 16(48), 2004855.

138 X. Ao, W. Zhang, Z. Li, J. G. Li, L. Soule, X. Huang and X. C. Zeng, Markedly enhanced oxygen reduction activity of single-atom Fe catalysts via integration with Fe nanoclusters, ACS Nano, 2019, 13(10), 11853-11862.

139 M. Liu, J. Lee, T. C. Yang, F. Zheng, J. Zhao, C. M. Yang and L. Y. S. Lee, Synergies of Fe single atoms and clusters on Ndoped carbon electrocatalyst for pH-universal oxygen reduction, Small Methods, 2021, 5(5), 2001165.

140 Y. Lei, F. Yang, H. Xie, Y. Lei, X. Liu, Y. Si and H. Wang, Biomass in situ conversion to $\mathrm{Fe}$ single atomic sites coupled with $\mathrm{Fe} 2 \mathrm{O} 3$ clusters embedded in porous carbons for the oxygen reduction reaction, J. Mater. Chem. A, 2020, 8(39), 20629-20636.

141 X. Wei, X. Luo, N. Wu, W. Gu, Y. Lin and C. Zhu, Recent advances in synergistically enhanced single-atomic site catalysts for boosted oxygen reduction reaction, Nano Energy, 2021, 105817.

142 Z. Wang, C. Zhu, H. Tan, J. Liu, L. Xu, Y. Zhang and X. Lu, Understanding the synergistic effects of cobalt single atoms and small nanoparticles: Enhancing oxygen reduction reaction catalytic activity and stability for zincair batteries, Adv. Funct. Mater., 2021, 2104735.

143 T. Jiang, W. Luan, L. Turyanska and Q. Feng, Enhanced electrocatalytic oxygen reduction reaction for Fe-N4-C by the incorporation of Co nanoparticles, Nanoscale, 2021, 13(13), 6521-6530.

144 S. H. Yin, J. Yang, Y. Han, G. Li, L. Y. Wan, Y. H. Chen and S. G. Sun, Construction of highly active metal-containing nanoparticles and $\mathrm{FeCo}-\mathrm{N}_{4}$ composite sites for the acidic oxygen reduction reaction, Angew. Chem., 2020, 132(49), 22160-22163.

145 L. Liang, H. Jin, H. Zhou, B. Liu, C. Hu, D. Chen and S. Mu, Cobalt single atom site isolated Pt nanoparticles for efficient ORR and HER in acid media, Nano Energy, 2021, 106221.

146 Z. Qiao, C. Wang, C. Li, Y. Zeng, S. Hwang, B. Li and G. Wu, Atomically dispersed single iron sites for promoting Pt and Pt3Co fuel cell catalysts: performance and durability improvements, Energy Environ. Sci., 2021, 14, 4948-4960.

147 P. Diao, M. Guo and Q. Zhang, How does the particle density affect the electrochemical behavior of gold nanoparticle assembly?, J. Phys. Chem. C, 2008, 112(17), 7036-7046.

148 Y. Kim, G. Collinge, M. S. Lee, K. Khivantsev, S. J. Cho, V. A. Glezakou and J. H. Kwak, Rücktitelbild: Surface density dependent catalytic activity of single palladium atoms supported on ceria (Angew. Chem. 42/2021), Angew. Chem., 2021, 133(42), 23212. 